$1-1-7$.

ANCR-1087

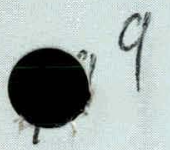

2403

UC- 25

$(1)$

\title{
METALLURGICAL EVALUATION OF WELDING AND HEAT TREATING PROCEDURES FOR THE \\ INCONEL 718 PBF IN-PILE TUBE
}

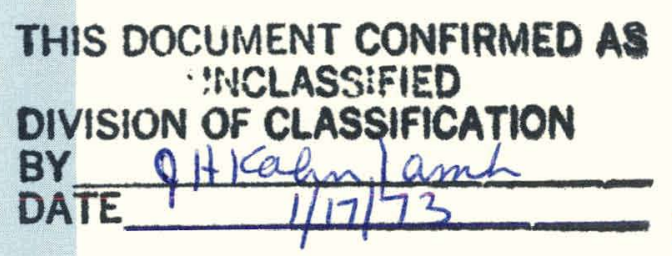

M. J. Graber

C. R. Brinkman

R. R. Hobbins

\section{Aerojet nuclear Company}

NATIONAL REACTOR TESTING STATION Idaho Falls, Idaho - 83401

\section{RS: MASTER}

PSTRIBUTION OF THS DOCUMENT IS OMLMTIES

DATE PUBLISHED - OCTOBER 1972

PREPARED FOR THE

\author{
U. S. ATOMIC ENERGY COMMISSION
}

IDAHO OPERATIONS OFFICE UNDER CONTRACT AT(10-1)-1375 


\section{DISCLAIMER}

This report was prepared as an account of work sponsored by an agency of the United States Government. Neither the United States Government nor any agency Thereof, nor any of their employees, makes any warranty, express or implied, or assumes any legal liability or responsibility for the accuracy, completeness, or usefulness of any information, apparatus, product, or process disclosed, or represents that its use would not infringe privately owned rights. Reference herein to any specific commercial product, process, or service by trade name, trademark, manufacturer, or otherwise does not necessarily constitute or imply its endorsement, recommendation, or favoring by the United States Government or any agency thereof. The views and opinions of authors expressed herein do not necessarily state or reflect those of the United States Government or any agency thereof. 


\section{DISCLAIMER}

Portions of this document may be illegible in electronic image products. Images are produced from the best available original document. 
Printed in the United States of America
Available from

National Technical Information Service

U. S. Department of Commerce

5285 Port Royal Road

Springfie1d, Virginia 22151

Price: Printed Copy $\$ 3.00$; Microfiche $\$ 0.95$

\section{LEGAL NOTICE}

This report was prepared as an account of work sponsored by the United States Government. Neither the United States nor the United States Atomic Energy Commission, nor any of their employees, nor any of their contractors, subcontractors, or their employees, makes any warranty, express or implied, or assumes any legal liability or responsibility for the accuracy, completeness or usefulness of any information, apparatus, product or process disclosed, or represents that its use would not infringe privately owned rights. 
Metals, Ceramics, And Materials

TID -4500

\title{
METALLURGICAL EVALUATION OF WELDING \\ AND HEAT TREATING PROCEDURES FOR THE INCONEL 718 PBF IN-PILE TUBE
}

By

M. J. Graber

C. R. Brinkman

R. R. Hobbins

This report was prepared as an account of work sponsored by the United States Government. Neither the United States nor the United States Atomic Energy Commission, nor any of their employees, nor any of Comirs meir contractors, subcontractor, or implied, or assumes any makes any waranty, expres or lor the occuracy, com legal liability or responsibulity for the accuracy, completeness or usefulness of any information, apparatus, product or process disclused, or represent
would not infringe privately owned rights.

\section{AEROJET NUCLEAR COMPANY} \\ Date Published - October 1972 \\ PREPARED FOR THE U.S. ATOMIC ENERGY COMMISSION \\ IDAHO OPERATIONS OFFICE \\ UNDER CONTRACT NO. AT (10-1) -1375
}




\section{ACKNOWLEDGMENTS}

The solving of the problems encountered during fabrication of the in-pile tube was a coordinated effort between the Metallurgy and Hot Cell Branch, Power Burst .Facility Program Operations of Aerojet Nuclear Company (ANC) and the tube fabricator, Standard Press Stee1 Company .

Much credit should be glven to A. L. Arwitage of the ANC Engineering Division who was placed in charge of expediting the work once it grew to project proportions. Credit should also be given to H. W. Black and Bob Locke of ANC who inspected and monitored qualification tests and fabrication procedures at the very cooperative vendor organization (particularly the assistance of John Fink) at Willow Grove, Pennsylvania. Valuable assistance in metallography and heat treating of samples came from B. G. Carlson and J. K. Crandall of ANC. 


\begin{abstract}
Problems were encountered during weldingland heat treating qualification testing and fabrication of the Power Burst Facility in-pile tube which was made of Inconel 718. Areas of localized low ductility in the welds were detected by bend testing. Solution heat treat temperatures high enough to dissolve and redistribute the Laves phase in the welds resulted in inadequate parent metal strength.

To solve the problems, the welds were given a higher localized solution heat treatment ( 1 hour at $2025^{\circ} \mathrm{F}$ ) and the entire assembly was then solution annealed 1 hour at $1925^{\circ} \mathrm{F}$ and duplex aged, at $1325^{\circ} \mathrm{F}$ and $1150^{\circ} \mathrm{F}$, for a total of 42 hours.
\end{abstract}


ACKNOWLEDGMENTS . . . . . . . . . . . . . . . . . . ii ABSTRACT . . . . . . . . . . . . . . . . . . . SUMMARY . . . . . . . . . . . . . . . . . . . . viii

I. INTRODUCTION . . . . . . . . . . . . . . . . . 1

II. LOCALIZED WELD EMBRITTLEMENT . . . . . . . . . . . . . 2

1. FRACTOGRAPHY AND METALLOGRAPHY OF FAILED BEND

SAMPLES . • . • • • • • • • • • • • • • • • • • • • • 4

2. MECHANICAL PROPERTIES OF BEND TEST MATERIAL . . . . . . 5

3. DISCUSSION OF LOCALIZED WELD EMBRITI'LEMENT • • • • • . 5

III. WELDING PROCEDURES . . . . . . . . . . . . . . . 20

1. HISTORY OF BEND TEST WELDS . . . . . . . . . . . . 20

2. TEST WELD PROGRAM ............... . . . 20

3. METALLURGICAL EXAMINATION OF TEST WELDS . . . . . . 21

IV. HEAT TREATMENTS . . . . . . . . . . . . . . . . . 33

1. METALLURGICAL EXAMINATION . . . . . . . . . . . . 33

2. DISCUSSIONS. . . . . . . . . . . . . . 34

V. FINAL QUALIFICATION OF WELDING PROCEDURES AND HEAT

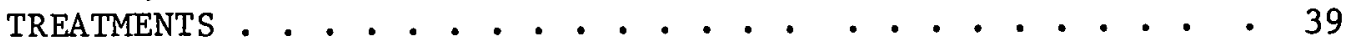

VI. HEAT TREATING AND VERIFICATION OF THE ACTUAL IN-PILE

TUBE . . . . . . . . . . . . . . . • • • • • 42

1. PLANNED HEAT-TREATING PROCEDURE . . . . . . . . . . 42

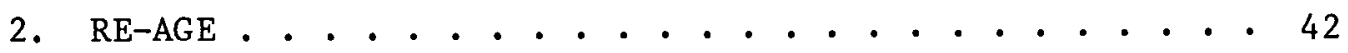

VII. FURTHER DISCUSSIUN . . . . . . . . . . . . . 50

VIII. CONCLUSIONS . . . . . . . . . . . . . . . . 51

IX. REFERENCES . . . . . . . . . . . . . . . . . . 52

APPENDIX A . . . . . . . . . . . . . . . . . 53 


\section{FIGURES}

1. Longitudinal section of the PBF-IPT . . . . . . . . . 3

2. Macrophotograph of fractured surface of the 30 degree bend test... . . . . . . . . . . . . . . . . . 7

3. Scanning electron microscope fractography of fractured surface of 30 degree bend test . . . . . . . . . . . 8

4. Scanning electron microscope fractography of fractured surface of 30 degree bend test at higher magnification. . . 8

5. Photomicrograph of fractured 30 degree bend test material. The section is longitudinal to the weld and roughly perpendicular to the fractured surface . . . . 9

6. Higher magnification view of fractured surface shown in Figure 5. The fracture followed the Laves phase stringers . . . . . . . . . . . . . . ... 10

7. Incipient crack from the 120 degree sample . . . . . . . 11

8. Higher magnification of incipient crack shown in Figure 7. The fracture followed the Laves phase stringers . . . . . . 12

9. Typical metallographic structure of the 180 degree bend sample at the face of the weld . . . . . . . . . . 13

10. Fractured surface of tensile specimen $\left(30^{\circ} \mathrm{B}\right)$ containing the $80 \mathrm{mil}$ inclusion. Striations resulting from Laves phase stringering is evident . . . . . . . . . . . . 14

11. Metallography of tensile specimen $\left(30^{\circ} \mathrm{C}\right)$, transverse to the dendrites and including the fractured surface. . . . . . . . . . . . . . . . 15

12. Fractured surface of impact sample $\left(30^{\circ} \mathrm{A}\right)$. . . . . . 16

13. Metallography including the fractured surface of $\left(30^{\circ} \mathrm{A}\right)$ impact sample... . . . . . . . . . . . . . . 16

14. Fractured surface of impact sample $\left(180^{\circ} \mathrm{D}\right)$. . . . . . 17

15. Metallography including the fractured surface of $\left(180^{\circ} \mathrm{D}\right)$ impact sample. . . . . . . . . . . . . . . . 17

16. Metallography of impact samples showing degree of recrystallization using $\mathrm{K}_{2} \mathrm{~S}_{2} \mathrm{O}_{5}$ as a tinting agent in the etchant........ . . . . . . . . . 18

17. Pseudobinary diagram for the formation of Laves phase . . 19 
18. Photomicrographs of weldments made by each welder using minimum current and argon cover gas . . . . . . . . . 24

19. Photomicrographs of weldments made by each welder using maximum current and argon cover gas . . . . . . . . . 25

20. Photomicrographs of weldments made by each welder using medium current and.argon cover gas... . . . . . . . . . . 26

21. Photomicrographs of weldments made by each welder using minimum current and helium cover gas . . . . . . . 27

22. Photomicrographs of weldments made by each welder using maximum current and helium cover gas . . . . . . . . . 28

23. Photomicrographs of weldments made by each welder using medium current and helium cover gas . . . . . . . . . . .

24. Typical high magnification photomicrographs of welds produced with argon covered gas at the three current settings . . . . . . . . . . . . . . . . 30

25. Typical high magnification photomicrographs of welds produced with helium cover gas at the three current settings . . . . . . . . . . . . . . 31

26. Typical microcracking observed . . . . . . . . . . 32

27. Photomicrographs of weldments made by each welder using the medium current procedure after heat treating 1 hour at $1925^{\circ}$ F................... 35

28. Photomicrographs of weldments made by each welder using the medium current procedure after heat treating 1 hour at $1975^{\circ}$ F. .................. .

29. Photomicrographs of weldments made by each welder using the medium current procedure after heat treating 1 hour at $2025^{\circ}$ F. . . . . . . . . . . . . . . .

30. Laves phase solution and redistribution after the $2025+25^{\circ} \mathrm{F}$ solution heat treatment.............. 38

31. Local anneal of nozzle weld mock-up . . . . . . . . . 40

32. Tensile sample location designations . . . . . . . . . . 44

33. Rockwe11 " $\mathrm{C}$ " hardness change as a function of re-age time at temperature . . . . . . . . . . . . . . . 


\section{TABLES}

I. Chemical Analysis . . . . . . . . . . . . . . 1

II. Mechanical Properties of Bend Test Material . . . . . . 5

III. Group I 718 Manual Weld Specimens 100\% Argon Torch

Shielding Gas ... . . . . . . . . . . . . . 22

IV. Group II 718 Manua1 Weld Specimens $75 \%$ Helium $25 \%$ Argon

Torch Shielding Gas . . . . . . . . . . . . . 23

V. Results of Mechanical Tests for Double Solution and

Double Age Heat Treated Weldments . . . . . . . . . 41

VI. Tensile Test Results for Single Solution and Double Age Heat Treated In-Pile Tube Parent Metal . . . . . . 41

VII. Tensile Test Results Obtained from Samples Attached to the In-Pile Tube During Planned Heat Treat

Procedures ............ . . . . . 4 45

VIII. Hardness as a Function of Time in Re-Aging Oven . . . . . 46

IX. Tensile Test Results of Samples (Previously Attached to the Tube During its Planned Heat Treatments) After Re-Aging. . . . . . . . . . . . . . . . . . 48

X. Tensile Test Results Obtained from Samples Attached to the In-Pile Tube During Both the Planned and Re-age Heat Treatments . . . . . . . . . . . . . . 49

XI. Results of 'l'ensile Test Containing Transvierse Welds . . . 54

XII. IPT Base Metal Tensile Tests . . . . . . . . . . 55

XIII. All Weld Tensile Tests . . . . . . . . . . 55 .

XIV. IPT Bend Test Results . . . . . . . . . . 56

XV. Comparison of Properties from $30^{\circ}$ Failed Bend Test Specimens Material to Properties of Unfailed Bend Test Specimen Material .. . . . . . . . . . . . 57 


\section{SUMMARY}

Although much information has been reported in the literature about the welding and heat treating of Inconel 718 , problems were encountered when the Power Burst Facility in-pile tube was fabricated from this material.

Inconel 718 is precipitation hardened by body centered tetragonal $\mathrm{Ni}_{3}$ ( $\mathrm{Cb}, \mathrm{Ti}, \mathrm{Al}$ ) called gamma prime. The precipitation of the gamma prime is sluggish which reduces the tendency to strain age crack. Alloy 718 is said to be one of the most readily weldable of the precipitation hardened nickel-base alloys. However, it has a large number of alloying elements and is metallurgically complex.

The literature indicates that an $8 \%$ elongation in weldments (a requirement for the in-pile tube) which have been solution heat treated at $1925 \mathrm{~F}$ followed by standard duplex aging, should easily be obtainable. Indeed, these values were attainable using a one inch gauge length tensile test, but when standard $5 \mathrm{~T}$ bend tests with longitudinal welds(which results in deformation of a relatively long portion of weld metal) were tested, localized areas of Laves phase embrittlement caused pre-mature fracture at a bend radius as low as 30 degrees. Hence, the first problem encountered was inadequate localized ductility in the weld metal.

Higher solution heat treat temperatures are known to improve ductility in the welds, but for this particular heat of Inconel 718 difficulty was experienced in achieving adequate strength for the main tube, 150 ksi yield, even with the $1925 \mathrm{~F}$ solution heat treat temperature. So the second problem encountered was inadequate strength in the parent metal.

The problems were solved by giving the welds a separate localized solution heat treatment at $2025^{\circ} \mathrm{F}$ before giving the entire assembly a $1925^{\circ} \mathrm{F}$ solution heat treatment followed by longer than the normal aging times. The assembly was first aged for the recommended 8 hours at $1325^{\circ} \mathrm{F}$ furnace cooled to $1150^{\circ} \mathrm{F}$ and held at $1150^{\circ} \mathrm{F}$ for 8 hours. When this proved to be inadequate the assembly was re-aged for 8 hours at $1325^{\circ} \mathrm{F}$, furnace cooled to $1150^{\circ} \mathrm{F}$ and held at $1150^{\circ} \mathrm{F}$ for 14 hours to give a total age plus re-age time of 42 hours. Since the welds were located on the inlet and outlet nozzles which were only required to have a yield of $127 \mathrm{ksi}$, the higher localized solution heat treatment of the welds was tolerable. The final minimum yield strength achieved for the main tube was $160 \mathrm{ksi}$. 


\section{INTRODUCTION}

The Power Burst Facility (PBF) in-pile tube (IPT) is a cylindrical pressure vessel designed for use in the $P B F$ reactor under transient conditions. The basic functions of the IPT are to provide a means of transporting experiments from the canal to the reactor and to provide the temperature, pressure, flow, coolant chemistry, and nuclear environment necessary for experimental programs. The overall configuration of the tube is shown in Figure 1 . There is an inlet and an outlet nozzle which were welded to the main tube. The design requires a minimum of $150 \mathrm{ksi}$ yield strength in the main tube and $127 \mathrm{ksi}$ yield strength in the nozzle with at least $8 \%$ elongation in both. Because of thermal stress considerations and space available the main tube was designed to 0.9 of the required yield strength. The purpose of this investigation was ( 1 ) to evaluate the metallurgical condition of the nozzle weldments and main tube as a result of failures in the welder qualification bend tests and (2) to conduct tests and make recommendations concerning heat treatments and welding procedures that would insure adequate strength and ductility.

The material selected for the IPT and nozzles is an age-hardenable nickel-chromium alloy called Inconel 718. It has been known that $(1)$ impact strength and ductility in welds of this material can be improved by the use of higher post weld solution heat-treatments but that higher. solution heat-treatments result in lower strength. The metallurgical problem encountered was to obtain adequate strength in the main tube without the loss of ductility in the nozzle welds.

The nozzles and IPT both come from the same heat of material. Their composition and that of the weld rod are shown in the accompanying table:

TABLE I

CHEMICAL ANALYSIS

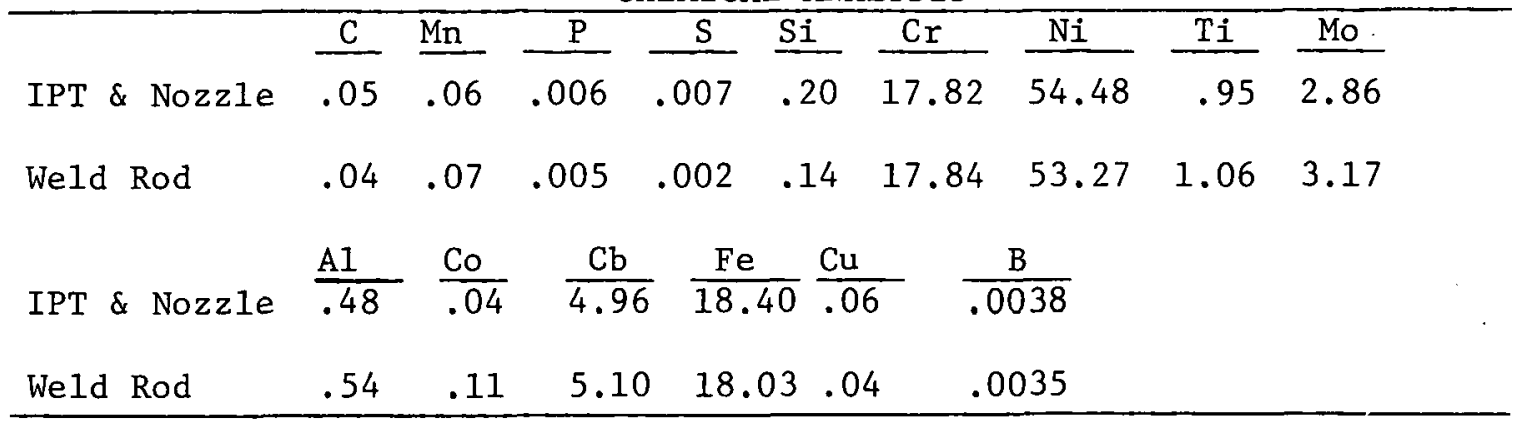

Ingots of this material were forged in various steps starting at furnace temperatures of $2050^{\circ} \mathrm{F}$ and ending at $1900^{\circ} \mathrm{F}$ resulting in maximum reductions from an $18^{\prime \prime}$ square to a $10^{\prime \prime}$ octagon. What was to be the upper portion of the tube was forged to a $111 / 2$ " octagon. A bulk head $111 / 2^{\prime \prime} \times 17^{\prime \prime}$ was formed where the nozzles were to be attached. 
Samples from the forgings and similar heats of material had been welded and heat treated to produce material qualification test samples to verify a single solution heat treatment of $1925^{\circ} \mathrm{F}$ followed by double aging at $1325^{\circ} \mathrm{F}$ and $1150^{\circ} \mathrm{F}$. Some of the bend tests of these welded single solution heat treated materials fractured indicating a problem with low localized weld ductility. This report contains information obtained from the examination of the failed bend tests, plus the evaluation of various welding and heat treating procedures which led to a solution to the problems. It also discusses what was done when tensile specimens, which were attached to the tube during its actual heat treatment, did not develop the required yield strength values.

\section{LOCALIZED WELD EMBRITTLEMENT}

When a series of welder and material qualification tests were run on the Inconel 718 material to be used for the IPT, two of the face $5 \mathrm{~T}$ bend tests produced by one welder using TIG, which contained welds longitudinal to the sample, fractured completely showing low ductility. One sample fractured after a 30 degree bend and the other after 120 degrees. Other TIG face bend samples by another welder passed the test with no failure after a 180 degree bend. Calculations show that if such a bend test would be completed to an angle of 180 degrees the outside fiber would have an elongation of about $9 \%$.

Although weld metal tensile samples, 8 transverse and 4 longtiudinal, were pulled before the bend tests were run the problem of low localized ductility was not detected*. The transverse samples all broke in the parent metal exhibiting elongations of 10 to $13 \%$. The longitudinal samples exhibited elongations ranging between 18 and $21 \%$. The bend test served the purpose of exposing a long section of weld metal to deformation so that areas of localized low ductility could be detected. Such areas were not detected in tensile samples with 1 " long gauge lengths.

A material examination was performed which mechanically and metallurgically compared the 30 degree bend sample to the 180 degree sample. An incipient crack in the 120 degree sample well away from the main fracture was also investigated. Samples of both the 30 degree material and the 180 degree material were made into tensile and impact specimens to check for differences in mechanical properties. It was found that variations in the amount of an interdendritic phase, called Laves phase, existed within the 30 degree and 120. degree material and to a lesser extent in the 180 degree material. In areas of high concentration (at fractured faces and 1ncipient cracks) the Laves phase is stringered along the dendritic grain boundaries, providing a path of reduced strength, reduced ductility and reduced toughness.

*See appendix "A". 


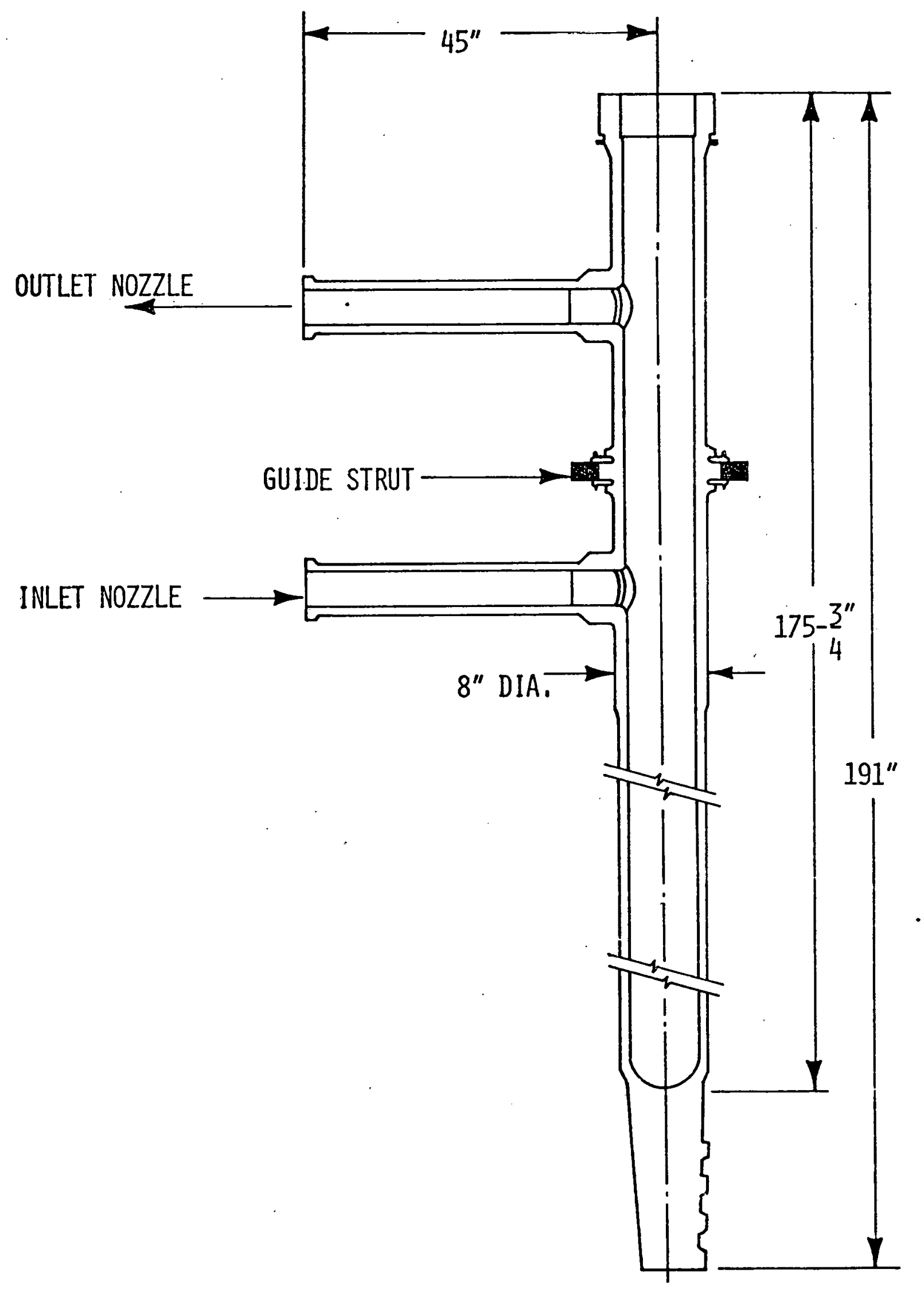

Figure 1 - Longitudinal section of the PBF -In-Pile Tube. 


\section{FRACTOGRAPHY AND METALLOGRAPHY OF FAILED BEND SAMPLES}

The macrophotography of the fractured face of the 30 degree bend specimen in Figure 2 shows a symmetrical pattern about a point on the outside fiber of the bend near the center of the weld face; suggesting the fracture originated in this region. There was no indication of a large inclusion or excessive porosity at this location or other areas of the fractured surface. Examination of the fractured surface at higher magnifications in the scanning electron microscope (SEM) (Figures 3 and 4 ) revealed a channeling or coring effect on the fractured face which produced striations at an interval of about $0.0004^{\prime \prime}$. At higher magnifications cracked particles of the Laves phase can be seen embedded in the fracture surface. Figure 5, a longitudinal metallographic section which included the face of the weld as one edge and the fractured surface as another edge, and Figure 6 at higher magnification, show that the fractured face follows the Laves phase stringering.

Metallographic viewing, as well as extensive SEM abservation, has shown that the fractures which occurred in the 30 degree and 120 degree samples, causing complete separation, were associated with an area of oriented Laves-phase.stringering. This stringering consistently retained its orientation in the various weld beads and was roughly perpendicular to the weld face and perpendicular to the axis of the weld.

A similar effect is seen in Figures 7 and 8 in an incipient crack from the 120 degree sample. The difference between this and the fractured area of the samples is that the Laves stringers do not continue through the material. They existed only in the surface weld beads. The crack terminated in the recrystallized material just beyond where the stringers terminated.

Although the 180 degree bend test samples exhibited small areas of stringered Laves phase, consistent orientation from weld bead to weld bead was not found and the quantity of Laves phase was much less. A typical longitudinal metallographic view of the 180 degree sample is shown in Figure 9 .

The ASTM standard grain size shows considerable variation in these materials and ran from medium to coarse, or size 4-5 for the 180 degree weld metal, and size 3-5 for the fractured weld metal sample. The only evidence of microcracking was associated with the Laves phase in stressed areas. 


\section{MECHANICAL PROPERTIES OF BEND TEST MATERIAL}

Four tensile samples and four Charpy V impact samples were prepared from the bend test weld metal material. The results are shown in Table II.

\section{TABLE II}

MECHANICAL PROPERTIES OF BEND TEST MATERIAL

\begin{tabular}{|c|c|c|c|c|c|c|}
\hline \multicolumn{2}{|c|}{$\begin{array}{c}\text { Sample } \\
\text { Designation } \\
\end{array}$} & $\begin{array}{c}\text { Yield } \\
\text { Strength } \\
\text { psi } \\
\end{array}$ & $\begin{array}{l}\text { Ultimate } \\
\text { Strength } \\
\text { pisi. }\end{array}$ & $\begin{array}{c}\% \\
\text { Elongation } \\
\text { in } 1^{\prime \prime} \\
\end{array}$ & $\begin{array}{c}\text { R.A. } \\
\%\end{array}$ & $\begin{array}{c}\text { Charpy V } \\
\text { ft. Ib. }\end{array}$ \\
\hline $30^{\circ}$ & (A) & ---- & --- - - & -- & -- & 19.8 \\
\hline $30^{\circ}$ & (B) & 153,000 & 173,000 & 4.5 & 8 & --- \\
\hline $30^{\circ}$ & (C) & 155,000 & 188,000 & 20 & 26 & --- \\
\hline $30^{\circ}$ & (D) & $\ldots$ & ----- & - & - & 22.2 \\
\hline $180^{\circ}$ & (A) & 165,000 & 197,000 & 22 & 33 & $-\cdots$ \\
\hline $180^{\circ}$ & (B) & ----- & $-\cdots$ & -- & -- & 26 \\
\hline $180^{\circ}$ & (C) & 160,000 & 192,000 & 20 & 39 & --- \\
\hline $180^{\circ}$ & (D) & --- & ------- & -- & -- & 27 \\
\hline
\end{tabular}

The 30 degree samples which had the more extensive, stringered and oriented Laves phase also had the poorer strengths, elongation, reduction of area and impact properties. An acceptable sized inclusion, $80 \mathrm{mils}$, was observed on the fractured face of one of the tensile samples $\left(30^{\circ} \mathrm{B}\right)$ which showed a $4.5 \%$ elongation. The 180 degree samples by comparison which had less Laves phase had more consistent and better properties.

The fractography and metallography of the tensile and impact samples produced from the 30 degree bend test material Figures 10,11 12 , and 13 again show the effects of larger quantities of Laves phase compared to the 180 degree material Figures 14 and 15 . It had been observed throughout the metallographic examinations that areas of high Laves phase did not show recrystallization. A special tinting etch was employed to illustrate this effect, Figure 16 , on the impact specimens.

\section{DISCUSSTON OF LOCALIZED WELD EMBRITTLEMENT}

There is considerable discussion in the literature about Laves phase in Inconel $718(2,3,4)$, its effect on strength, ductility, toughness and what promotes its formation and how to get rid of it. It is reported that Laves phase in castings is not affected by heat 
treatment below $2100^{\circ} \mathrm{F}$. Weldment ductilities are known to be benefited by a factor of 3 , by lowering welder heat inputs by a factor of 2 before a $1900^{\circ} \mathrm{F}$ solution anneal and double age. Also heat treatments of $1900^{\circ} \mathrm{F}$ and above show improvement in impact strength. A pseudobinary diagram (4), Figure 17, shows the relationship between columbium plus tantalum content and the formation of Laves phase as a function of temperature. From this diagram one would expect that the higher the columbium content and the slower the cooling rate from the melt to $22100^{\circ} \mathrm{F}$ the greater is the amount of Laves phase produced.

One would expect that some combination of low heat input during welding to promote rapid cooling and/or solution heat treat temperatures in excess of $1900^{\circ} \mathrm{F}$, but below $2100^{\circ} \mathrm{F}$, would have been adequate to insure the minimum $8 \%$ elongation. Even though strength is a function of columbium content, the amount of work in an ingot, and aging temperatures (1400 vs 1325 and 1200 vs 1150), one might also have expected that adequate strength, $150 \mathrm{ksi}$, yield could be combined with adequate ductility at some point in this solution heat treat range. In general, this initial attempt wherein the welds were solution heat treated at $1925^{\circ} \mathrm{F}$ and aged at $1325^{\circ} \mathrm{F}$ for 8 hours and $1150^{\circ} \mathrm{F}$ for 8 hours (furnace cooling between the two aging temperatures) met these requirements when evaluated by tensile test results. However, the bend test evaluation showed that there were isolated areas of stringered Laves phase providing a path of weakness and low ductility and that the stringered Laves phase was associated with areas where recrystallization had not occurred during heat treatment of the welds. The welds produced by one of the welders (whose designation was $\mathrm{W}-2$ ) showed almost complete recrystallization while the welds of the other welder (whose designation was $\mathrm{W}-4$ ) using nominally the same technique retained extensive dendritic areas. Since a stringer-free microstructure was not reliably produced,it was elected to undergo a weld and heat treating procedure evaluation to characterize these particular heats of material, if possible overcome the human factor, and the interaction between the two. 


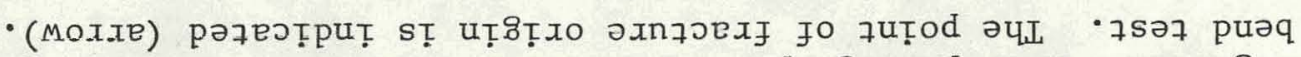

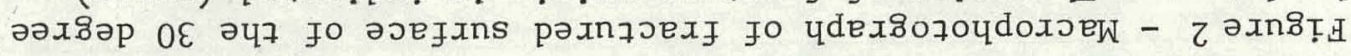
$\mathrm{X \varepsilon}$ кч

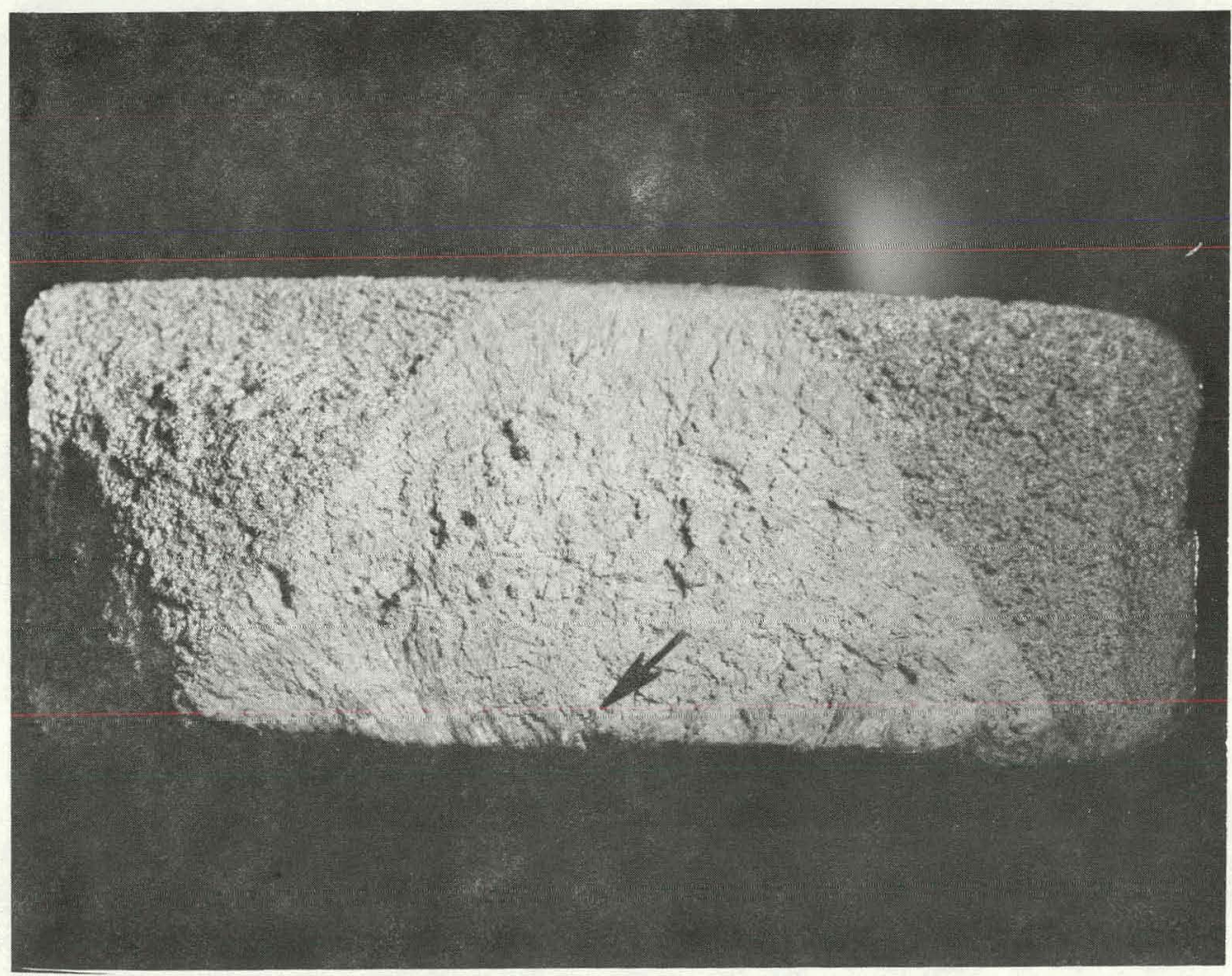




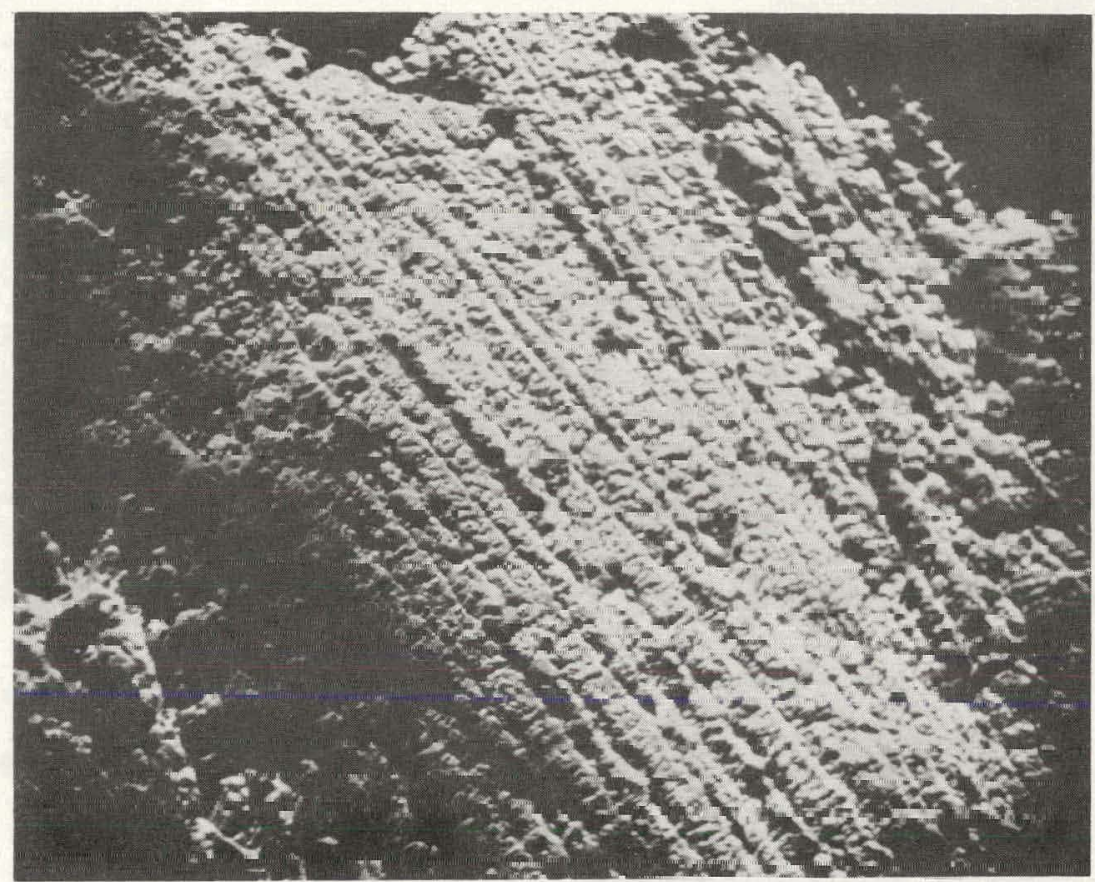

SEM Fractography

Figure 3 - Scanning electron microscope fractography of fractured surface of 30 degree bend test.

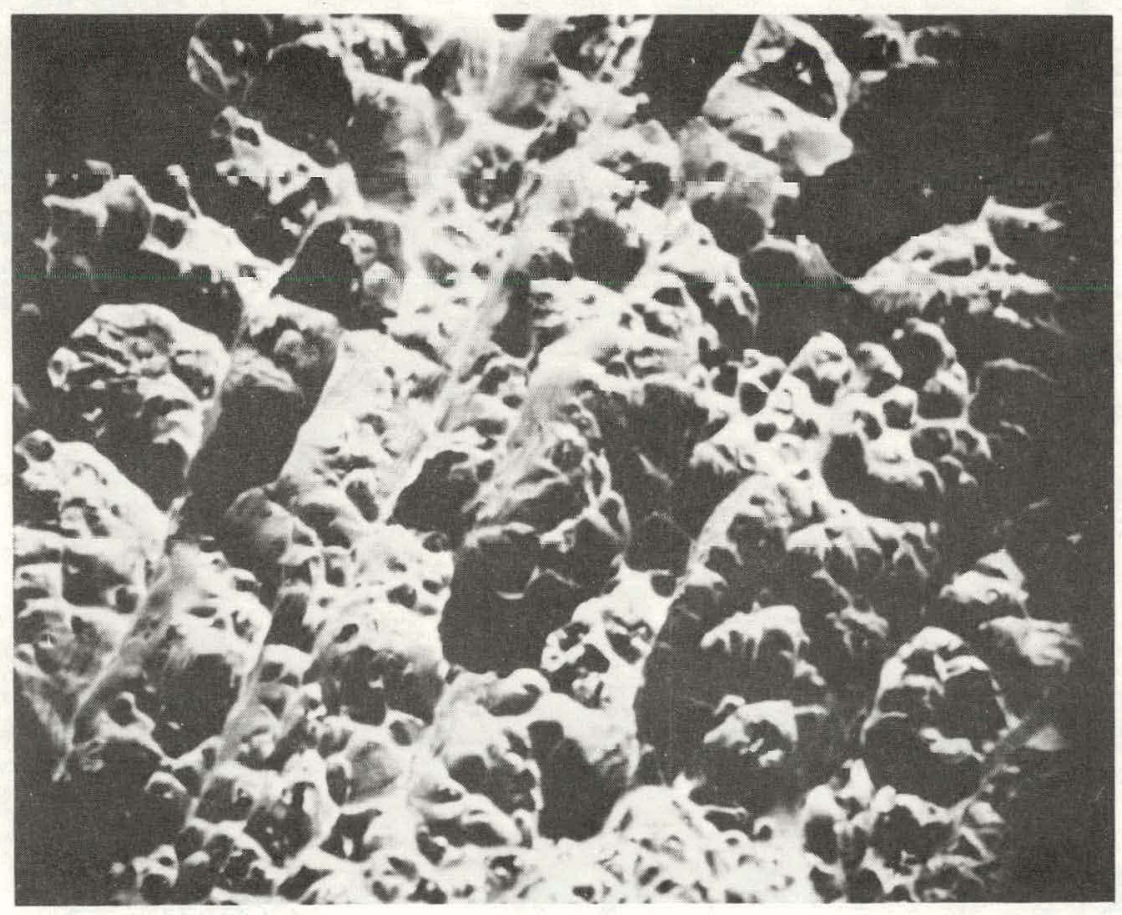

SEM Fractography

$1000 \mathrm{X}$

Figure 4 - Scanning electron microscope fractography of fractured surface of 30 degree bend test at higher magnification. 


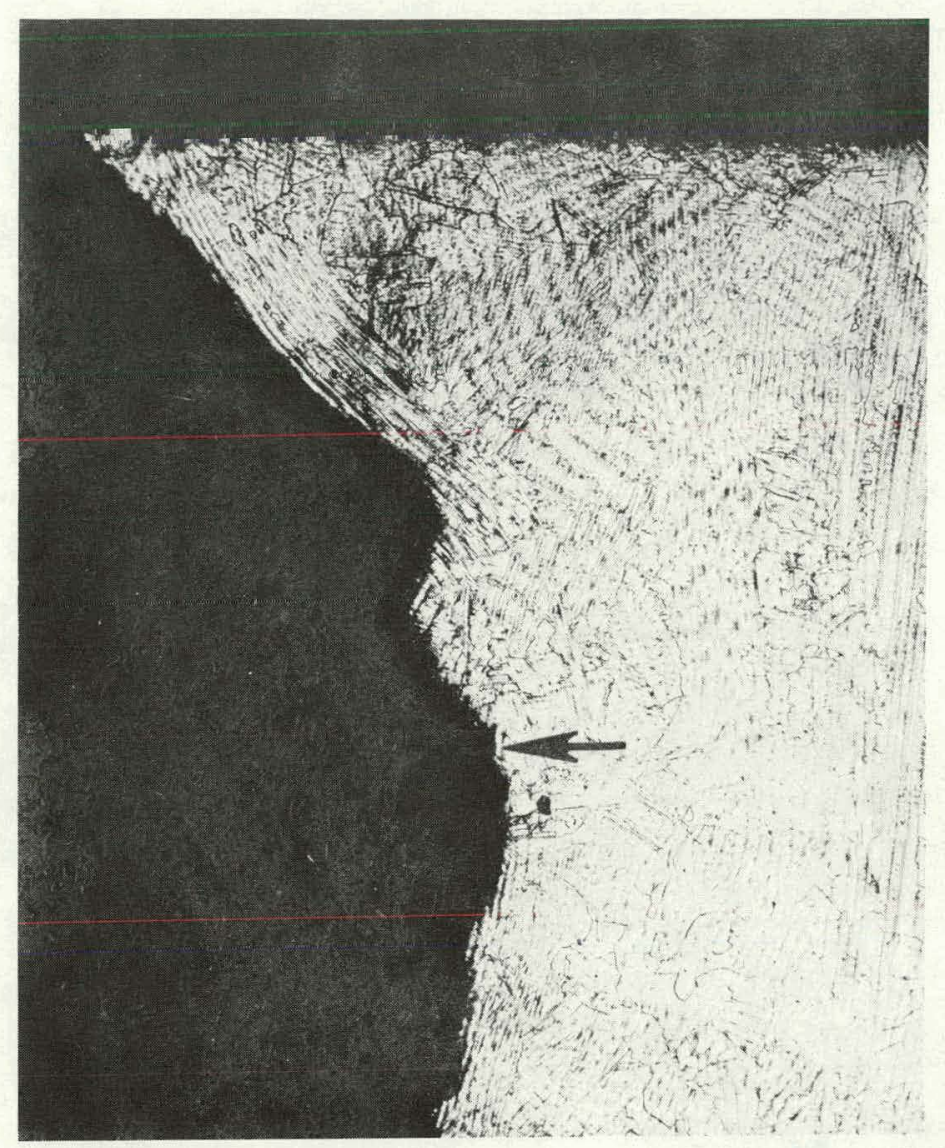

*HCL-Methano1 Etch

Figure 5 - Photomicrograph of fractured 30 degree bend test material. The section is longitudinal to the weld and roughly perpendicular to the fractured surface. The arrow indicates the fractured surface. *10\% HC1 in Methano1 


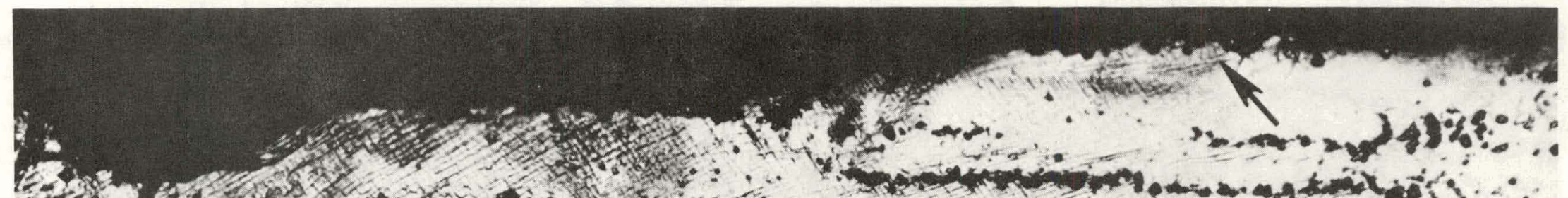

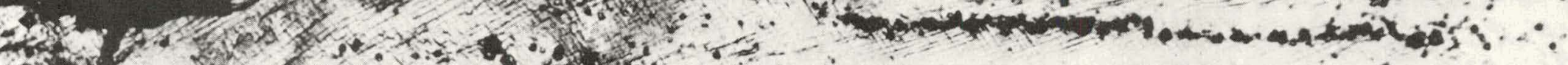

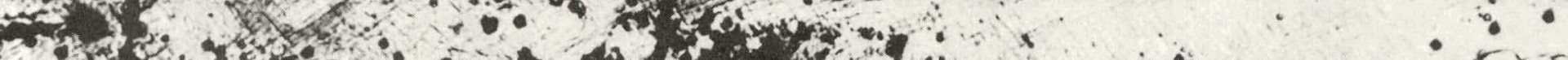

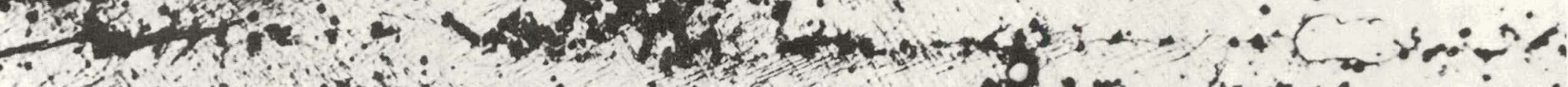

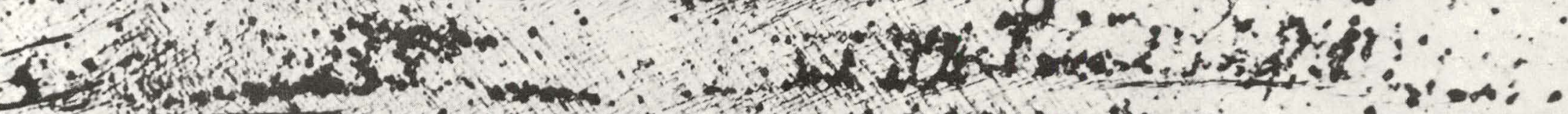

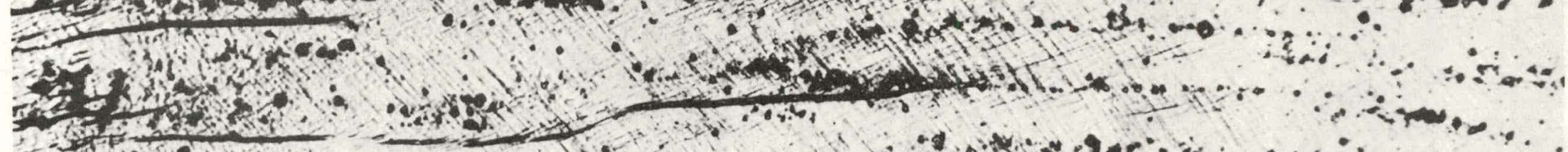

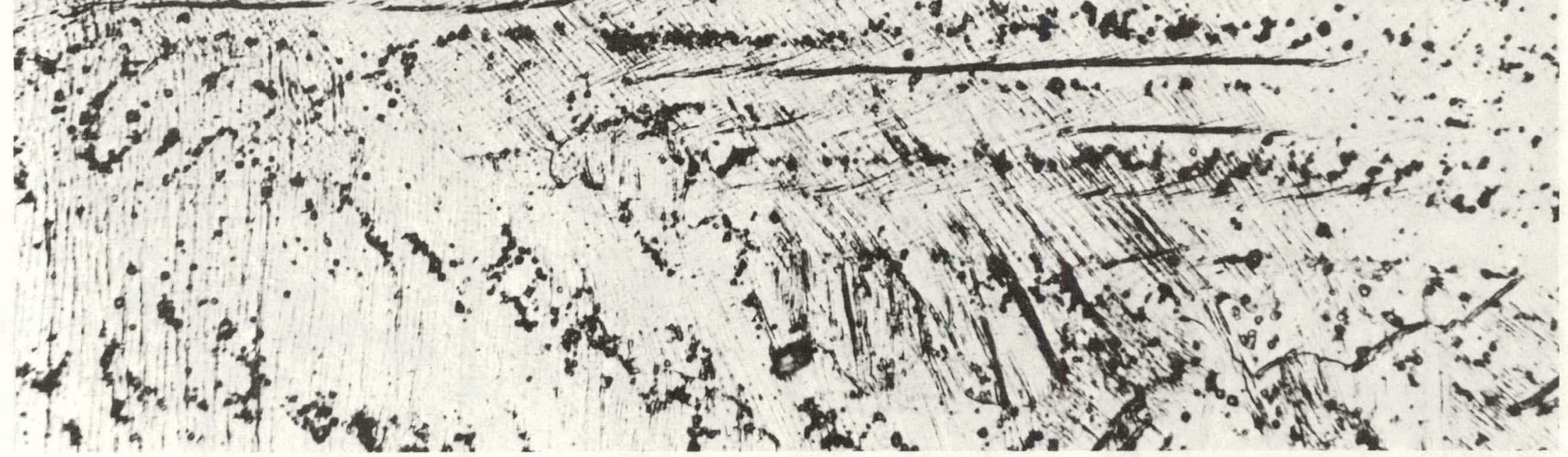

HC1-Methano1 Etch

$500 \mathrm{X}$

Figure 6 - Higher magnification view of fractured surface shown in Figure 5. The fracture followed the Laves phase stringers, arrow. 


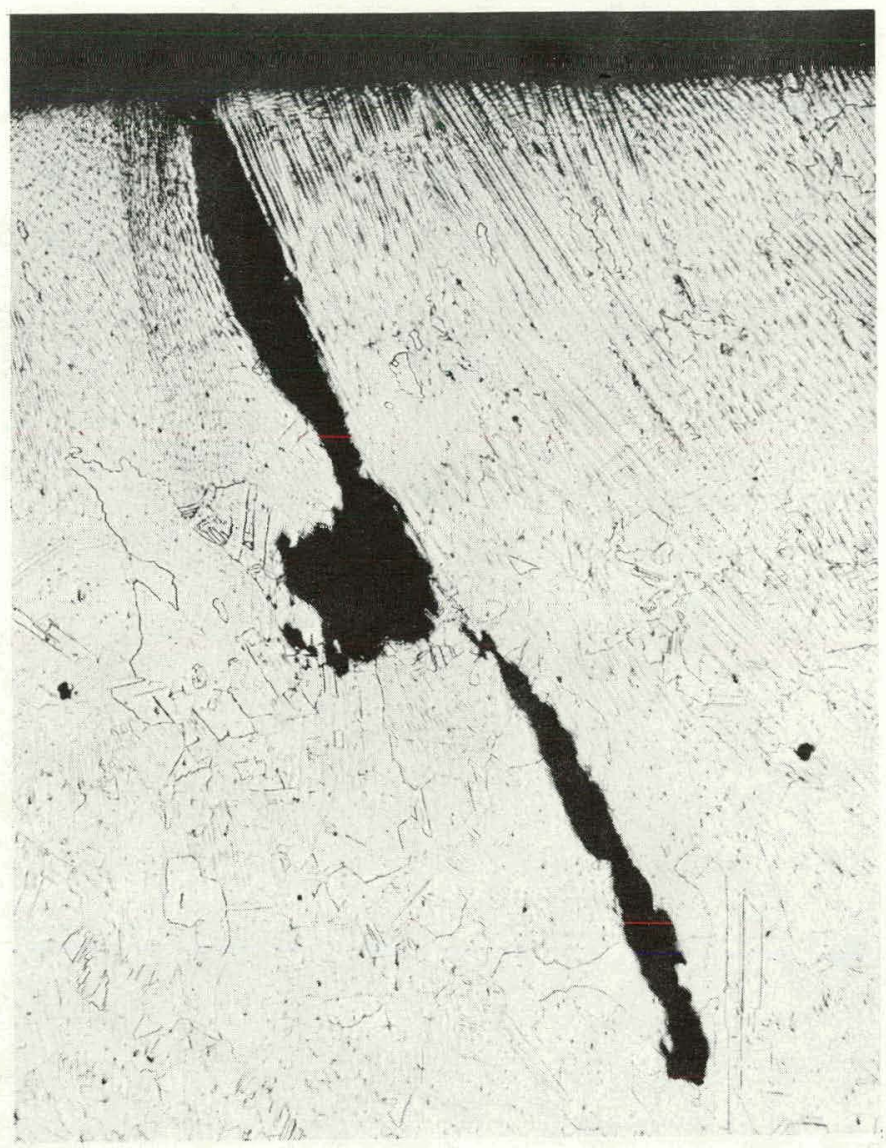

HC1 Methanol Etch

$50 \mathrm{X}$

Figure 7 - Incipient crack from the 120 degree sample. 


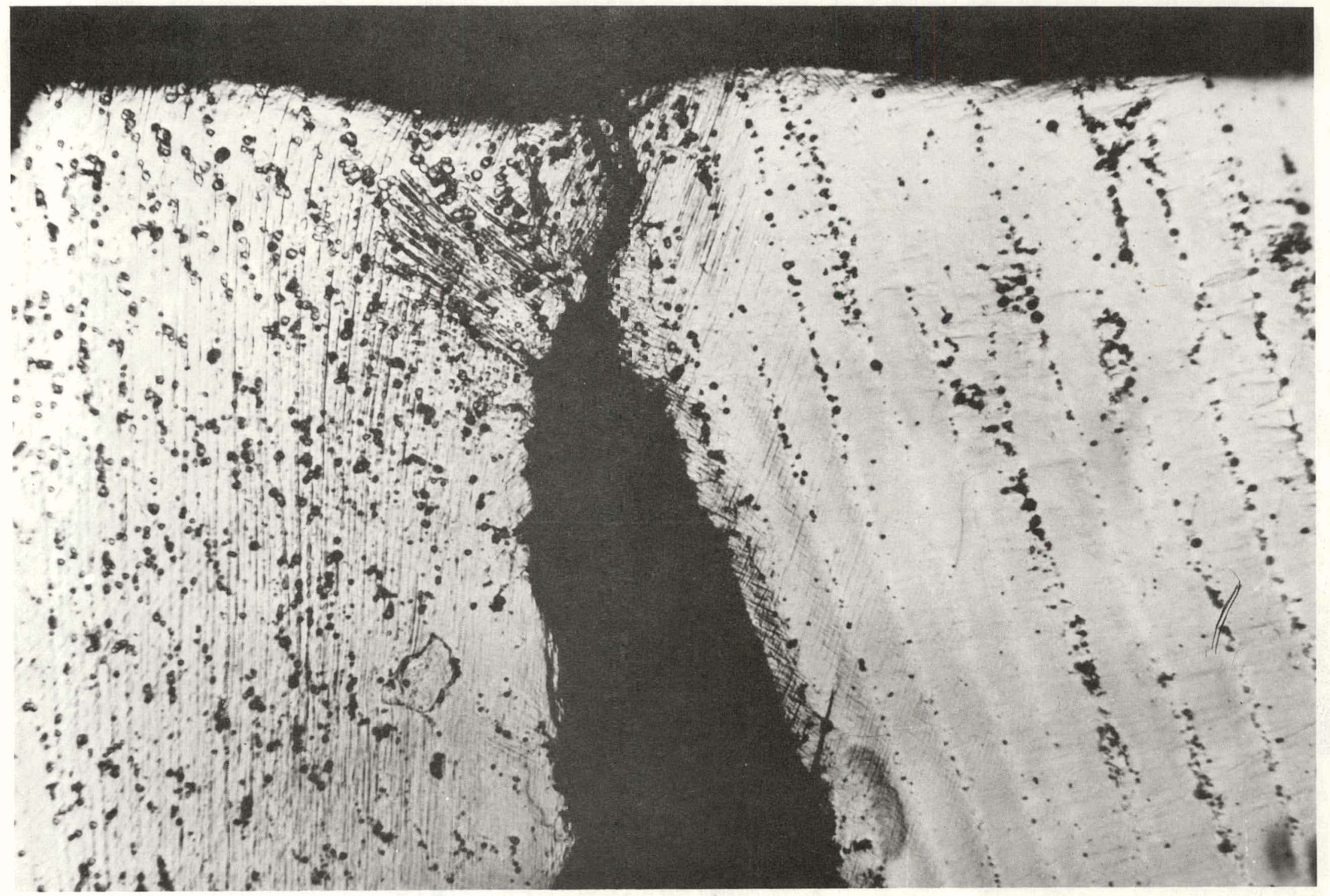

HC1-Methanol Etch

Figure 8- Higher magnification of incipient crack shown in Figure 7. The fracture followed the Laves phase stringers. 


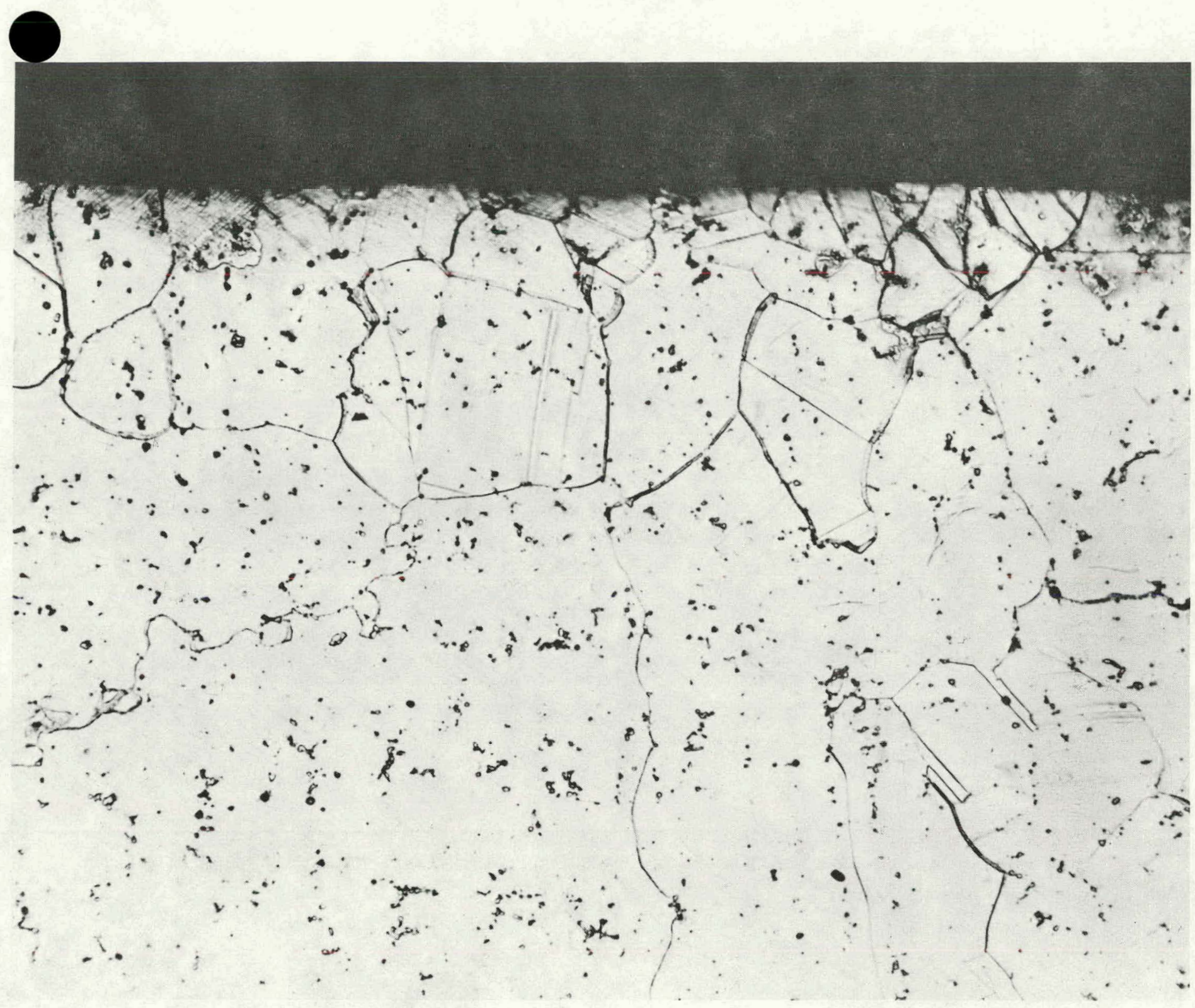

HC1 Methano1 Etch

$500 \mathrm{x}$

Figure 9 - Typical metallographic structure of the 180 degree bend sample at the face of the weld. 


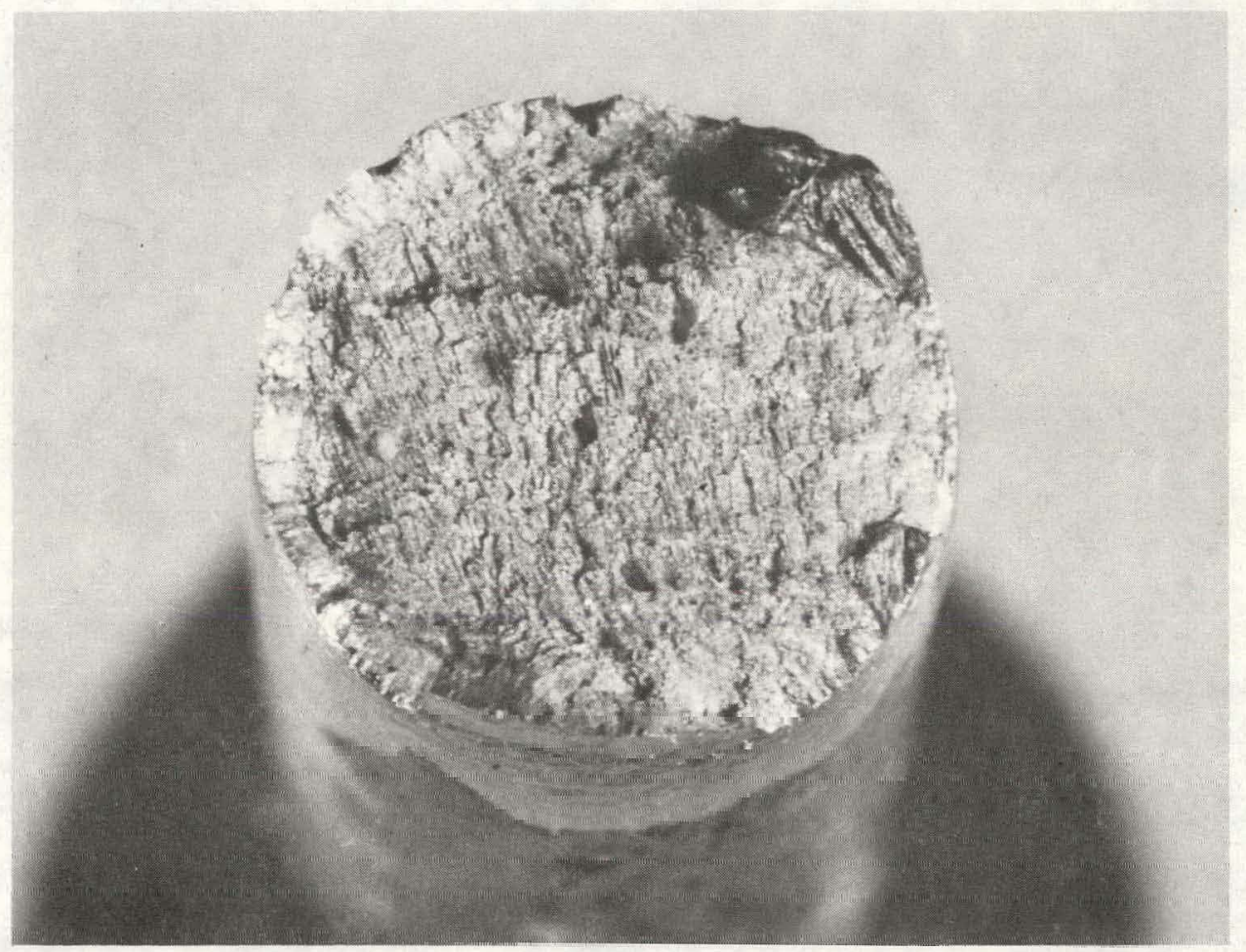

Macrophotograph

$\sim 10 \mathrm{X}$

Figure 10- Fractured surface of tensile specimen $\left(30^{\circ} \mathrm{B}\right)$ containing the $80 \mathrm{mil}$ inclusion. Striations resulting from Laves phase stringering is evident. 


\section{$\bullet$}

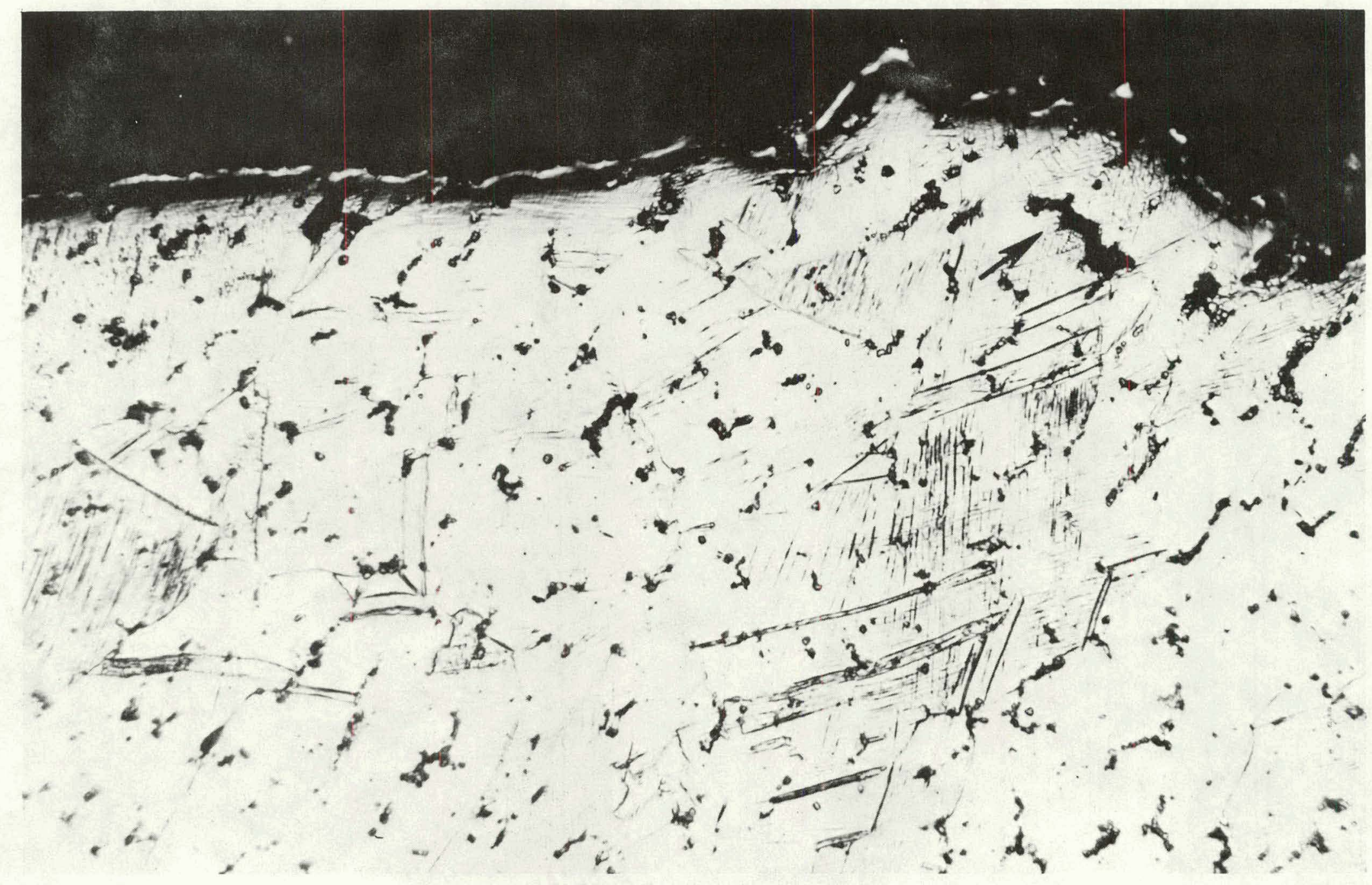

HC1-Methanol Etch

Figure 11 - Metallography of tensile specimen $\left(30^{\circ} \mathrm{C}\right)$, transverse to the dendrites and including the fractured surface. Note the microcracking at the Laves stringers, arrow. 


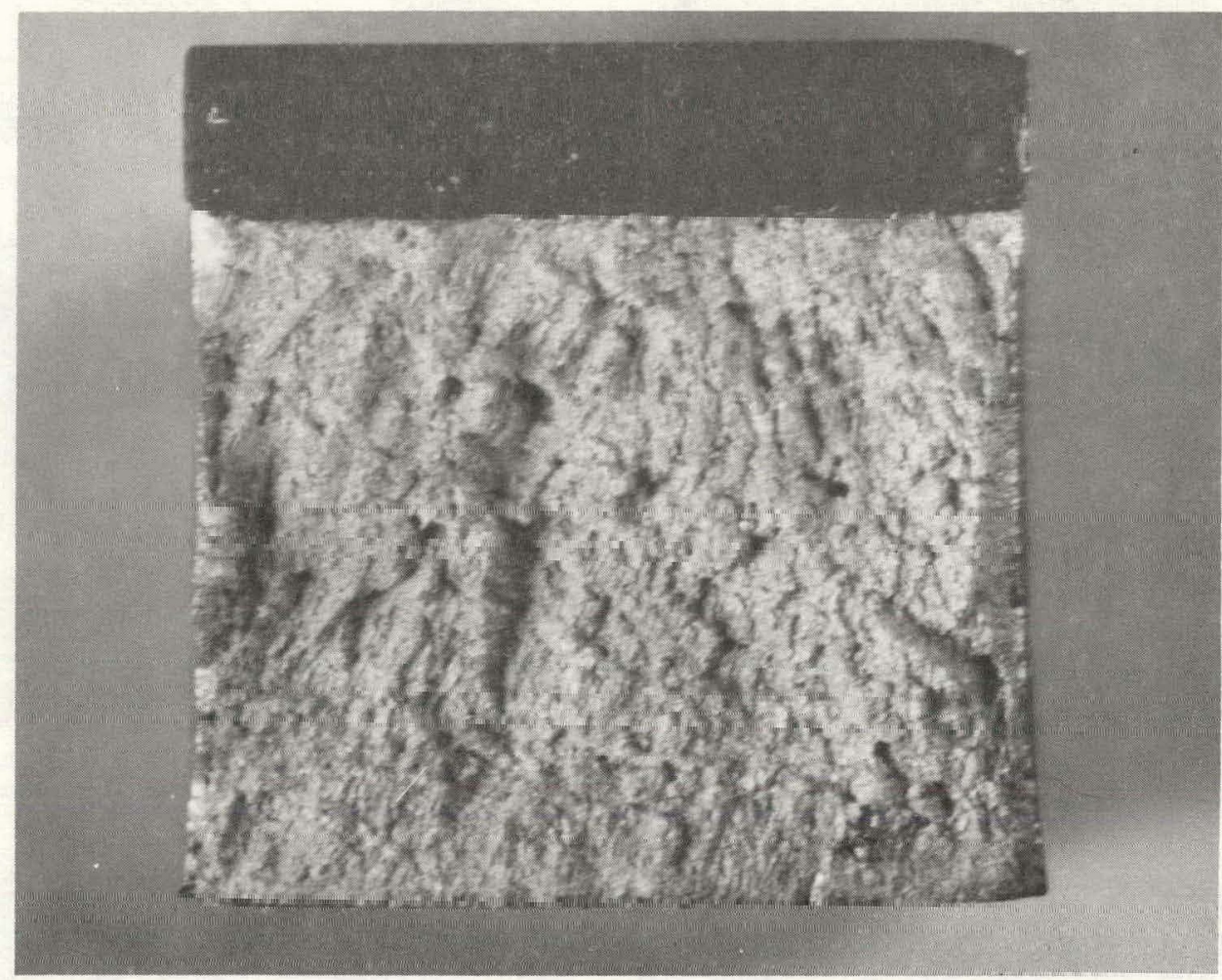

Macrophotograph

v $\mathrm{X}$

Figure 12 - Fractured surface of impact sample $\left(30^{\circ} \mathrm{A}\right)$.

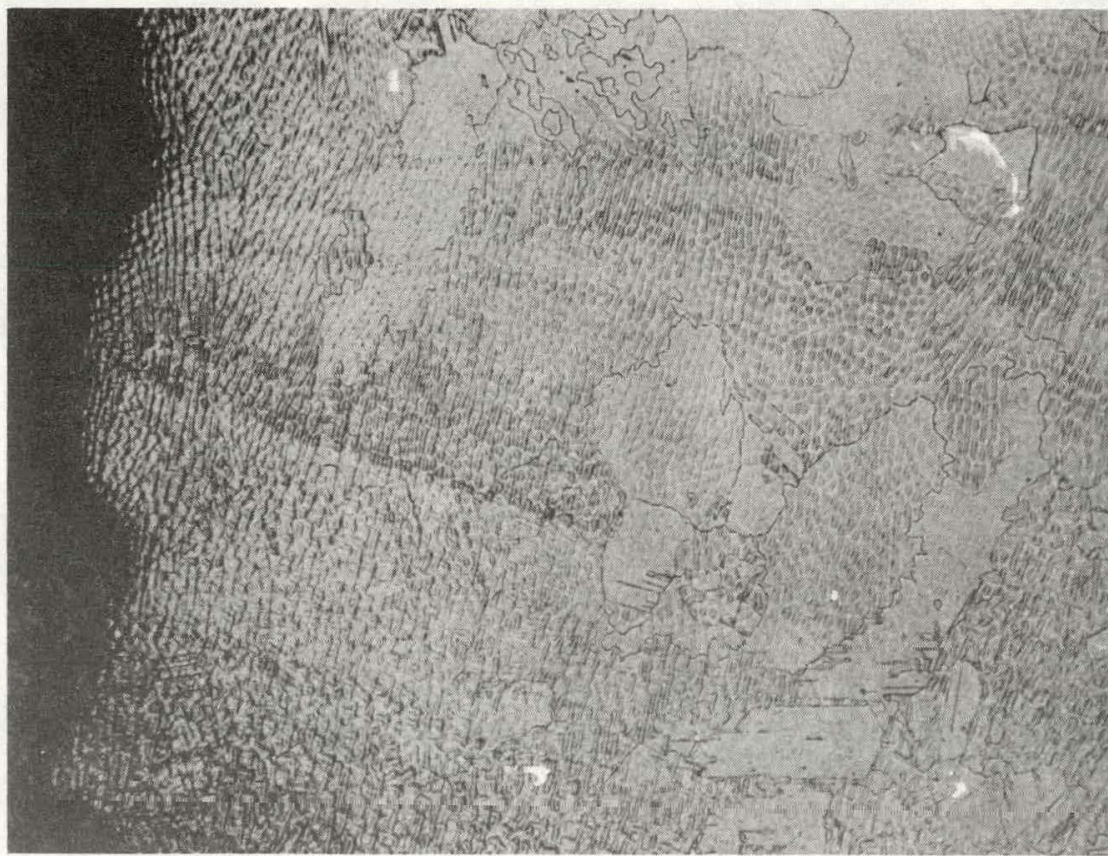

HC1-Methano1 Etch

Figure 13 - Metallography including the fractured surface of $\left(30^{\circ} \mathrm{A}\right)$ impact sample. 


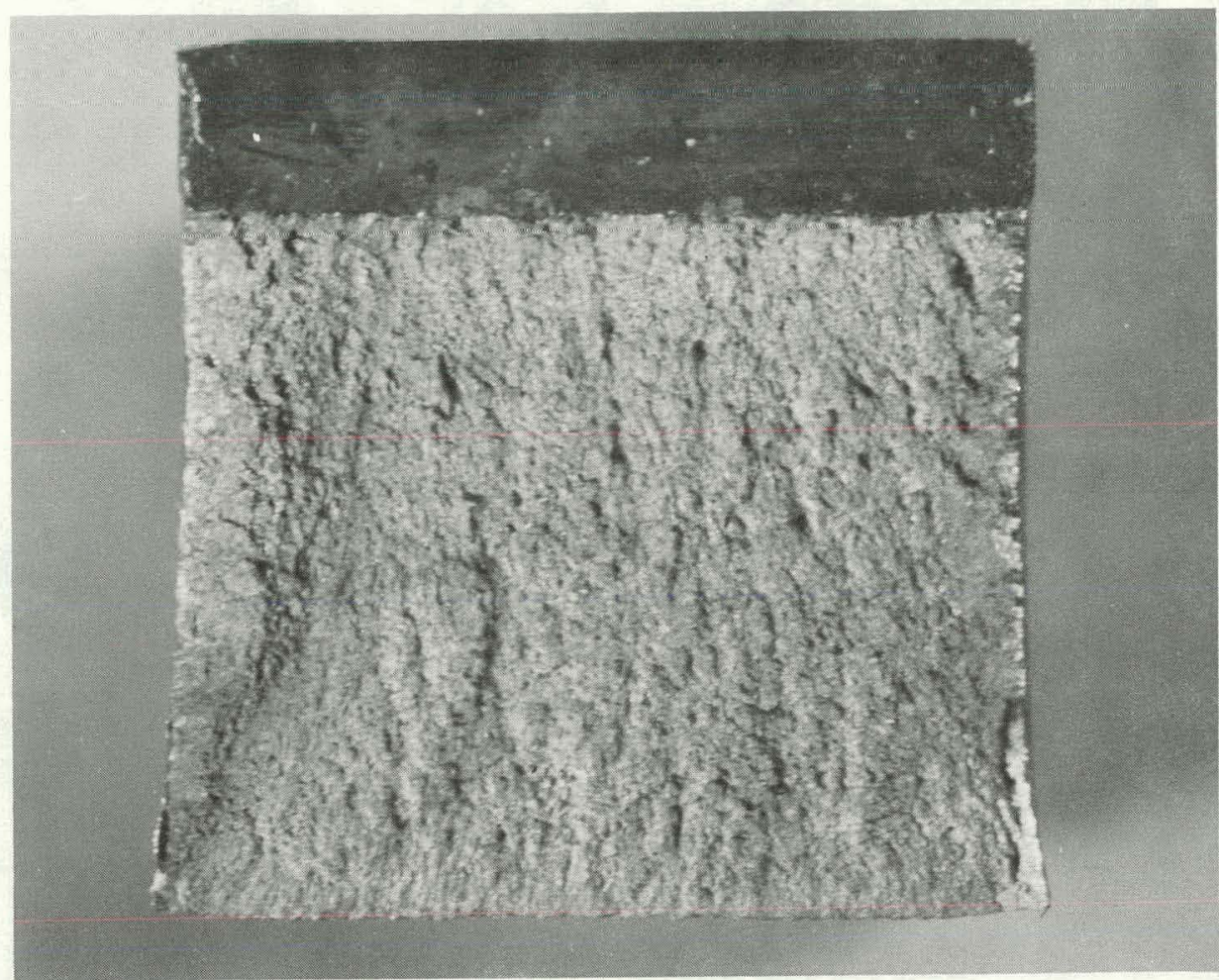

Macrophotograph

Figure 14 - Fractured surface of impact sample $\left(180^{\circ} \mathrm{D}\right)$.

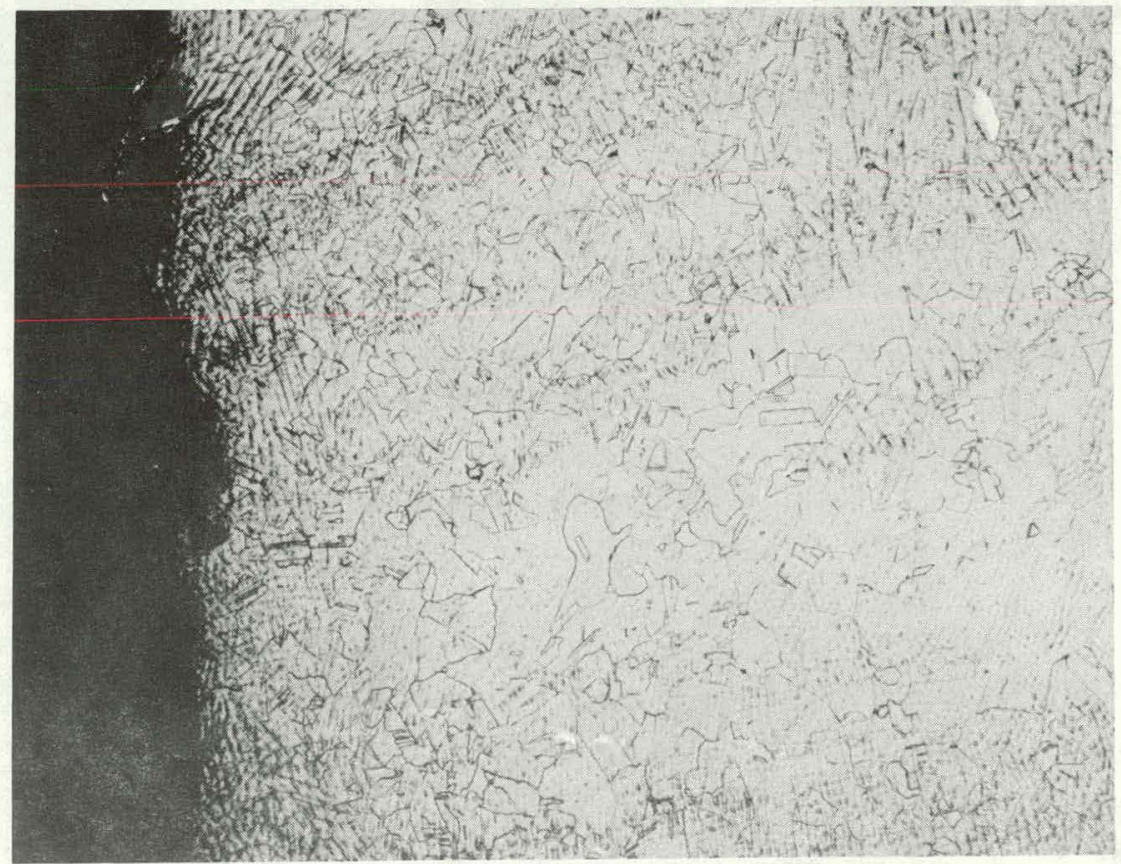

HC1-Methano1 Etch

Figure 15 - Metallography including the fractured surface of $\left(180^{\circ} \mathrm{D}\right)$ impact sample. 


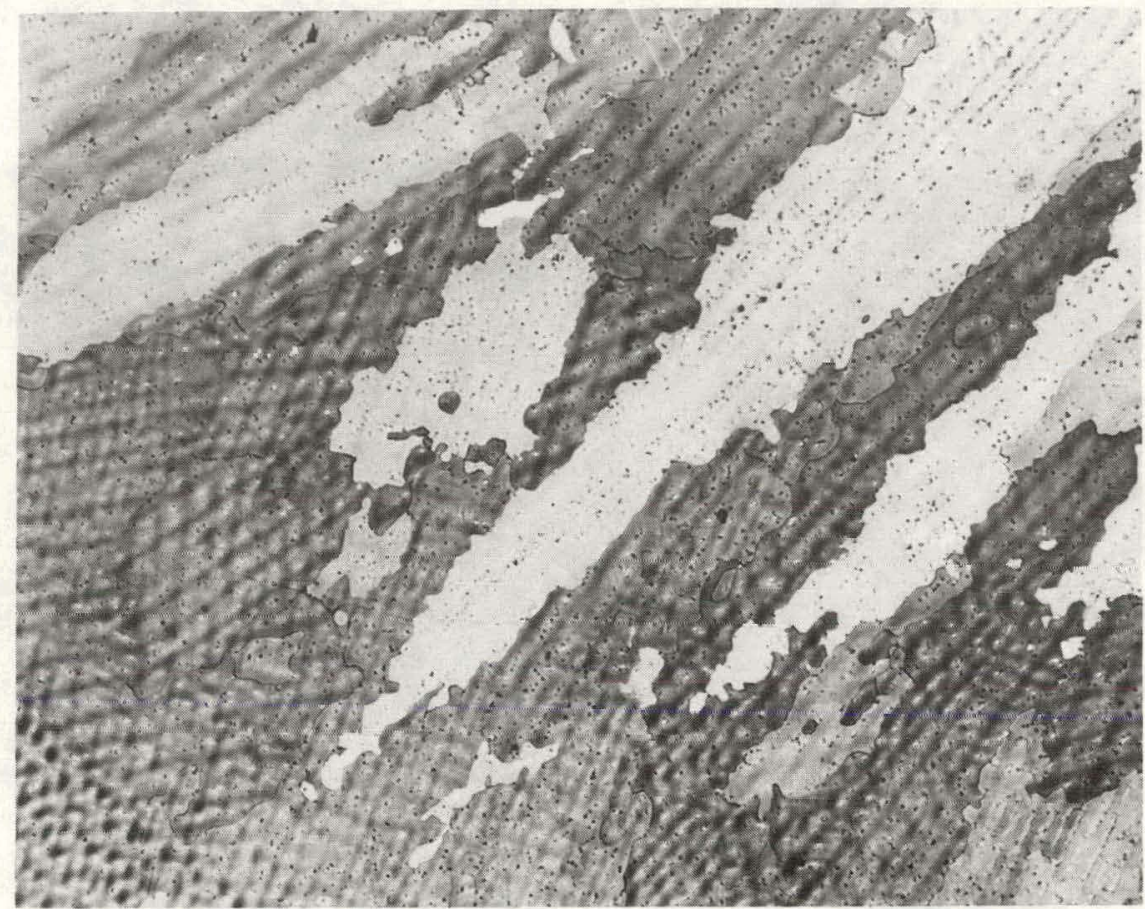

HC1-Methanol Tint

100X

Sample $30^{\circ} \mathrm{A}$

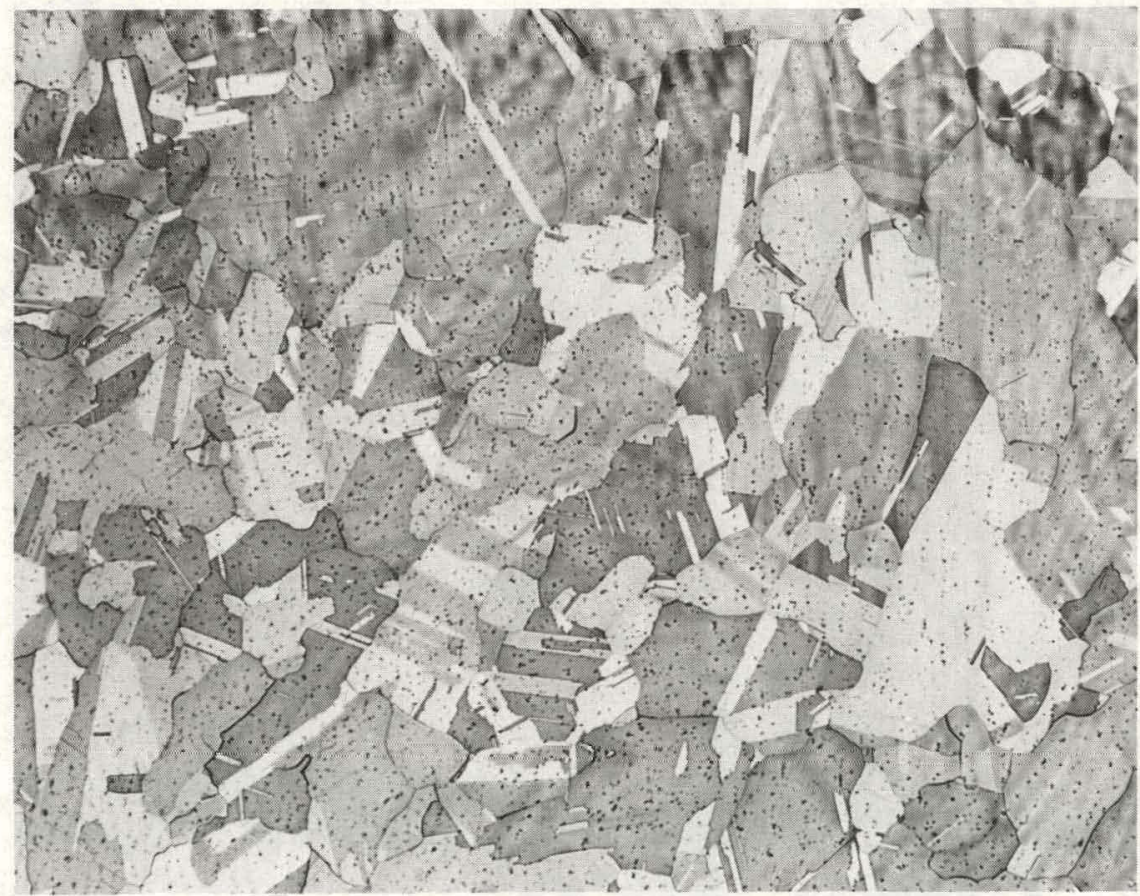

HC1-Methanol Tint

Sample $180^{\circ} \mathrm{D}$

100x

Figure 16 - Metallography of impact samples showing degree of recrystallization using $\mathrm{K}_{2} \mathrm{~S}_{2} \mathrm{O}_{5}$ as a tinting agent in the etchant. 


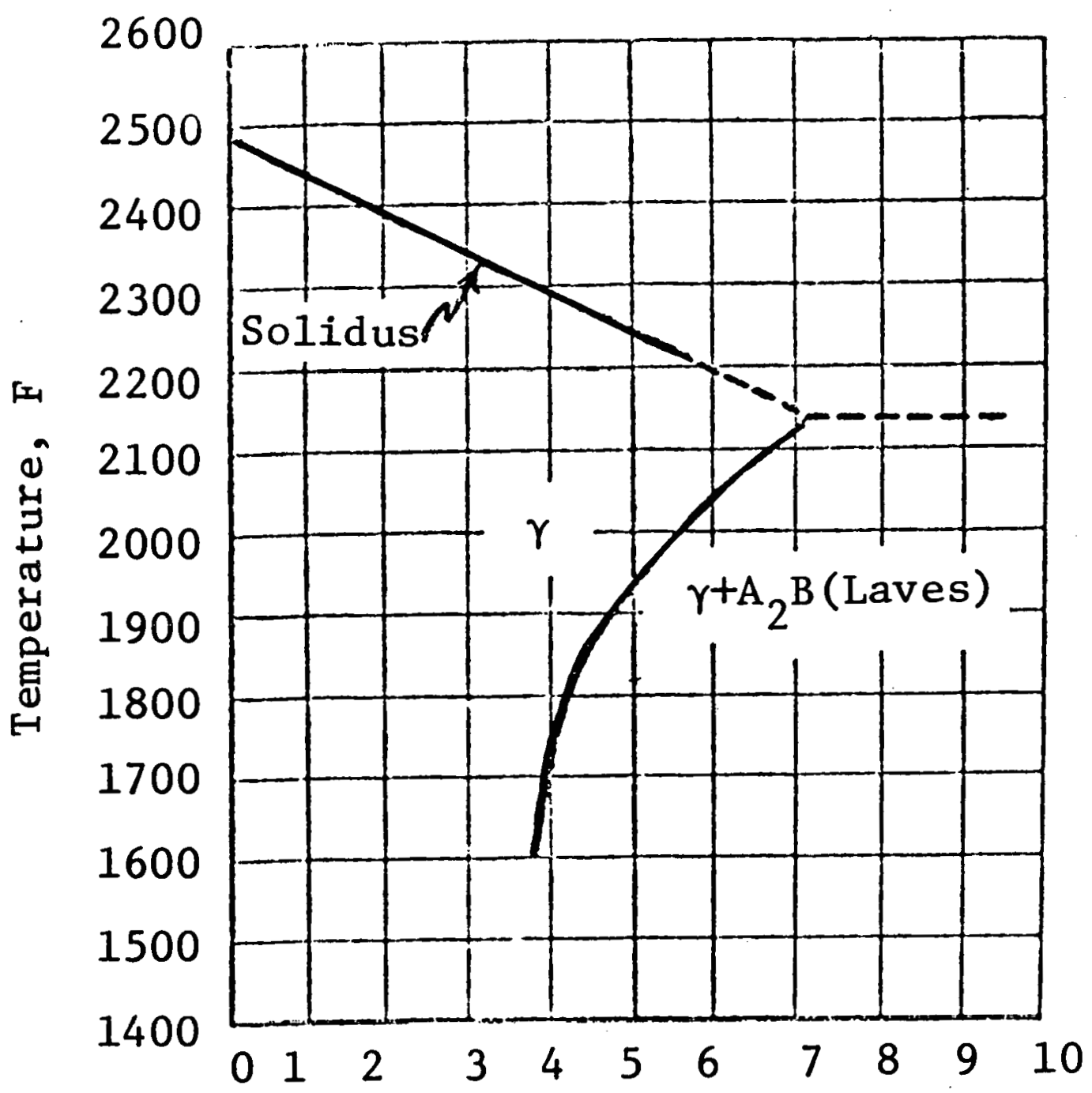

718 Base

Columbium + Tantalum Content, per cent

Figure 17 - Pseudobinary diagram for the formation of Laves phase. 


\section{WELDING PROCEDURES}

In order to determine why the $\mathrm{W}-4$ welds performed differently from the $\mathrm{W}-2$ and to determine what was necessary to produce a consistantly good weld, the history of previous welding procedures was reviewed, and a new series of carefully monitored test weld procedures was evaluated.

\section{HISTORY OF BEND TEST WELDS}

A review of the previous welding techniques suggests that the $W-4$ welds had higher heat inputs, since this welder required more total weld time which included cleaning and grinding between passes. The W- 4 and W-2 welds were made with separate machines but the same make and model number (Miller 非30A/BP). Both used about 20 cubic feet per hour of argon purge gas and both used about 145 amps for the first pass (with 0.050" weld filler rod) and 155 amps for subsequent passes ( $3 / 32$ " filler rod). Both welders used a small carbide cone-shaped burning tool followed by a power driven stainless wire brush to clean between passes. Tempil sticks were used to insure the interpass temperatures did not exceed $350^{\circ} \mathrm{F}$.

\section{TEST WELD PROGRAM}

An additional objective of the test welds was to determine if the Laves phase formation could be minimized by controlling those weld parameters which affect cooling rates.

To investigate the possibilities, a series of six $\mathrm{V}$ type weld joints were prepared by different heat inputs, (1) minimum current, minimum interpass temperature (2) maximum current, maximum interpass temperature and (3) medium current and medium interpass temperature, each with two different cover gases (1) $100 \%$ argon and (2) $75 \%$ helium, $25 \%$ argon. The weld parameters for the twelve welds were monitored and are tabulated in Tables III and IV. Pre-weld and postweld temperatures were monitored using Tempil sticks just prior to arc ignition and within 15 seconds after completion of a pass. On the "minimum" and "medium" welds the interpass temperature was controlled to maintain a pre-weld temperature at or below $150^{\circ} \mathrm{F}$ and $200 \mathrm{~F}$ respectively. On the maximum welds no interpass temperature control was used and the temperatures varied from $280^{\circ} \mathrm{F}$ to $400^{\circ} \mathrm{F}$. In every case but one, the $\mathrm{W}-4$ welder who produced the low ductility welds had lower heat input than the $\mathrm{W}-2$ welder, which, is contrary to expectations. 
Observations of the two welders during these tests revealed some differences in welding technique. While the $\mathrm{W}-4$ welder tended to maintain a steady, unwavering welding arc, W-2 welded with a slight circular oscillation which agitated or lightly stirred the molten puddle. The $W-4$ welder held a closer arc-to-work distance than did $W-2$. The $W-4$ welder fed considerably more wire into the arc than did $W-2$ producing a higher crown on the weld beads.

It was also observed that the selection of shielding gases had an effect on such welding characteristics as penetration, pattern, and bead contour. Changes in arc-length created smaller voltage changes with argon than with the argon-helium combination, an advantage for manual tungsten-arc welding. Since argon does not have as high a conductivity as helium, the all argon cover gas produced a hot spot directly below the arc giving rise to a " $U$ " shaped penetration bottom compared to a parabolic shape for the helium containing cover gas. The helium additions improved the weldability or flow characteristics of the weld metal making higher weld speeds possible. The resultant heat imputs were in the range of 20,000 to 40,000 joules per in. with either cover gas.

\section{METALLURGICAL EXAMINATION OF TEST WELDS}

Figures 18 through 23 show low magnification photomicrograph composites of the twelve welds and Figures 24 and 25 show typical high magnification photographs, all in the as-welded condition. It was found for the range of heat inputs tried in this study that the formation of Laves phase could not be suppressed. Long stringers of interdendritic Laves phase were formed during each welding procedure and by each welder. No one procedure could be selected as having less Laves phase.

Microcracking was observed in the heat affected zone in every "minimum" and "maximum" current argon cover gas weld, produced by each of the welders. Typical microcracking is shown in Figure 26 Microcracking was not observed in any of the "medium" current argon or any of the helium cover gas welds. The parent metal for all of these test welds was from the same heat of material and in the same metallurgical condition, so grain size was not a factor(5). 


\section{TABLE III}

GROUP I 718 MANUAL WELD SPECIMENS $100 \%$ ARGON TORCH SHIELDING GAS

\begin{tabular}{|c|c|c|c|c|c|c|}
\hline \multirow{2}{*}{$\begin{array}{l}\text { Direct Current } \\
\text { "Nelding Condition }\end{array}$} & \multicolumn{2}{|c|}{$\begin{array}{l}\text { No. } 1 \text { - Min. Current } \\
\text { Min. Inter-Pass Temp }\end{array}$} & \multicolumn{2}{|c|}{$\begin{array}{l}\text { No. } 2 \text { - Max. Current } \\
\text { Max. Inter-Pass Temp }\end{array}$} & \multicolumn{2}{|c|}{$\begin{array}{l}\text { No. } 3 \text { - Med. Current } \\
\text { Med. Inter-Pass Temp }\end{array}$} \\
\hline & $\mathrm{W}-4$ & $\mathrm{~W}-2$ & $W-4$ & $\mathrm{~W}-2$ & $W-4$ & $\mathrm{~W}-2$ \\
\hline Amperage & 94 & 106 & 153 & 153 & 146 & 140 \\
\hline Arc Voltage (v) & 12 & 11.8 & 13.6 & 14.0 & 13.7 & 14.2 \\
\hline Weld Pass Length (in.) & $5 \frac{1}{4} "$ & $5 \frac{1}{4} "$ & $5 \frac{1}{4} "$ & $5 \frac{1}{4}$ & $5 \frac{1}{2}$ & $5 \frac{1}{2}$ \\
\hline Arc Time per Pass (Sec) & 89 & 115 & 108 & 124 & 96 & 94 \\
\hline Weld Travel Speed (ipm) & 3.54 & 3.28 & 2.91 & 2.54 & 3.28 & 3.36 \\
\hline Weld Heat In-Put (joules per in.) & 19118 & 27392 & 42971 & 46661 & 39942 & 34011 \\
\hline $\begin{array}{l}\text { Weld Rod Used per Pass (1n.) } \\
\text { Weld Rod Dia }=3 / 32 \text { (in.) }\end{array}$ & 7.0 & $47 / 8$ & $137 / 8$ & $123 / 4$ & $911 / 16$ & $83 / 8$ \\
\hline Pre-Weld Part Temp. $\left({ }^{o} F\right)$ & 150 & 150 & 400 & 400 & 200 & 200 \\
\hline Post-Weld Part Temp $\left({ }^{o} F\right)$ & 443 & 537 & 800 & 812 & 458 & 470 \\
\hline Shielding Gas (argon) Flow Rate (cfh) & 20 & 20 & 20 & 20 & 20 & 20 \\
\hline
\end{tabular}


$\underline{\text { TABLE IV }}$

GROUP II 718 MANUAL WELD SPECIMENS

$75 \%$ Helium - 25\% ARGON TORCH SHIELDING GAS

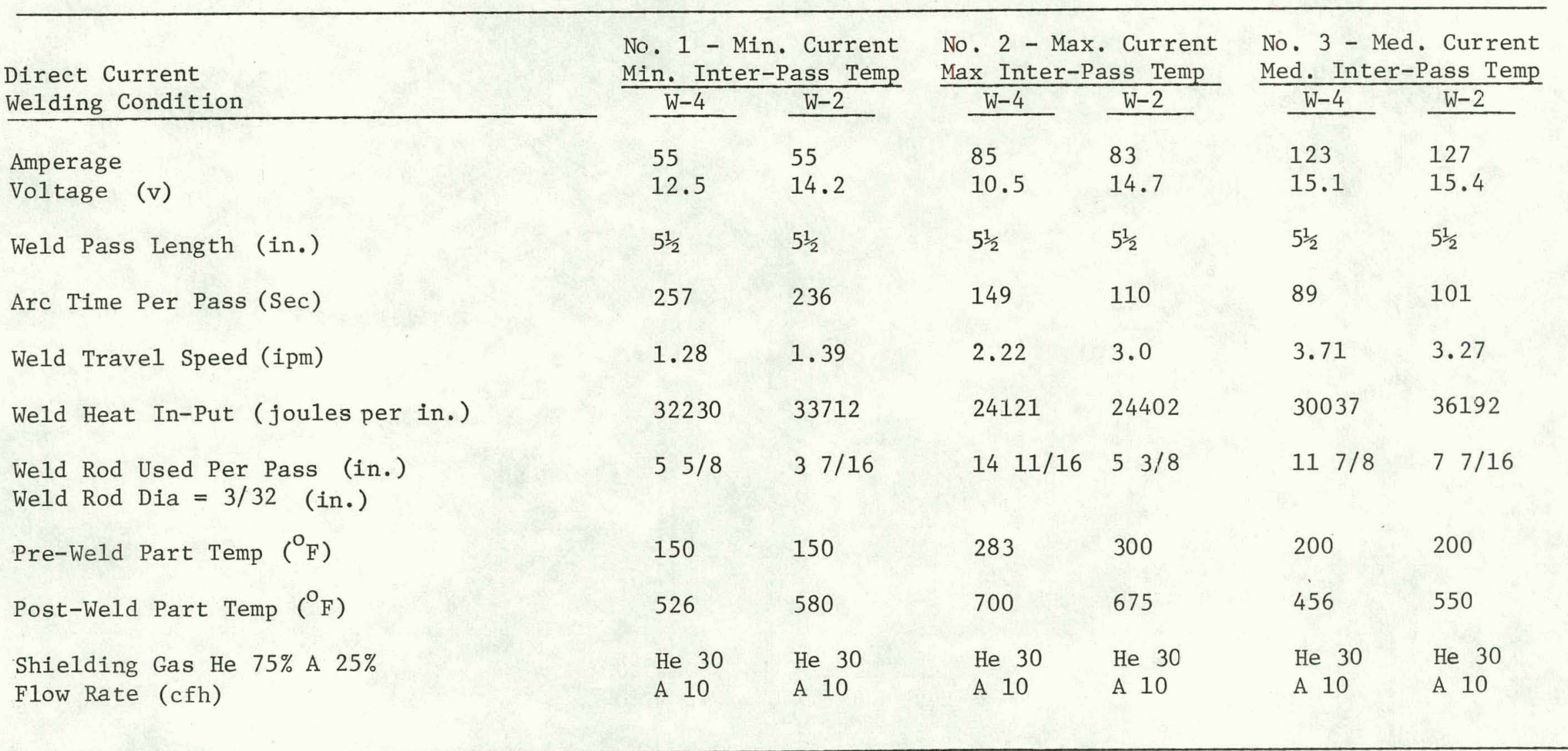




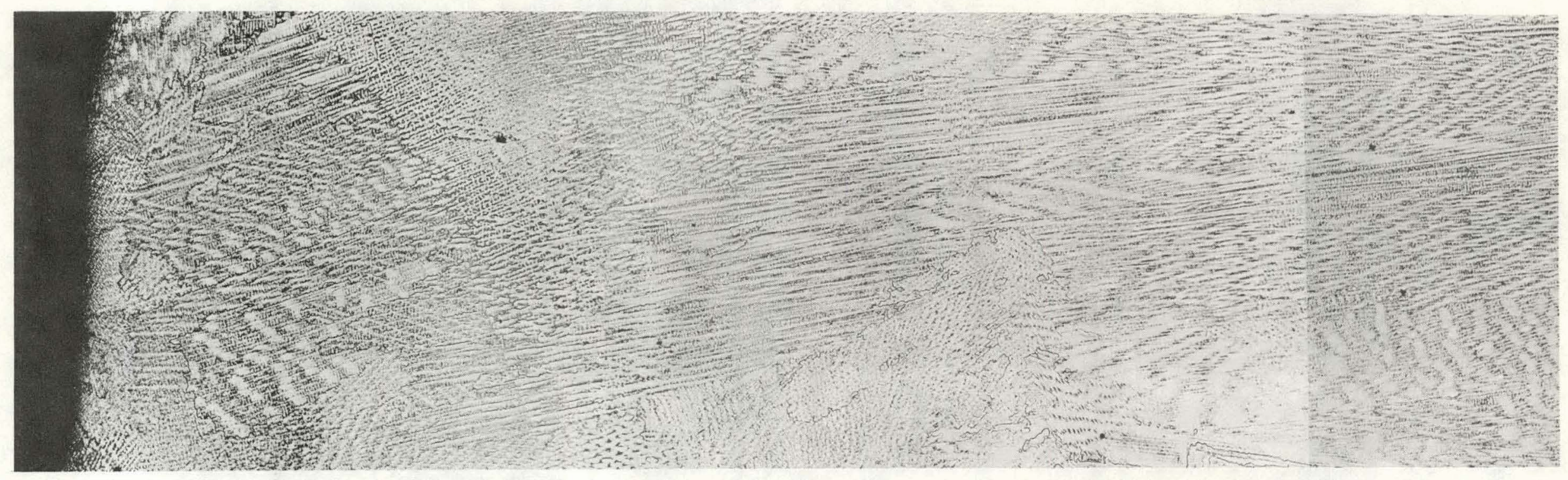

HC1-Methano1 Etch

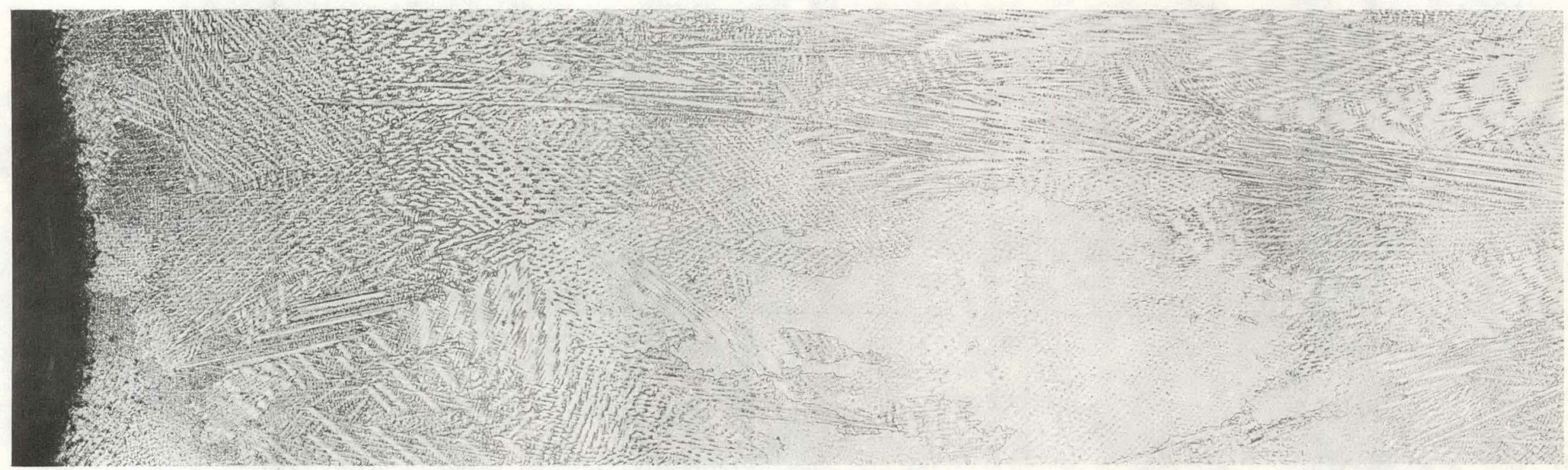

HC1-Methanol Etch

Figure 18 - Photomicrographs of weldments made by each welder using minimum current and argon cover gas. 


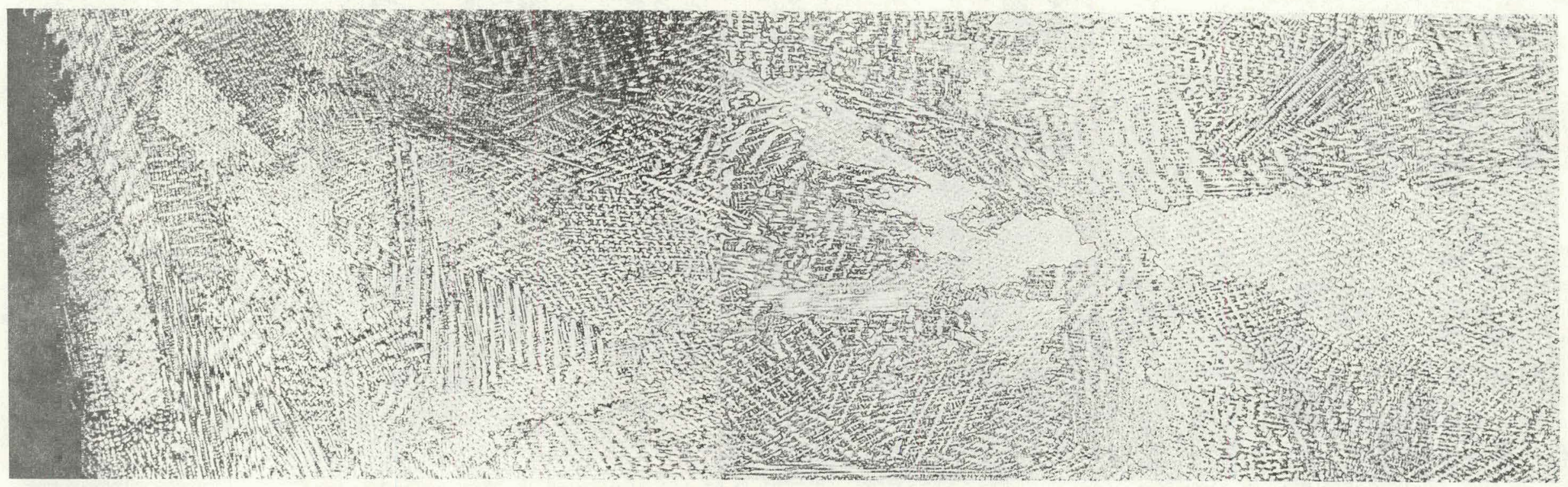

HC1-Methanol Etch

Welder W-2

$50 x$

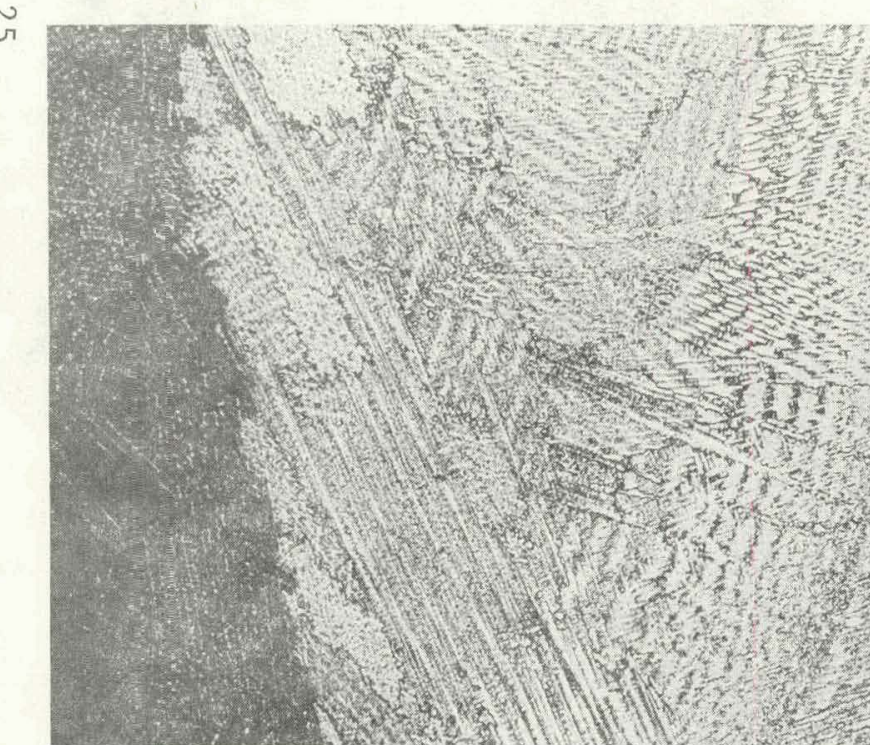

HCl-Methanol Etch

We1der $\mathrm{W}-4$

$50 \mathrm{X}$

Figure 19 - Photomicrographs of weldments made by each welder using maximum current and argon cover gas. 


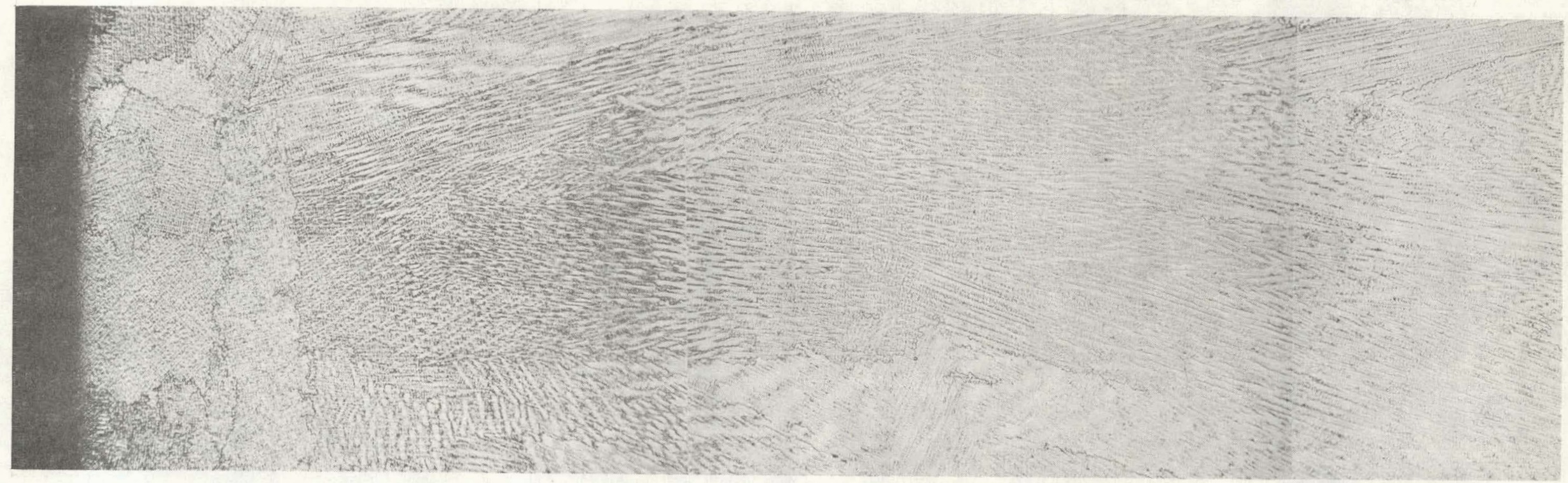

HC1-Methanol Etch

Welder W-2

$50 \mathrm{x}$

N

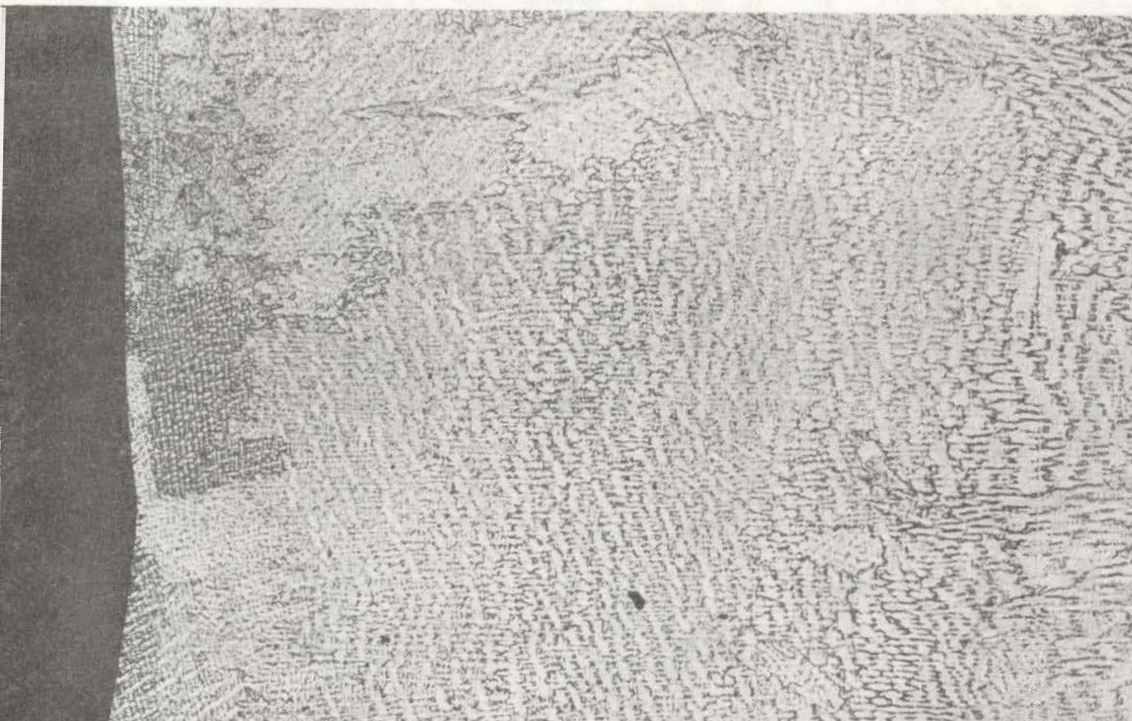

HC1-Methanol Etch

Welder W-4

$50 \mathrm{X}$

Figure 20 - Photomicrographs of weldments made by each welder using medium current and argon cover gas. 

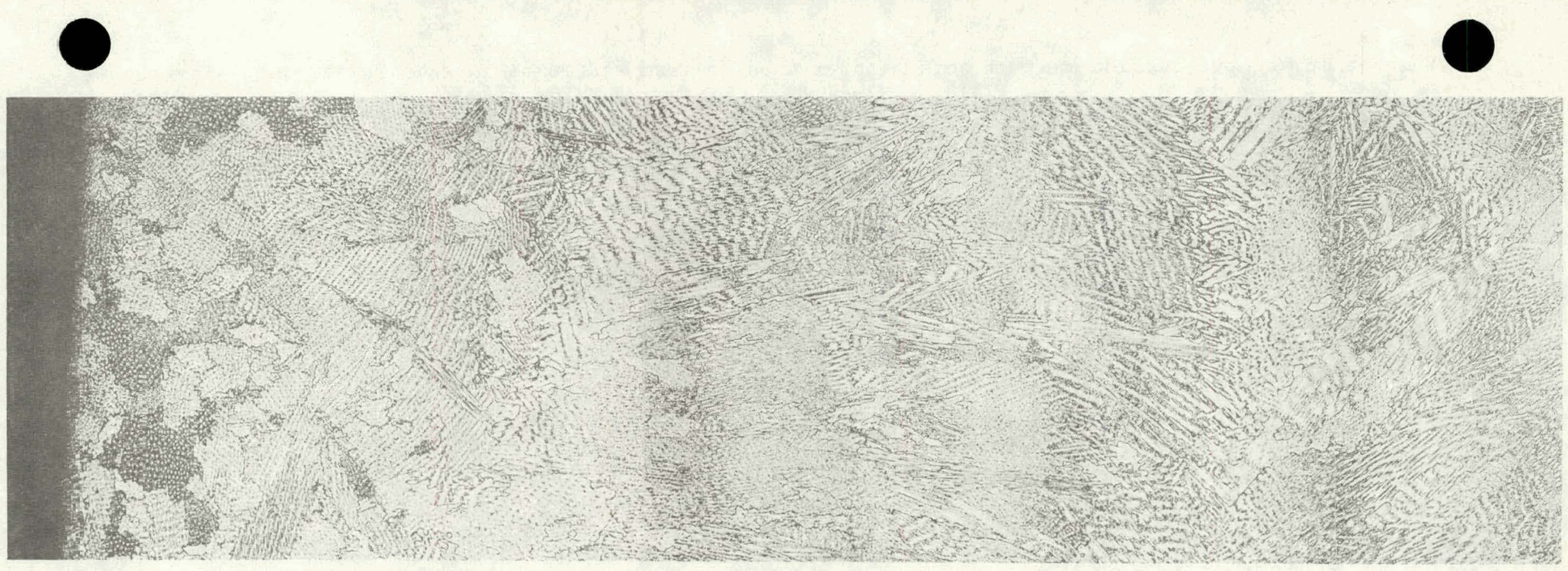

\section{HC1-Nethano1 Etch}

Welder W-2

$50 \mathrm{X}$

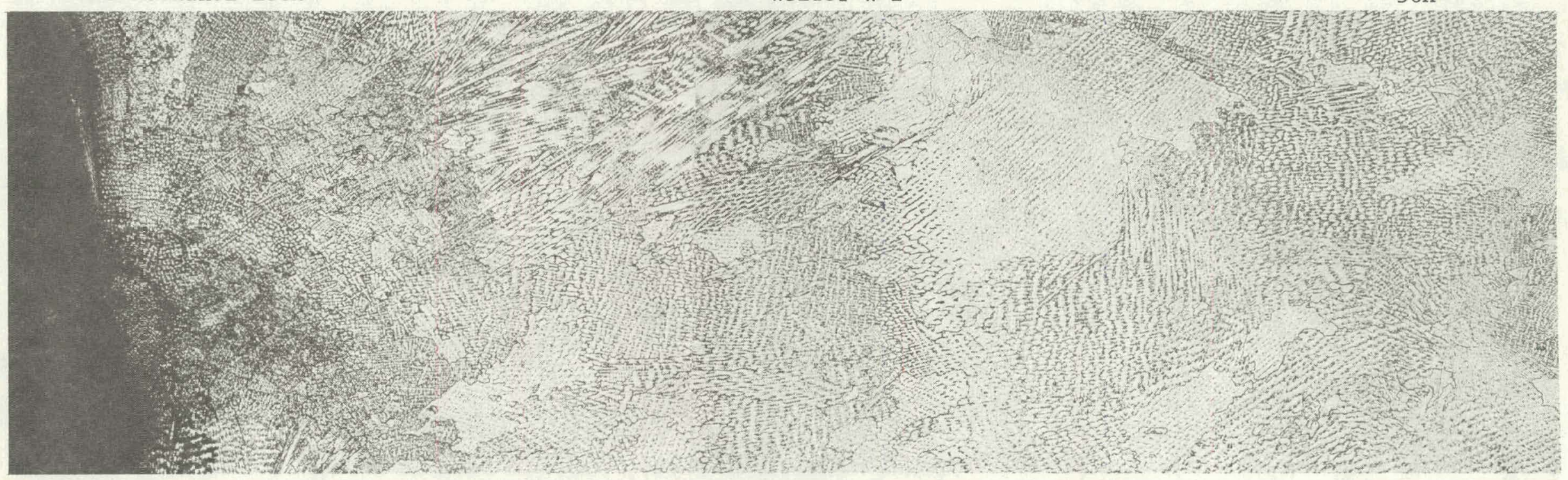

HC1-Nethenol Etch

We1der W-4

Figure 21 - Photomicrographs of weldments made by each welder using minimum current and helium cover gas. 


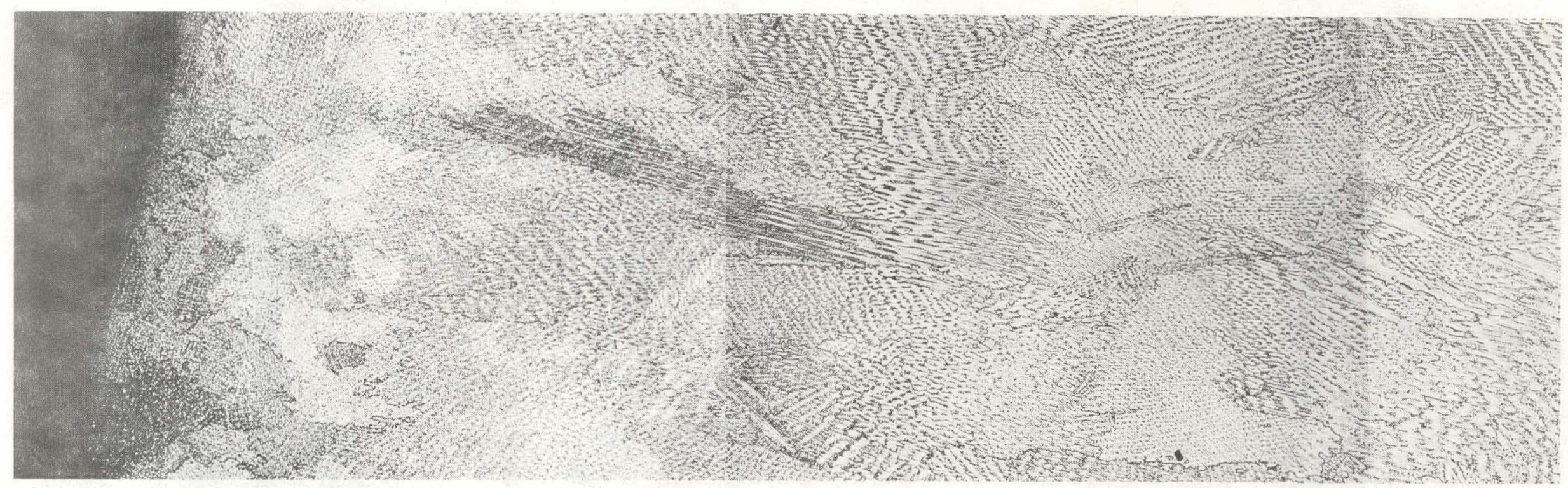

HC1-Methanol Etch

Welder W-2

$50 x$

$\infty$

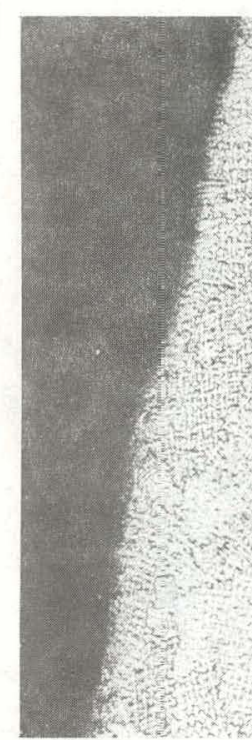

(3)

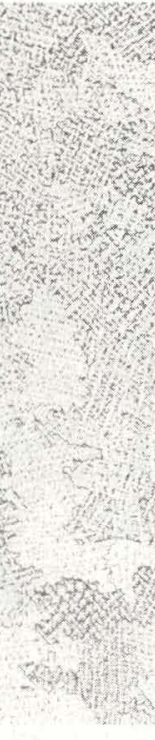

sos

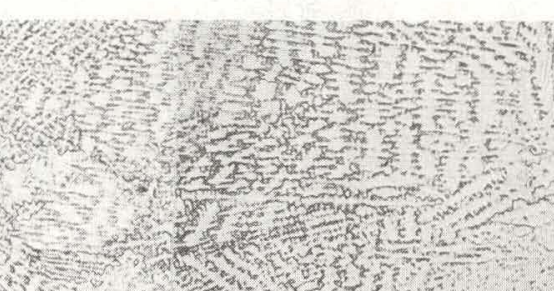

HC1-Methanol Etch

Welder $\mathrm{W}-4$

Figure 22 - Photomicrographs of weldments made by each welder using maximum current and helium cover g: 


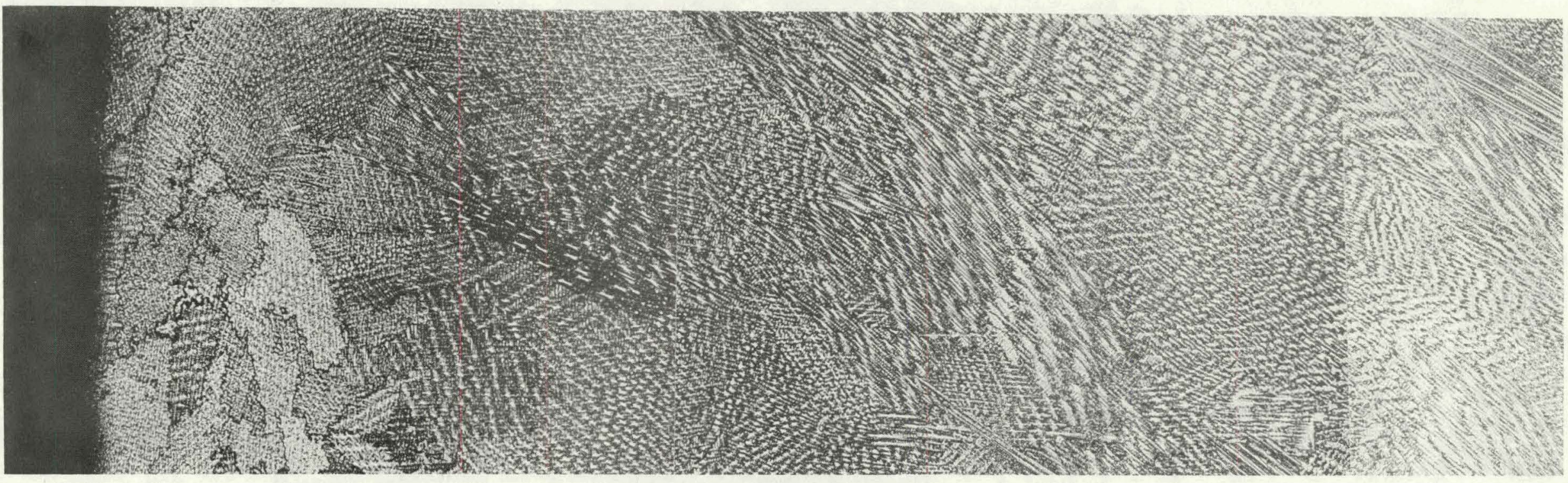

HC1-Methanol Etch

Welder W-2

$50 \mathrm{X}$

กั

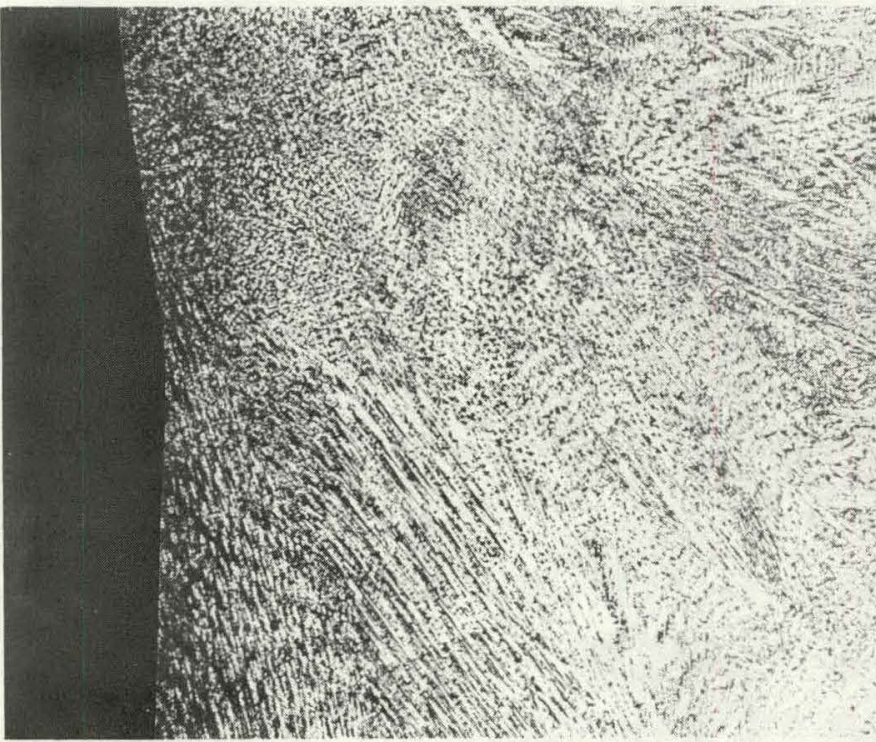

HC1-Methanol Etch

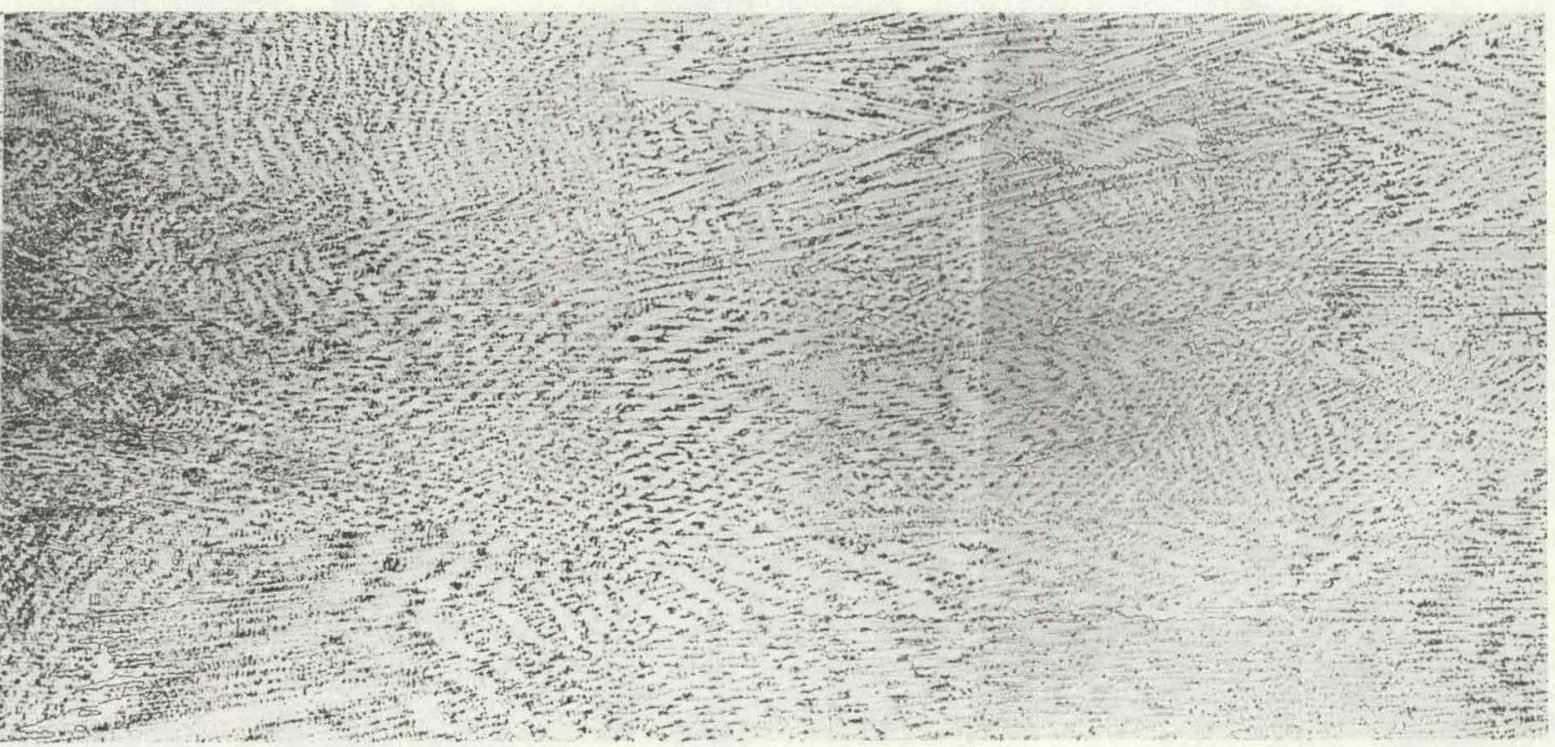

Welder W-4

50X

Figure 23- Photomicrographs of weldments made by each welder using medium current and helium cover gas. 


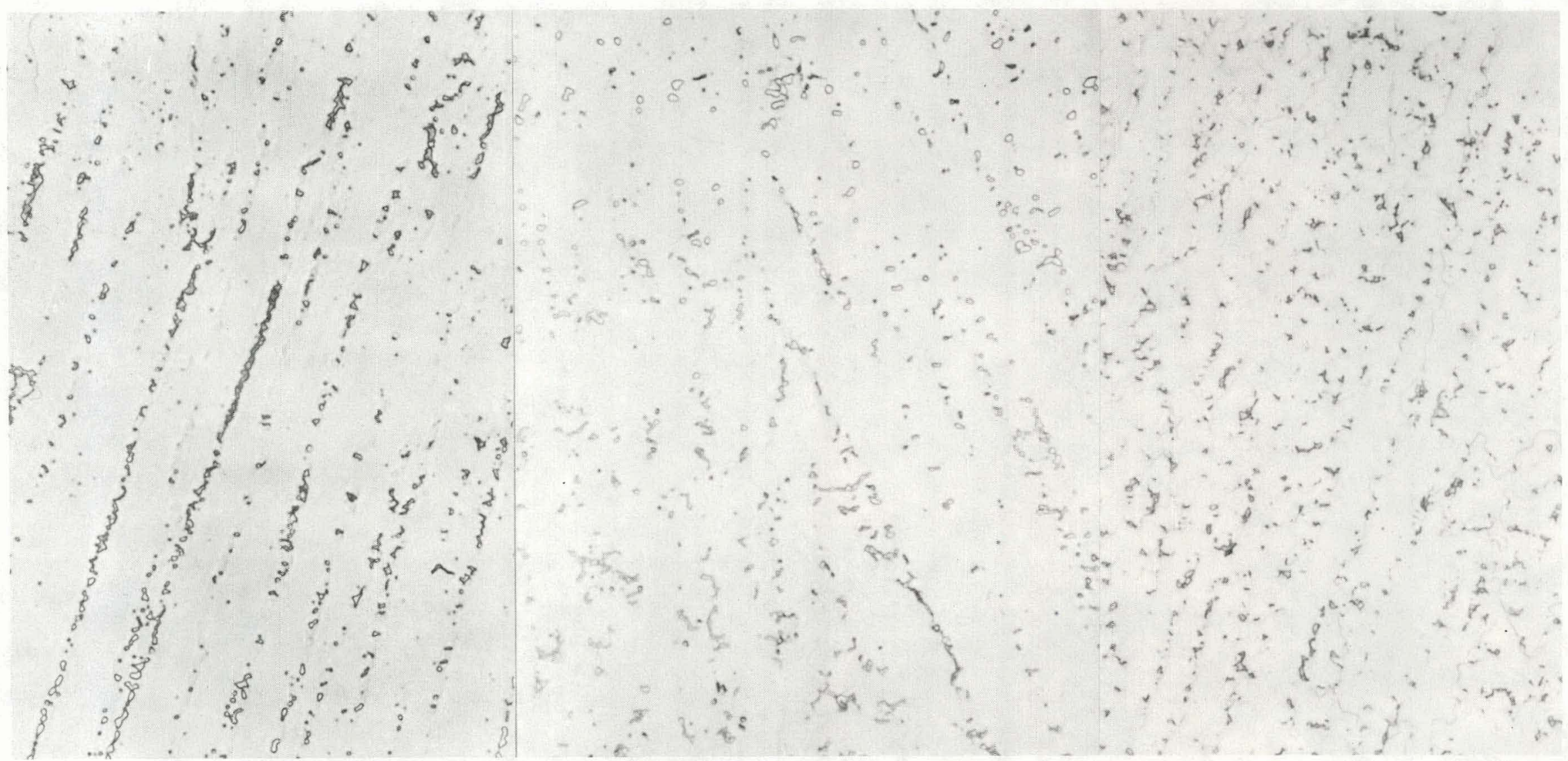

HC1-methano1 etch Minimum

Figure 24 - Typical high magnification photomicrographs of welds produced with argon covered gas at the three current settings. 


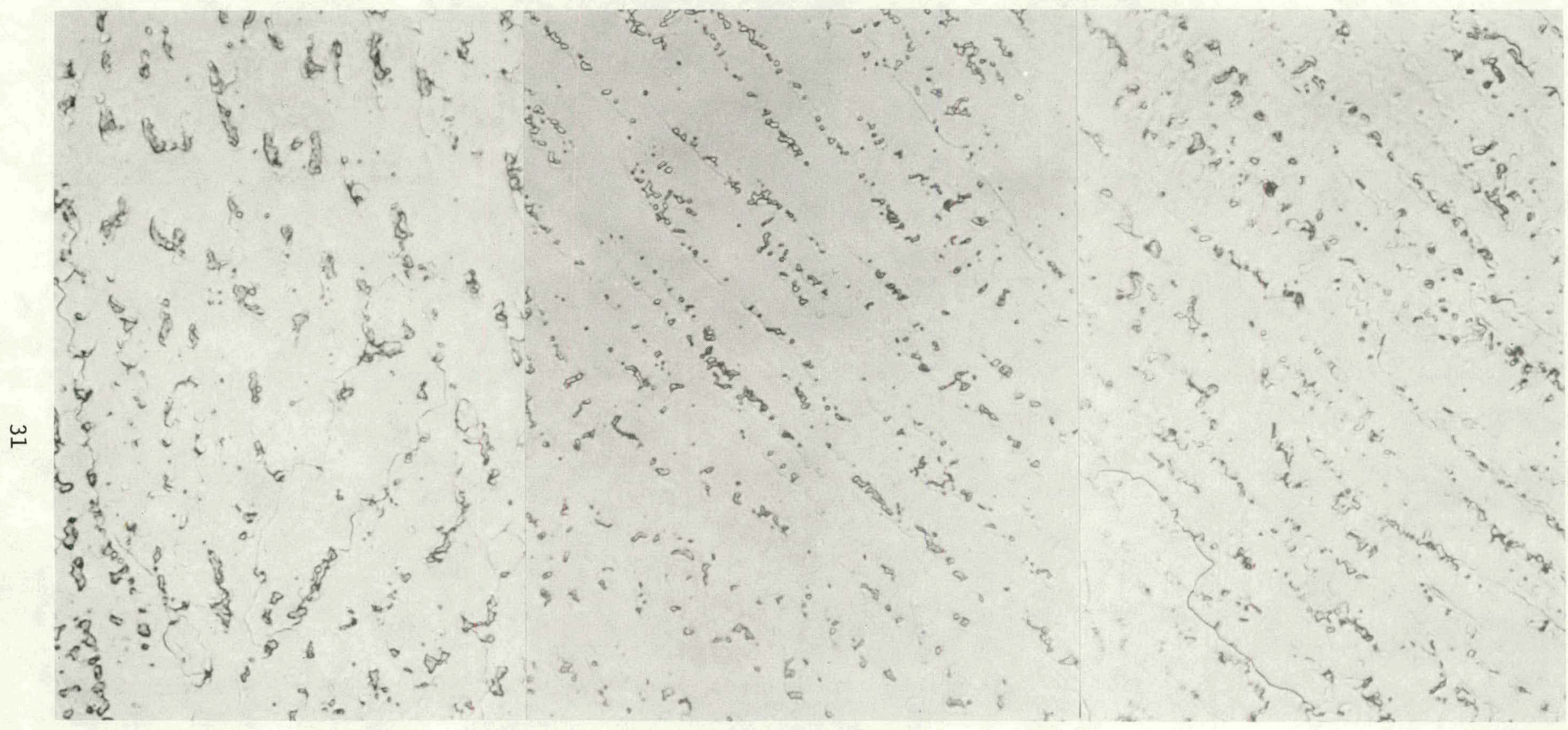

Hel-methanol etch

Figure 25 - Typical high magnification photomicrographs of welds produced with helium cover gas at the three current settings. 


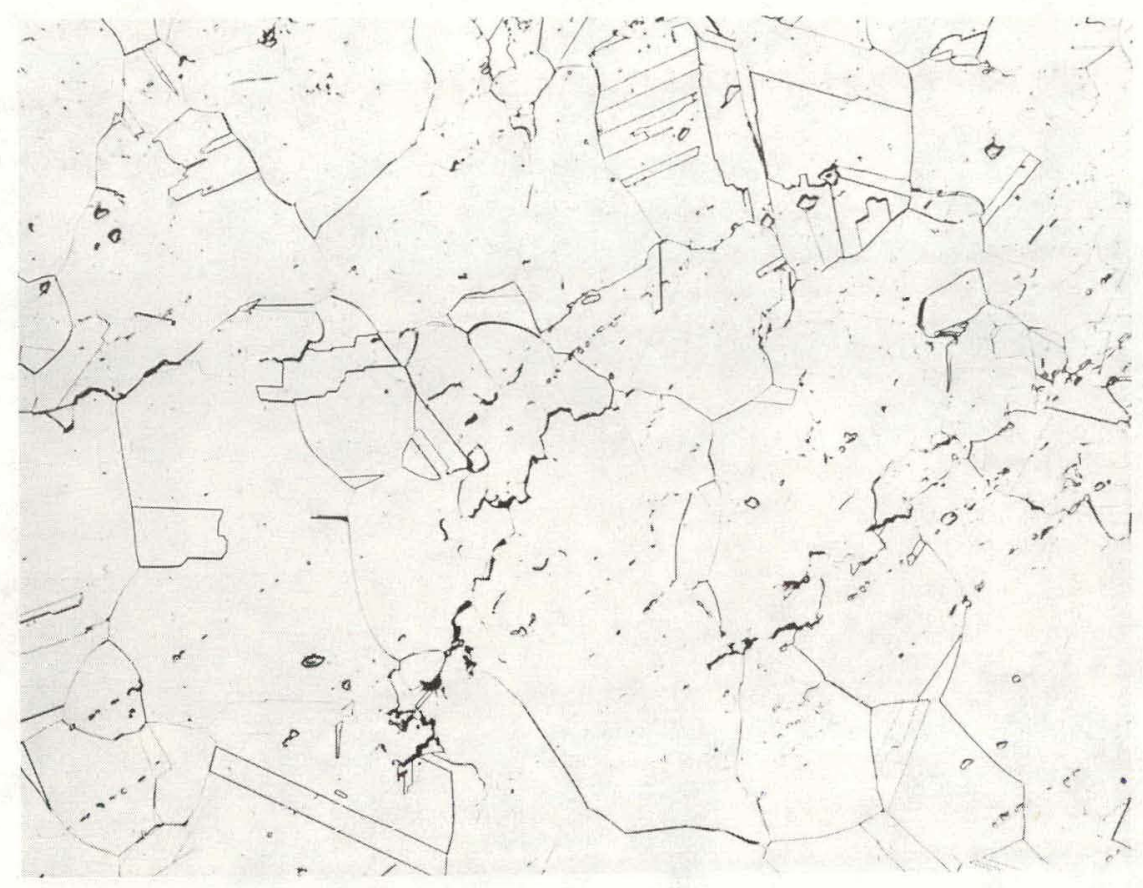

HC1-Methanol Etch

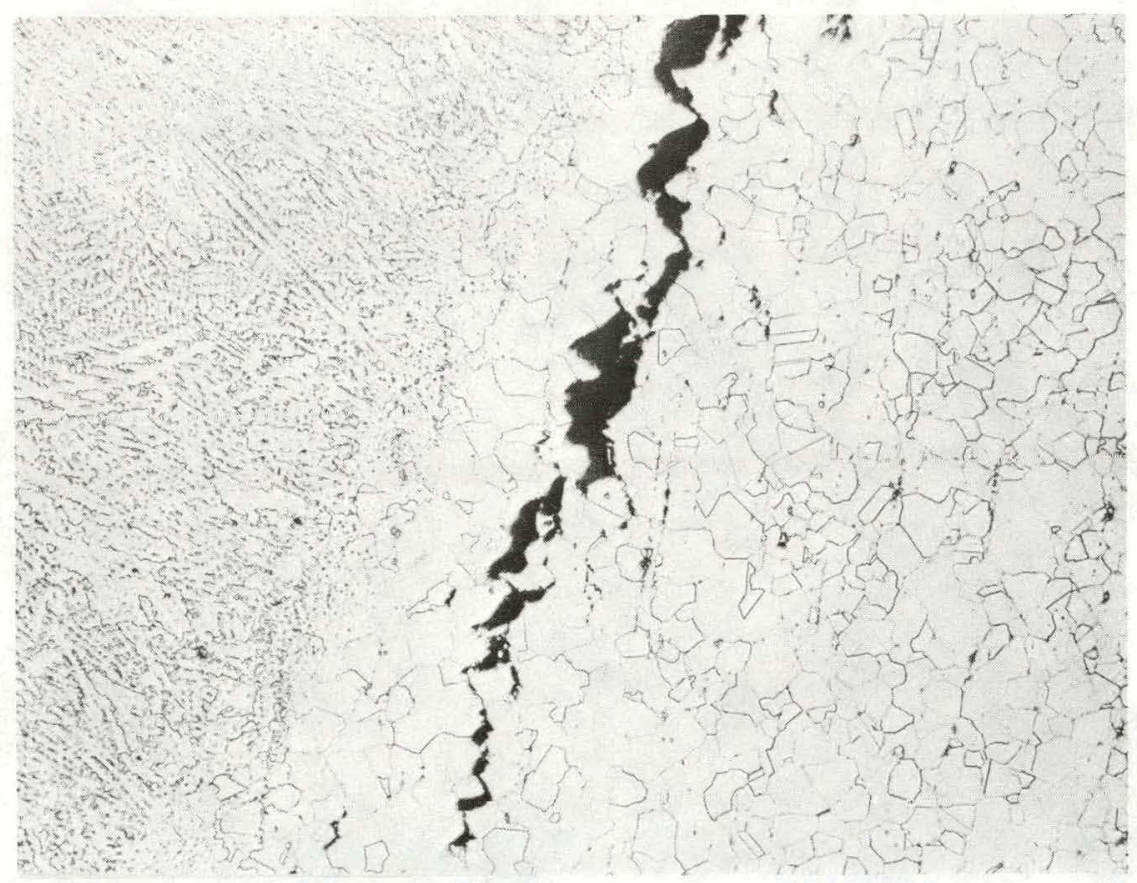

Figure 26 - Typical microcracking observed. 


\section{HEAT TREATMENTS}

Samples of the $W-2$ medium current argon and the $W-4$ medium current argon weldments were given one hour solution heat treatments at five different temperatures. This totaled ten samples, one of each kind for one hour at each of the following fahrenheit temperatures: $1875_{-0}^{+25}, 1925_{-0}^{+25}, 1975_{-0}^{+25}, 2025 \stackrel{+25}{-0}$, and $2100 \begin{aligned} & +25 \\ & -0\end{aligned}$.

\section{METALLURGICAL EXAMINATION}

The progress of Laves phase dissolution could be detected as the temperature was increased, Figures 27, 28, and 29. It is seen that after the $2025+25^{\circ} \mathrm{F}$ temperature for one hour the solution of the

$$
-0
$$

Laves phase was adequate, for both weld types, throughout the weld except for a surface layer, Figure 30. It is apparent that the redistribution and solution of the Laves phase is associated with recrystallization as well as solution heat treat temperatures. A layer of surface grains which did not recrystallize retained the interdendritic stringered Laves phase, while in the body of the weld where recrystallization was complete the Laves phase was no longer stringered and was greatly reduced in amount.

It was observed that there was no dissolution of the Laves phase at the $1875+25^{\circ} \mathrm{F}$ temperature in either the $\mathrm{W}-2$ or $\mathrm{W}-4$ samples. It - 0

even appeared that additional Laves phase had precipitated, increasing the width of the stringers. Curiously, the W-2 sample showed extensive recrystallization after the $1925+25^{\circ} \mathrm{F}$ heat treat temperature while - 0

the $\mathrm{W}-4$ sample showed very little recrystallization. The $\mathrm{W}-2$ sample, therefore, exhibited extensive redistribution and solution of the Laves phase compared to the other. As with the high temperature samples, the recrystallized $\mathrm{W}-2$ material also had a layer of dendritic material at the weld face surface which contained the stringered Laves phase. At $1975+25^{\circ} \mathrm{F}$ both types showed extensive recrysta1$-0$

lization and again, the dendritic surface layer with the Laves phase. The $2100+25^{\circ} \mathrm{F}$ samples were similar to the $2025+25^{\circ} \mathrm{F}$ samples but with - 0 $-0$

more dissolution of the Laves phase.

The thickness of the un-recrystallized layer decreased with increased heat treating temperature. At $1925^{\circ} \mathrm{F}$, the W-2 sample surface layer was $0.100^{\prime \prime}$, the maximum at $1975^{\circ} \mathrm{F}$ was also $0.100^{\prime \prime}$ in the $\mathrm{W}-4$ sample and at $2025^{\circ} \mathrm{F}$ the layer in the $\mathrm{W}-4$ sample was down to $0.050 "$. 


\section{DISCUSSIONS}

The observations made during this study have contributed to our understanding of the erratic mechanical behavior experienced in the bend tests. The facts that: (1) Laves phase redistribution and solution is related to recrystallization, (2) the W-4 sample after the $1925^{\circ} \mathrm{F}$ solution treatment retained extensive areas of un-crystallized materia1, and (3) the surface layer grains in the $\mathrm{W}-2$ sample after the $1925^{\circ} \mathrm{F}$ treatment did not recrystallize, explain why the $\mathrm{W}-4$ bend samples could fracture and separate completely along the Laves phase stringers of the un-recrystallized areas and the $W-2$ bend samples could have incipient cracks in the un-recrystallized surface areas which would arrest in underlying recrystallized material.

In order to insure recrystallization and therefore break-up of interdendritic Laves phase stringering, solution heat treat temperatures somewhat above $1975+25^{\circ} \mathrm{F}$ are desirable. $-0$

Solution heat treating in the range of $2100^{\circ} \mathrm{F}$ or above makes the material susceptible to microcracking if weld repairs are needed and even at the $2100^{\circ} \mathrm{F}$ treatment an un-recrystallized surface layer contains stringered Laves phase. Solution heat treatments below $1900^{\circ} \mathrm{F}$ produce material which has reduced Charpy impact strength.

Because of these considerations, a localized solution heat treatment of the weld at $2025^{\circ} \mathrm{F}$ followed by a $1925^{\circ} \mathrm{F}$ heat treatment of the entire assembly, followed by double aging appeared to be a way to insure adequate ductility in the weld $(8 \%)$ and adequate strength in the main tube (150 ksi yield). 


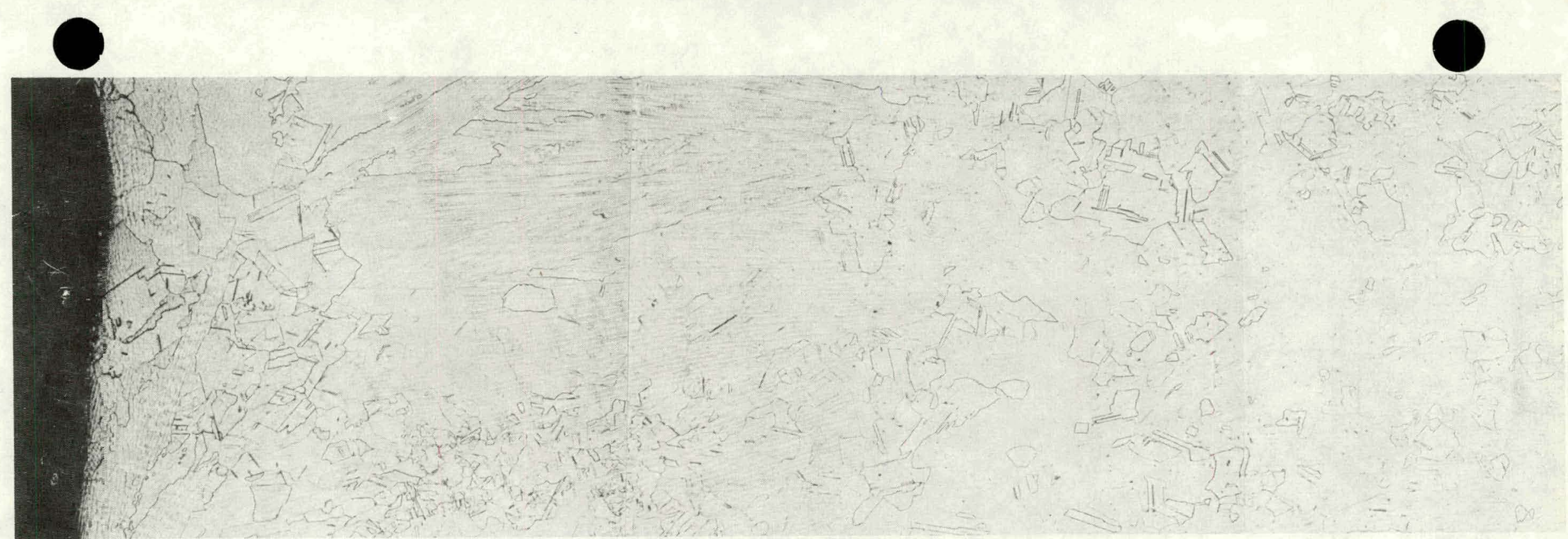

HC1-Methanol Etch
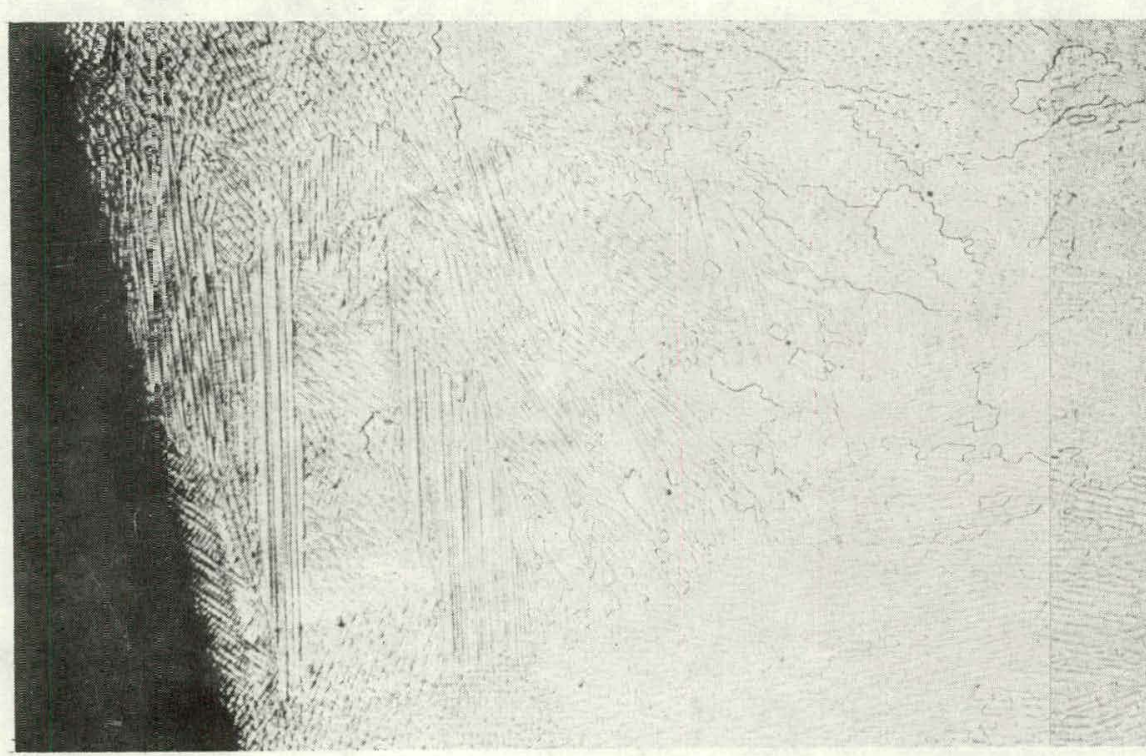

FC1-Methanol Etch

W-4

Figure 27 - Photomicrographs of weldments made by each welder using the medium current procedure after heat treating 1 hour at $1925^{\circ} \mathrm{F}$. 


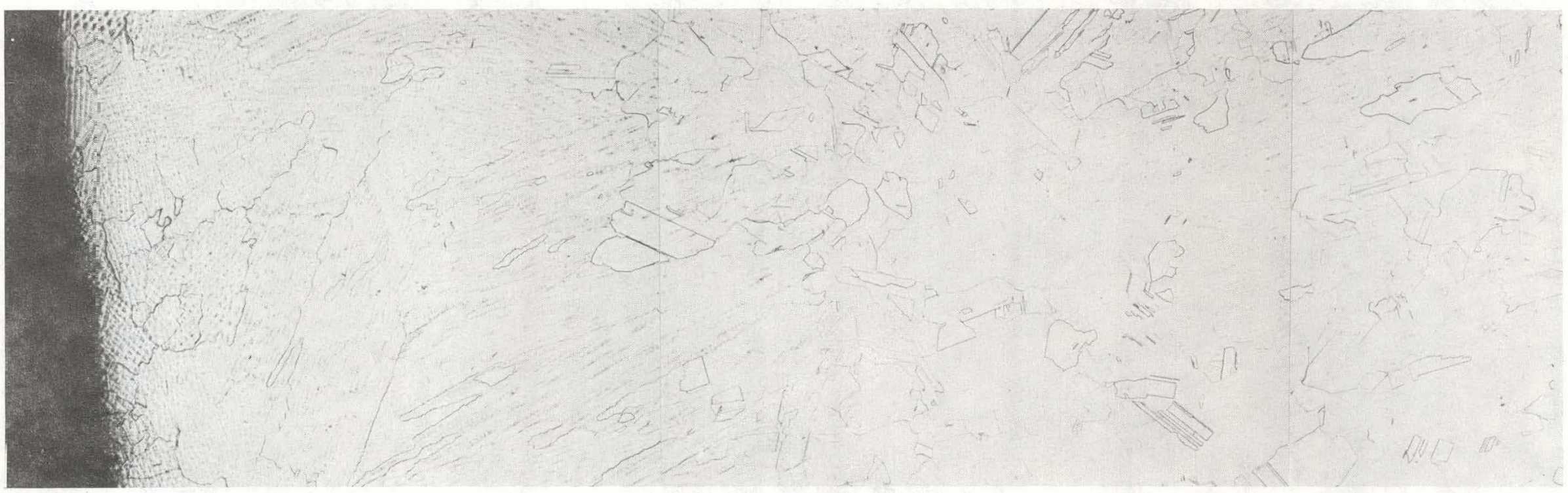

HC1-Methanol Etch

W-2

$50 \mathrm{X}$

a

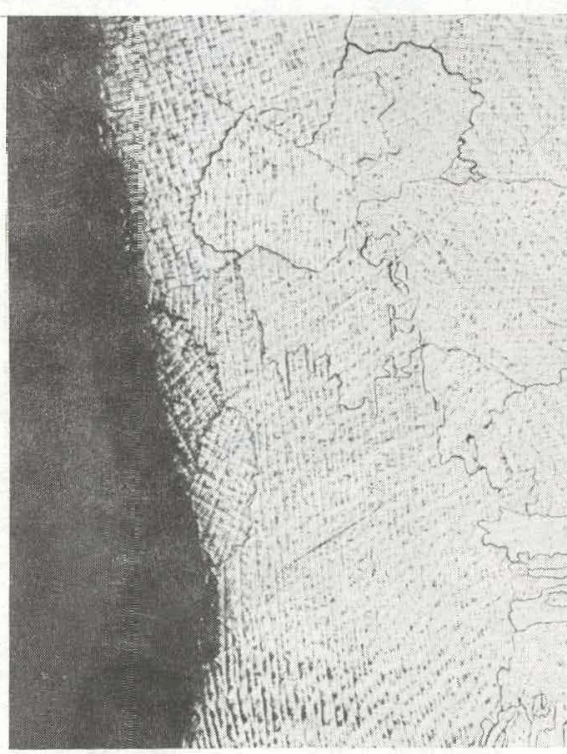

HC1-Methano1 Etch

W-4

Figure 28 - Photomicrographs of weldments made by each welder using the medium current procedure after heat treating 1 hour at $1975^{\circ} \mathrm{F}$. 


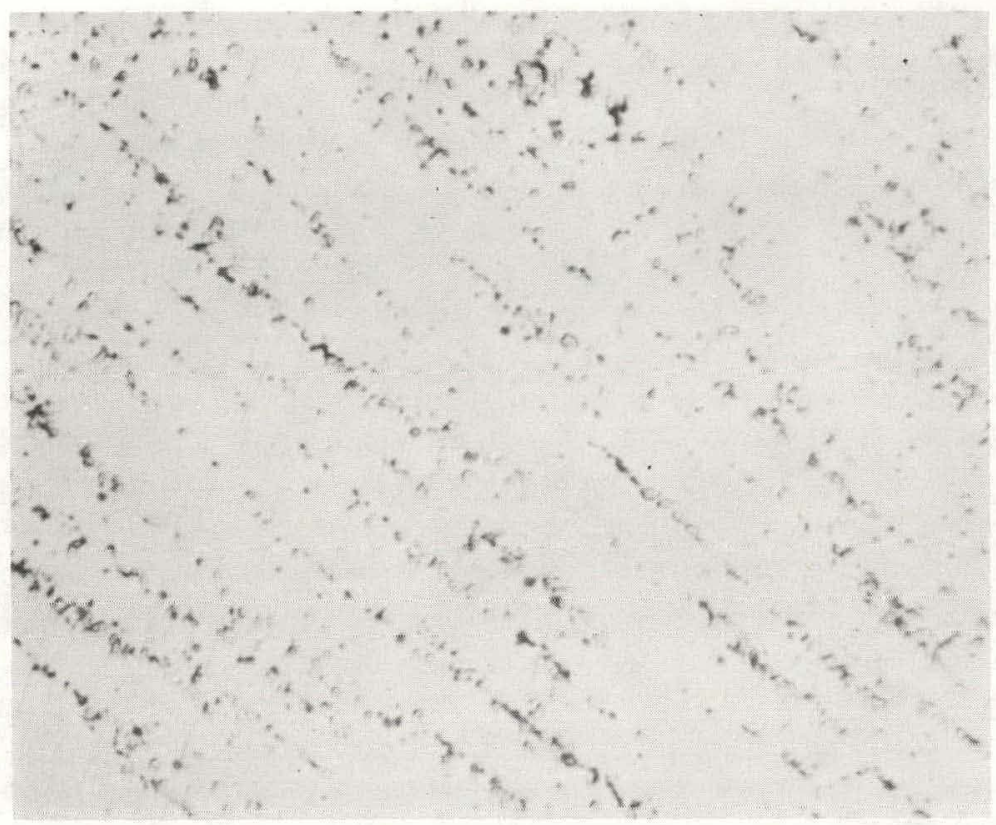

HC1-Methanol Etch

Un-recrystallized surface layer

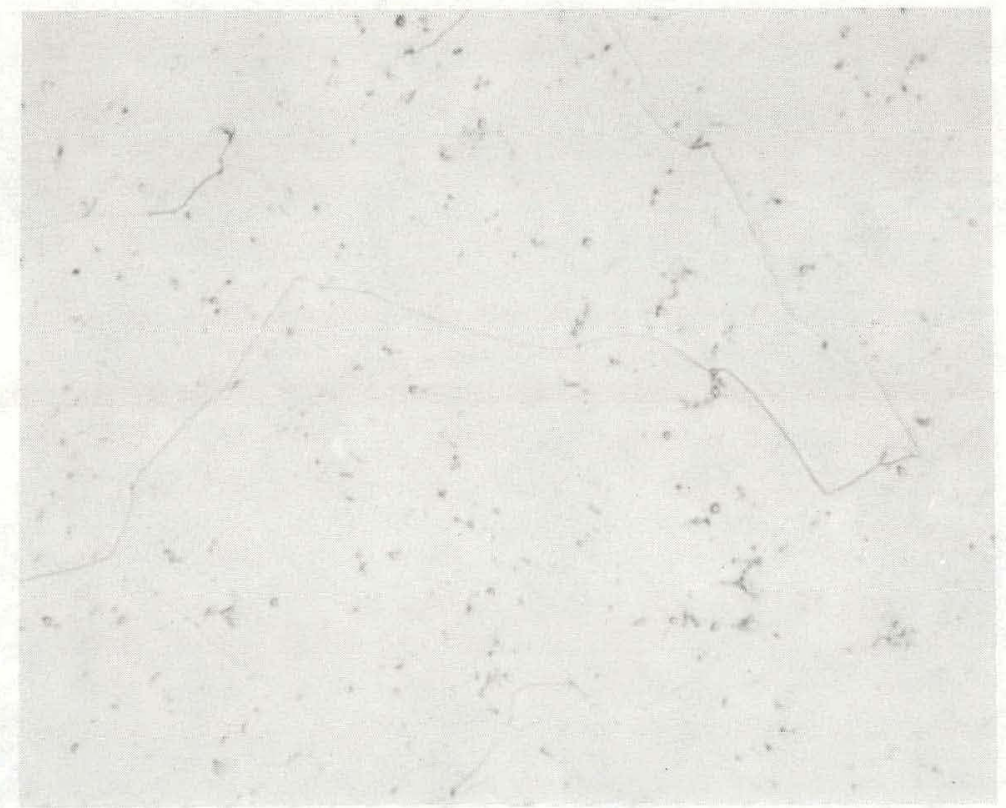

HC1-Methanol Etch

Recrystallized area

Figure 30- Laves phase solution and redistribution after the $2025+25^{\circ} \mathrm{F}$ solution heat treatment. 


\section{FINAL QUALIFICATION OF WELDING PROCEDURES AND HEAT TREATMENTS}

In order to determine if the weld could be successfully given a localized heat treatment at $2025^{\circ} \mathrm{F}$ prior to the $1925^{\circ} \mathrm{F}$ plus double age treatments to overcome the Laves phase embrittlement, a mock-up weld was made. Transverse tensile tests and impact tests in this simulated nozzle weld as well as tensile tests on parent metal from the in-pile tube forging with one solution heat treatment, the $1925^{\circ} \mathrm{F}$, followed by the double age are reported herein.

Figure 31 is a diagram of the simulated nozzle weld heat treating mock-up. Ring 1 and ring 2 are the Inconel 718 material joined by a "medium" Argon test weld. Ring 3 and a base plate are stainless steel extensions to provide a heat sink. The test weld and adjacent parent material were heated to $2025 \pm 25^{\circ} \mathrm{F}$ for an hour by induction heating and air cooled. The entire simulation was then solution heat treated at $1925+25^{\circ} \mathrm{F}$ for one hour and air cooled. It was then aged at 1325 $-0$

$\pm 15^{\circ} \mathrm{F}$ for eight hours, furnace cooled at the rate of $100^{\circ} \mathrm{F}$ per hour and aged for eight hours at $1150 \pm 15^{\circ} \mathrm{F}$.

Material removed from the surface of the in-pile tube forging in the bulk head'near the nozzle region was used to determine properties of the in-pile tube. Material from this location was solution heat treated at $1925+25^{\circ} \mathrm{F}$ for one hour and aged for eight hours at the $-0$

$1325 \pm 15^{\circ} \mathrm{F}$ and eight hours at $1150 \pm 15^{\circ} \mathrm{F}$ temperatures with the furnace cool between aging temperatures.

The tensile and impact data for the simulated nozzle weld samples are tabulated in Table V. All of the samples were produced transverse to the weld. All of the tensile samples except one, or 12 out of the 13 tests, had more than the required $127.0 \mathrm{ksi}$ yield strength. The one outlier had $121.0 \mathrm{ksi}$ yield strength. A11 of the tensile samples had more than the required $8 \%$ elongation. Three of the samples 2-4, 4-4, and 6-3 had reduced ductility associated with an acceptable sized inclusion in the weld. Grain size in the weld metal after heat treating ranged from ASTM 2 to. 4 and. 1 to 2 in the parent metal adjacent to the weld. The impact values were better than expected.

The tensile values for the in-pile tube material are shown in Table VI. All samples were above the required $150 \mathrm{ksi}$ yield and $8 \%$ elongation. The grain size after heat treating ranged from ASTM 3 to 5 . 


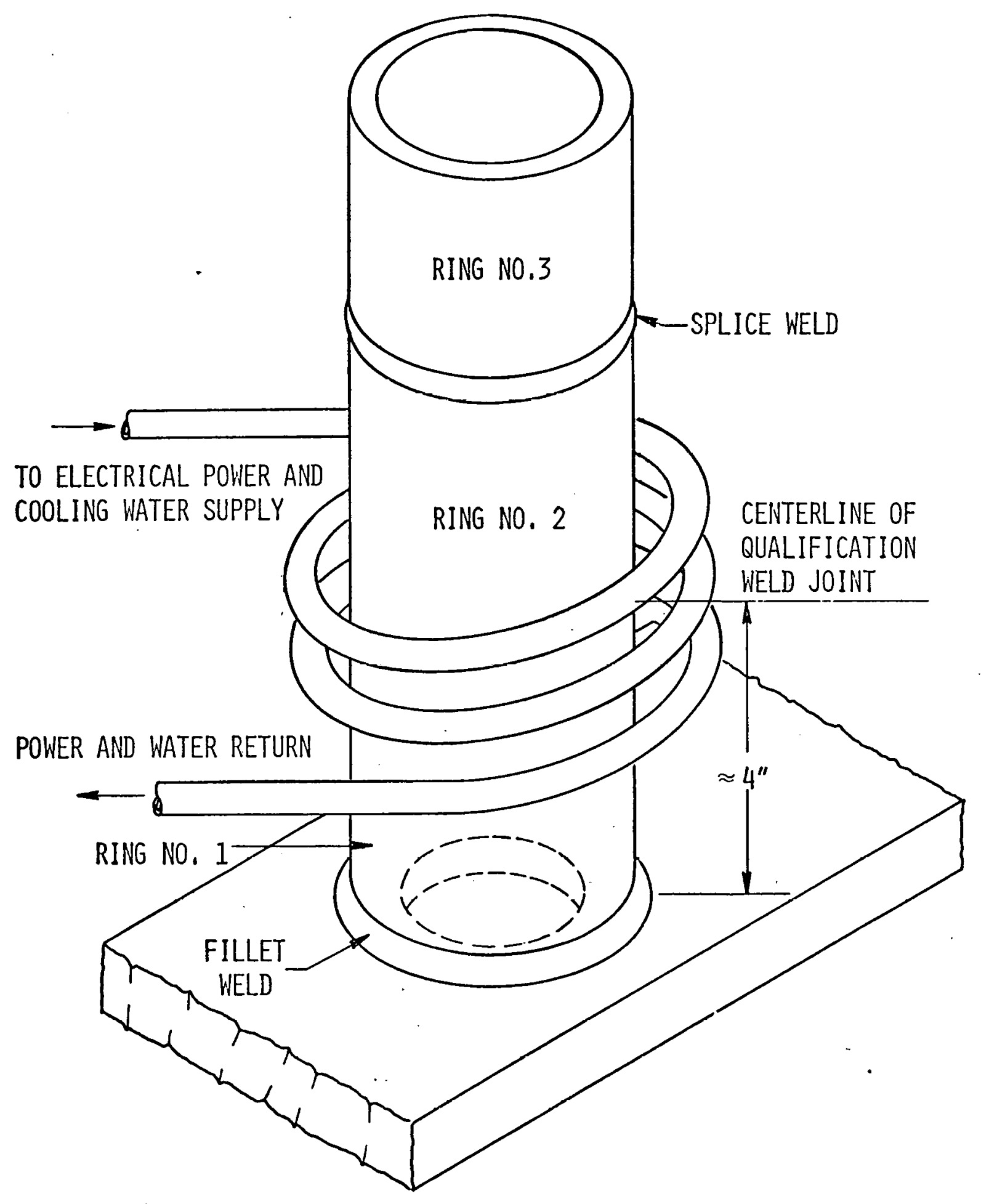

Figure 31 - Local anneal nozzle weld mock-up. 
TABLE V

RESULTS OF MECHANICAL TESTS FOR DOUBLE SOLUTION AND DOUBLE AGE HEAT TREATED WELDMENTS

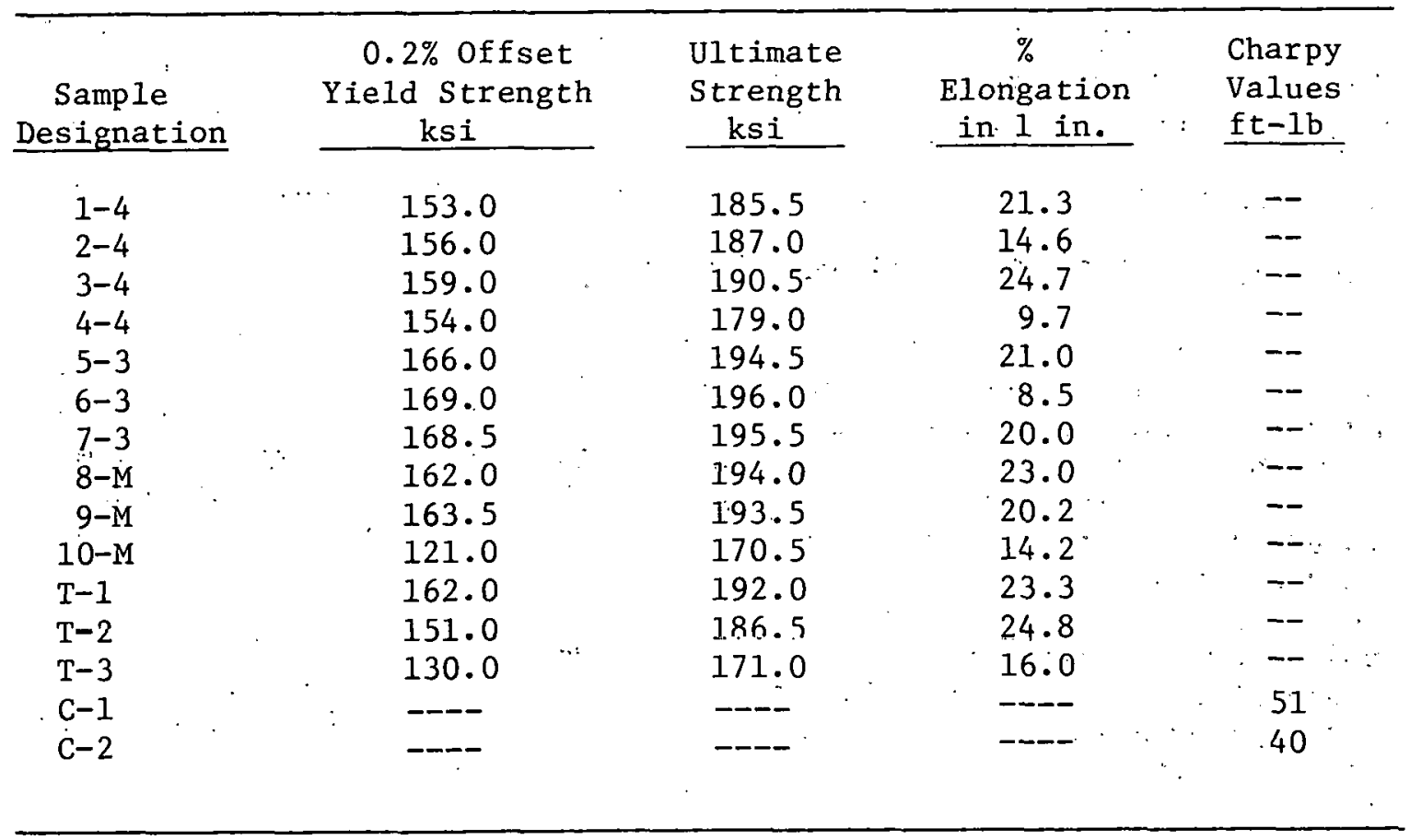

TABLE VI

TENSILE TEST RESULTS FOR SINGLE SOLUTION AND DOUBLE AGE HEAT TREATED IN-PILE TUBE PARENT METAL .

\begin{tabular}{|c|c|c|c|c|c|c|c|c|}
\hline & $\begin{array}{c}\text { Sample } \\
\text { Designation }\end{array}$ & & $\begin{array}{c}0.2 \% \text { offset } \\
\text { Yield Strength } \\
\text { ksi } \\
\end{array}$ & $\begin{array}{l}\text { U1timate } \\
\text { Strength } \\
\text { ksi } \\
\end{array}$ & & $\begin{array}{l}\text { Elongation } \\
\text { in } 1 \text { in. }\end{array}$ & & $\because$ \\
\hline & $I-1$ & & 154.6 & 185.6 & & 26.9 & & \\
\hline ; & $I-2$ & : & 151.0 & 183.0 & & 26.2 & $\cdot$. & \\
\hline & $I \div 3$ & & 155.6 & 183.0 & . & 24.2 & . & \\
\hline & $I-4$ & & 158.4 & 184.0 & & 23.8 & & $\therefore$ \\
\hline
\end{tabular}




\section{HEAT TREATING AND VERIFICATION OF THE ACTUAL IN-PILE TUBE}

\section{PLANNED HEAT TREATING PROCEDURE}

The in-pile tube was heat-treated in the manner which was planned. The nozzle welds were given a local solution heat treatment at $2000^{\circ} \mathrm{F}$ $+50^{\circ} \mathrm{F}$. The entire assembly was solution heat treated at $1900+50^{\circ} \mathrm{F}$ and then aged at $1300+50^{\circ} \mathrm{F}$ for eight hours, furnace cooled at $100^{\circ} \mathrm{F}$ ' and then aged at $1300+50^{\circ}$ per hour to $1125+50^{\circ} \mathrm{F}$ and held for eight hours.

$$
-0
$$

Tensile samples were attached to the tube after the localized heat treatment and remained with the assembly during its solution and aging treatment at the locations designated in Figure 32. Material for the tensile samples was removed from the in-pile tube forging adjacent to the actual in-pile tube wall and from the approximate axial location. In addition to the 13 locations shown, material removed from the top head was designated as location 14. Samples from each axial (number) location were taken at four azimuthal points 90 degrees apart and these points were designated A, B, C, and D. The eight nozzle samples designated 10 and 11 contained a transverse weld. These eight were first given a furnace solution heat treatment at $2025^{\circ} \mathrm{F}$ to simulate the localized treatment of the weld area before being attached to the tube.

It was intended to test all the samples upon completion of the heat treatments. However, it was found that the strength requirements of the main tube, $150 \mathrm{ksi}$ minimum yield, was not achieved. After thirteen of the parent metal samples were tested and only one met the minimum it was decided to discontinue testing until the problem could be solved. The data obtained at this time, which includes the values for the eight welded specimens, are shown in Table VII. The yield strength values ranged from $136.2 \mathrm{ksi}$ to $151.2 \mathrm{ksi}$ which was adequate for the nozzle requirement $(127 \mathrm{ksi})$ only. In all cases, the elongation was more than the required $8 \%$.

\section{2. $\underline{\text { RE-AGE }}$}

It was of considerable interest at this point to try to understand why the parent metal samples attached to the tube did not respond to heat treatment the same way that the previous qualification samples did. But more than this, it was desirable to use this knowledge to decide what could be done to bring the tube properties up to where they should be. 
Three questions that were considered are: (1) Since the parent metal used for qualification came from the surface of the forging was the material truly representative of the tube wall material?, (2) Did the greater temperature range $\left(50^{\circ} \mathrm{F}\right)$ experienced during heat treating of the tube compared to $\left(25^{\circ} \mathrm{F}\right)$ for the qualification samples affect the properties?,(3) In either case, what minimum heat treating effort could one utilize to increase the yield strength to $150 \mathrm{ksi}$ or above?

There were, of course, a number of approaches one could take. The least effort would be to re-age or extend the aging time(6). This would minimize the possibility of distortion and the amount of scaling and produce the least divergence between the history of qualification samples and the actual tube. To investigate this possibility, the butt ends of the tested tensile samples were hardness checked(at room temperature) as a function of re-aging time, Table VIII, Figure 33. It was found that after two hours at $1325^{\circ} \mathrm{F}$ the Rockwell hardness $\left(R_{C}\right)$ unexpectedly dropped two points. After four hours the two points were recovered, but then the hardness remained essentially the same as the starting hardness for the remainder of the $1325^{\circ} \mathrm{F}$ part of the re-age cycle. The hardness increased rapidly after cooling to $1150^{\circ} \mathrm{F}$. After 26 hours of total aging time, samples showed as much as three points hardness increase and ranged from $R$, 41 to 42.5. It appeared that the increased hardness was achieved at the $1150^{\circ} \mathrm{F}$ temperature and that the $1325^{\circ} \mathrm{F}$ age was contributing nothing. To check this observation, a sample from the A-12 tensile specimen was re-aged at $1150^{\circ} \mathrm{F}$ only. But after 28 hours it showed only one point increase in hardness.

On the basis of these hardness increases, it was decided to reage some of the tensile specimens that had not yet been tested; to determine if the hardness increases represented sufficient strength increases. Three specimens $\mathrm{C}-13, \mathrm{~B}-3$, and $\mathrm{D}-2$ were re-aged at $1150^{\circ} \mathrm{F}$ for a total of 48 hours. Four other specimens $B-5, B-7, C-6$ and B-14 were re-aged at $1325^{\circ} \mathrm{F}$ for 8 hours, furnace cooled for two hours to $1150^{\circ} \mathrm{F}$ and held at $1150^{\circ} \mathrm{F}$ for 14 hours giving a total re-aging time of 24 hours. The results, Table IX, show that the $1325-1150^{\circ} \mathrm{F}$ re-age combination produced the desired results while the straight $1150^{\circ} \mathrm{F}$ reage did not.

The remaining tensile samples were then re-distributed over the length of the tube assembly which was re-aged according to the 24 hour $1325-1150^{\circ} \mathrm{F}$ combination. These final tensile samples which had heen with the tube throughout all of its heat treatments confirmed the final desirable results, Table $x$, with a minimum yield strength of $160.0 \mathrm{ksi}$ and a minimum elongation of $16 \%$. 


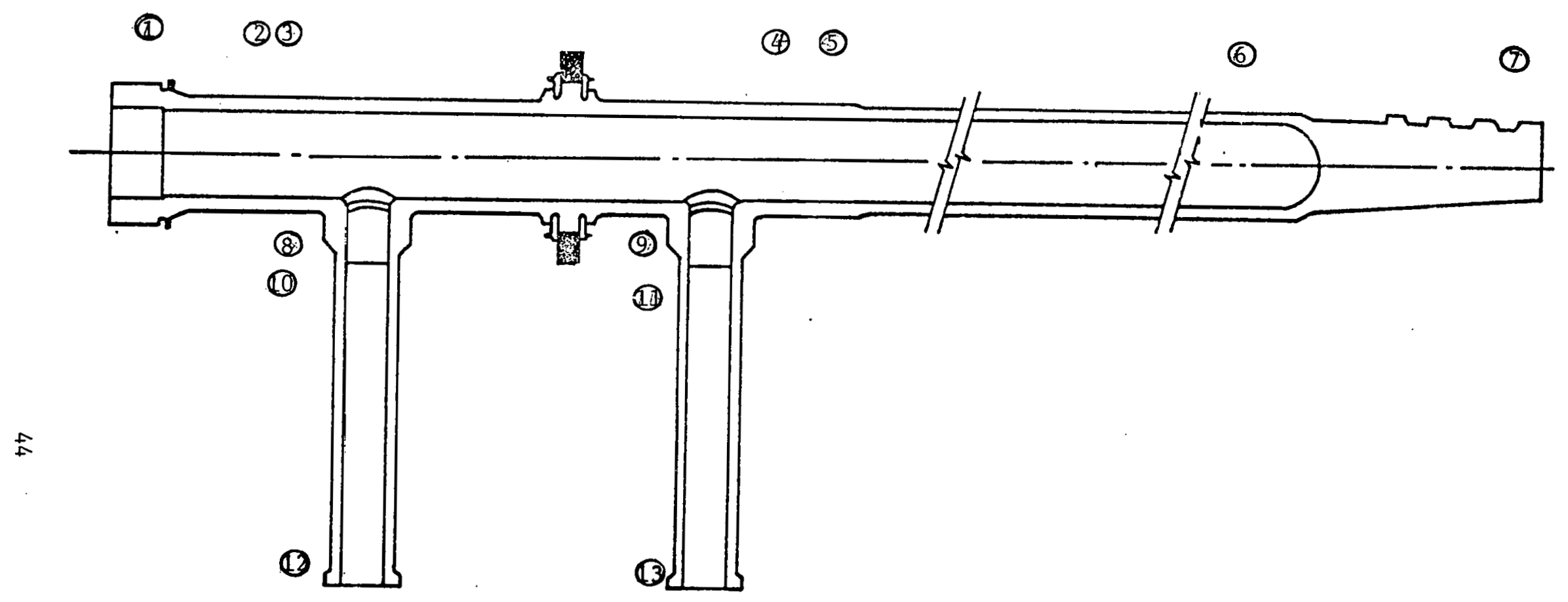

Figure 32 - Tensile sample location designations. 


\section{TABLE VII}

TENSILE TEST RESULTS OBTAINED FROM SAMPLES ATTACHED TO THE

IN-PILE TUBE DURING PLANNED HEAT TREAT PROCEDURES

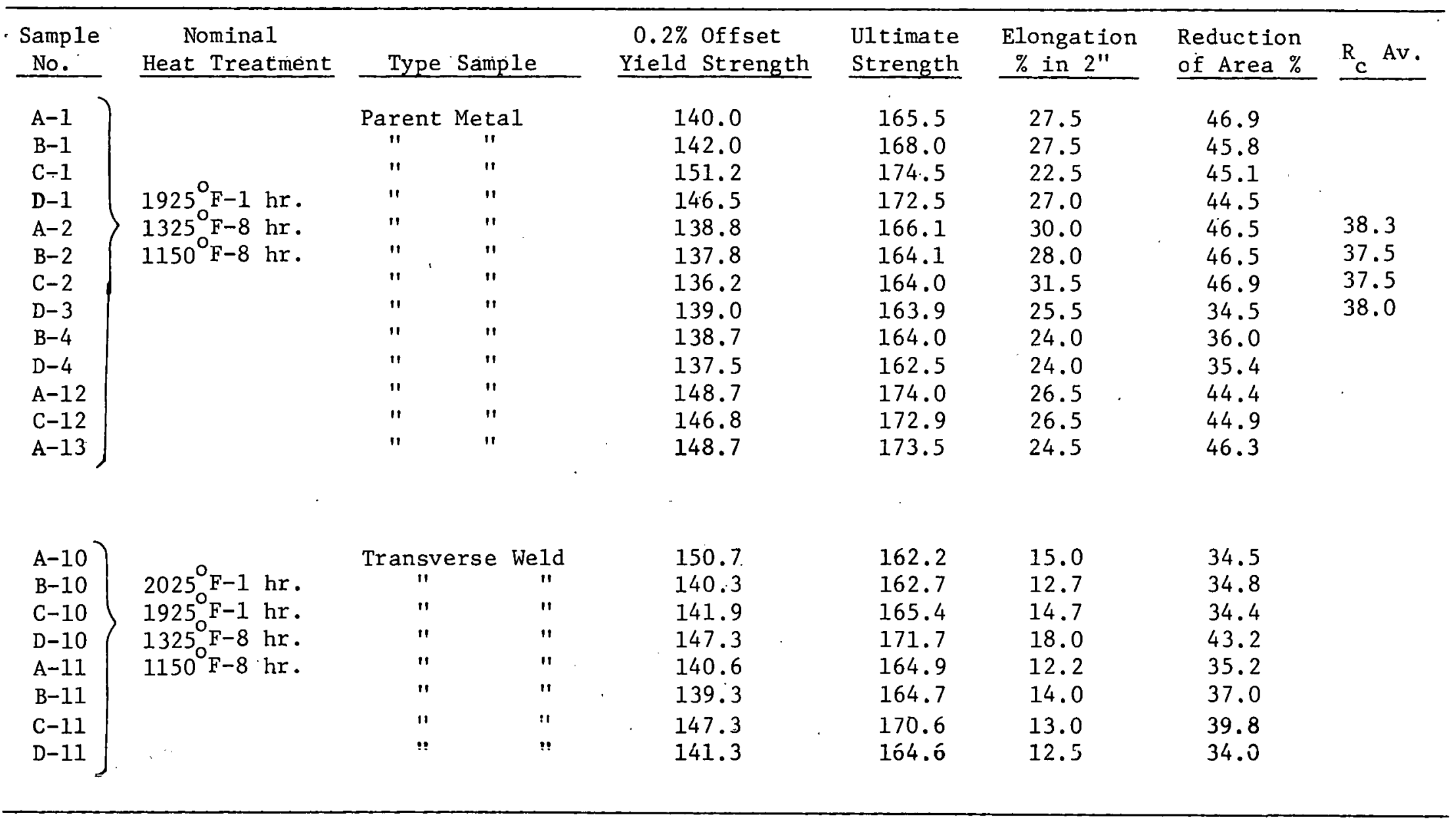


TABLE VIII

HARDNESS AS A FUNCTION OF TIME IN RE-AGING OVEN

\begin{tabular}{|c|c|c|c|c|c|}
\hline $\begin{array}{l}\text { Sample } \\
\text { No. } \\
\end{array}$ & $\begin{array}{c}\text { Temperature } \\
\text { of Oven } \\
\mathrm{O}_{\mathrm{F}} \\
\end{array}$ & $\begin{array}{c}\text { Hardness } \\
\text { Before } \\
\text { Re-aging } \\
\mathrm{R}_{\mathrm{C}} \\
\end{array}$ & $\begin{array}{l}\text { Hardness } \\
\text { After } \\
\text { Re-Aging } \\
\mathrm{R}_{\mathrm{C}} \\
\end{array}$ & $\begin{array}{c}\text { Hardness } \\
R_{c} 44 \\
\text { Test } \\
\text { Block } \\
\end{array}$ & $\begin{array}{c}\begin{array}{c}\text { Time in Oven } \\
\text { hoùrs }\end{array} \\
\end{array}$ \\
\hline$A-1$ & 1.325 & 39.0 & 37.0 & 44.0 & 2 \\
\hline$B-1$ & 1325 & 37.5 & 37.5 & 44.2 & 4 \\
\hline $\mathrm{D}-3$ & 1325 & 38.0 & 37.5 & 44.5 & 6 \\
\hline$D-4$ & 1325 & 38.5 & 38.5 & 43.9 & 7.5 \\
\hline$A-2$ & 1325 to 1150 & 38.0 & 38.5 & 44.0 & 9 \\
\hline $\mathrm{C}-2$ & 1150 & 38.0 & 40.0 & 44.0 & 11 \\
\hline$B-2$ & 1150 & 37.0 & 40.5 & 44.5 & 13 \\
\hline$B-1$ & 1150 & 38.0 & 41.0 & 44.0 & 15 \\
\hline$C-1$ & 1150 & 40.0 & 41.0 & 44.5 & 17 \\
\hline$A-13$ & 1150 & 39.5 & 42.5 & 44.5 & 26.5 \\
\hline $\mathrm{D}-1$ & 1150 & 40.0 & 42.0 & 44.5 & 28.5 \\
\hline$A-12$ & 1150 & 39.5 & 42.0 & 44.5 & 28.5 \\
\hline $\mathrm{C}-12$ & 1150 & 39.5 & 41.5 & 44.5 & 28.5 \\
\hline
\end{tabular}




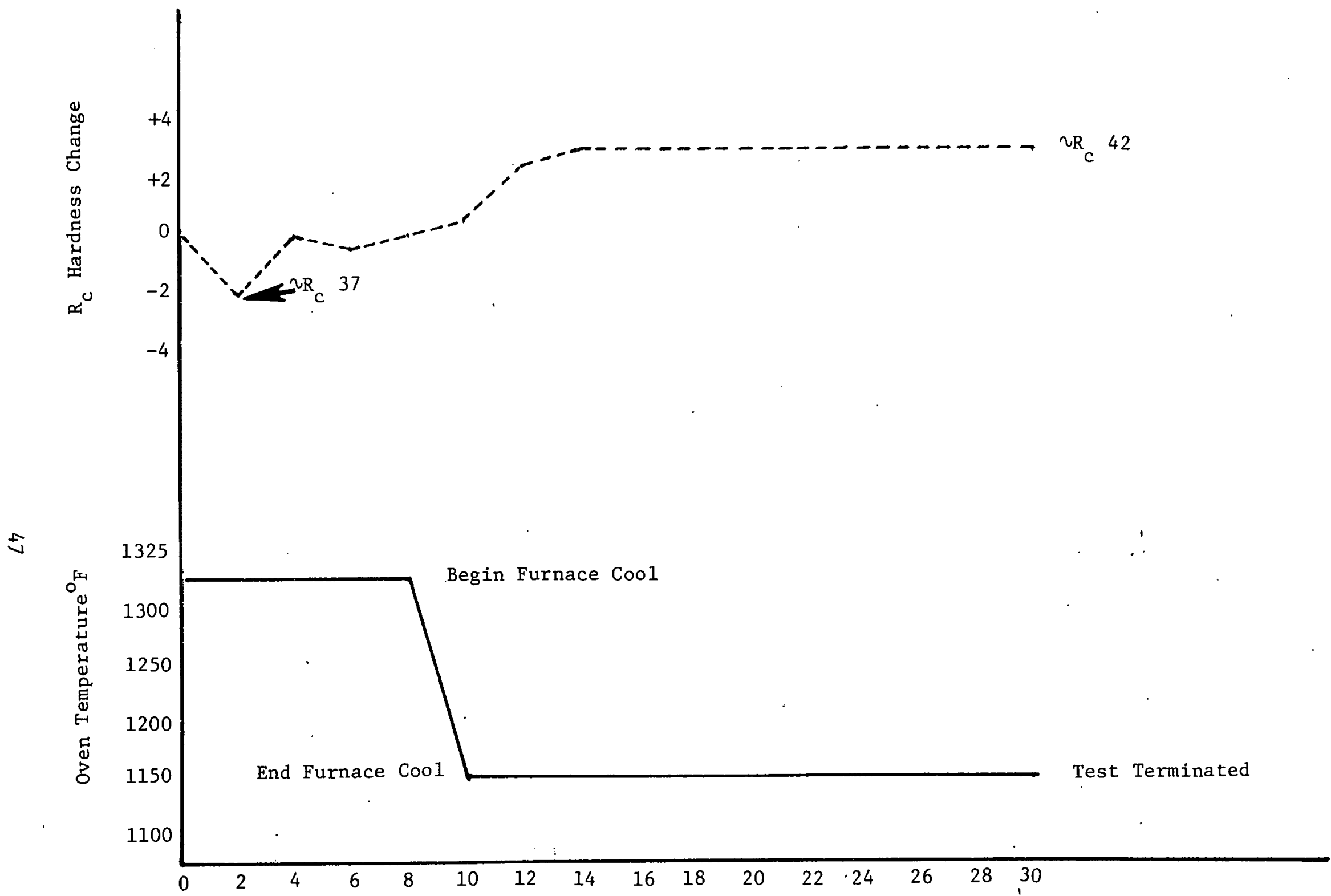

Re-Age Time, Hours

Figure 33 - Rockwell "C" hardness change as a Function of re-age time at temperature. 
TABLE IX

TENSILE TEST RESULTS OF SAMPLES (PREVIOUSLY ATTACHED TO THE TUBE DURING ITS PLANNED HEAT TREATMENTS) AFTER RE-AGING

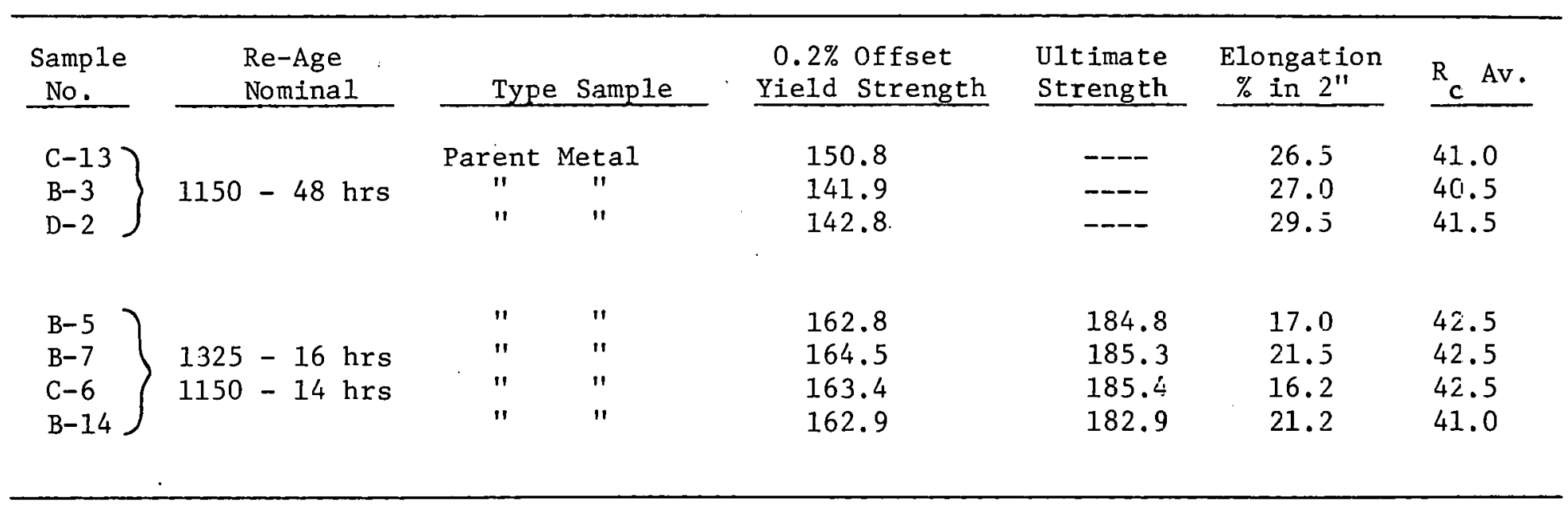


TABLE $X$

TENSILE TEST RESULTS OBTAINED FROM SAMPLES ATTACHED TO THE IN-PILE TUBE DURING BOTH, THE PLANNED AND RE-AGE HEAT TREATMENTS

\begin{tabular}{|c|c|c|c|c|c|c|c|c|}
\hline $\begin{array}{l}\text { Sample } \\
\text { No. }\end{array}$ & $\begin{array}{c}\text { Nominal } \\
\text { Heat Treatment }\end{array}$ & Type & Sample & $\begin{array}{r}0.2 \% \text { Offset } \\
\text { Yield Strength } \\
\end{array}$ & $\begin{array}{l}\text { U1timate } \\
\text { Strength }\end{array}$ & $\begin{array}{l}\text { Elongation } \\
\% \text { in } 2^{\prime \prime} \\
\end{array}$ & $\begin{array}{l}\text { Reduction } \\
\text { of Area \% }\end{array}$ & $\mathrm{R}_{\mathrm{c}}$ \\
\hline$A-5$ & & Parent & Metal & 161.1 & 182.7 & 17.2 & 27.5 & 41 \\
\hline$C-5$ & & 11 & $"$ & 162.4 & 182.4 & 17.2 & 25.9 & 41.5 \\
\hline$D-5$ & & $"$ & $"$ & 160.6 & 182.4 & 17.5 & 28.7 & 41.5 \\
\hline$A-6$ & $1925^{\circ} \mathrm{F}-1 \mathrm{hr}$. & $"$ & $"$ & 161.6 & 181.4 & 16.0 & 30.7 & 42 \\
\hline$B-6$ & $1325^{\circ} \mathrm{F}-16$ hr. & $"$ & $"$ & 163.1 & 182.9 & 17.0 & 29.7 & 41.5 \\
\hline $\mathrm{D}-6$ & $1150^{\circ} \mathrm{F}-22 \mathrm{hr}$ & $"$ & $"$ & 165.5 & 185.2 & 21.0 & 41.7 & 41.5 \\
\hline$A-7$ & & $"$ & $"$ & 165.4 & 183.4 & 13.7 & 27.8 & 42 \\
\hline $\mathrm{C}-7$ to $\mathrm{A}-4$ & & $"$ & $"$ & 162.4 & 182.4 & 16.7 & 29.9 & 40.5 \\
\hline $\mathrm{D}-7$ & & $"$ & $"$ & 164.4 & 185.4 & 15.2 & 29.3 & 40.5 \\
\hline $\mathrm{A}-14$ to $\mathrm{B}-1$ & & $"$ & $"$ & 161.0 & 183.6 & 23.0 & 41.5 & 40 \\
\hline $\mathrm{C}-14$ to $\mathrm{C}-2$ & & $"$ & $"$ & 160.0 & 181.1 & 23.2 & 43.0 & 41.5 \\
\hline $\mathrm{D}-14$ to $\mathrm{A}-3$ & & $"$ & $"$ & 160.0 & 180.6 & 21.5 & 42.2 & 41.0 \\
\hline
\end{tabular}




\section{FURTHER DISCUSSION}

Additional work prior to fabrication could have been done to determine optimum properties of the particular heats of Inconel $718(4)$ used for the PBF in-pile tube. It has been shown, DMIC 217, page 4, that some strength increase, which depends on aluminum content, can be derived by using a $1400^{\circ} \mathrm{F}$ initial age temperature rather than $1325^{\circ} \mathrm{F}$. The recent trend is to use a $1400-1200^{\circ} \mathrm{F}$ age cycle if the material is solution heat treated in the 1900 to $1950^{\circ} \mathrm{F}$ range $(7)$. However, at the time when the initial qualification tests were performed considerably more data were available for the $1325-1150^{\circ} \mathrm{F}$ aging cycle to show that this would prodyce a good compromise between strength, toughness, and ductility $(1,8)$. If more work had been done, (1) to determine. how to promote weld recrystallization at lower solution heat treat temperatures, (2) to determine what strengths could be achieved for various solution heat treat temperatures above the recrystallization temperature, and (3) to determine the effects of longer age times for the various solution heat treat temperatures, a single solution heat treat and age procedure might have been developed which would have eliminated the need for localized heat treating of the welds. The optimum welding and single heat treating procedure for this application would (1) eliminate localized Laves phase embrittlement so that elongation in all parts of the weld would be $8 \%$ or greater, (2). produce a fully recrystallized weld, (3) keep grain size in the parent metal small, ASTM size 4-6, (4) have a yield strength above $150 \mathrm{ksi}$, and (5) prevent the formation of micro cracks. Although it is not known whether optimum properties were attained, the minimum $160 \mathrm{ksi}$ yield and $16 \%$ elongation finally achieved were more than adequate.

The Charpy impact values for weld metal solution heat treated at $1925^{\circ} \mathrm{F}$ and double aged were $19.8 \mathrm{ft}-1 \mathrm{bs}$ for a un-recrystallized area and $27 \mathrm{ft}-1 \mathrm{bs}$ for a recrystallized area, once again, illustrating the benefit of recrystallization. Samples that had been double solution heat treated at 2025 and $1925^{\circ} \mathrm{F}$ before aging gave surprisingly high values of 40 and $51 \mathrm{ft}-1 \mathrm{bs}$ which would indicate that extra time at temperature might be beneficial to the toughness of alloy 718 welds.

The weld studies showed that one has greater weld parameter latitude considering microcracking tendencies if $75 \%$ helium, $25 \%$ argon, rather than $100 \%$ argon is used for cover gas. However, the welding procedure used for the actual nozzle weldments was the medium current $100 \%$ argon cover gas procedure because much of qualification work utilized this procedure and the welders were more experienced with it. The welds were crowned purposely so that, in grinding flush, the. un-recrystallized layer containing Laves phase stringering would be removed. 


\section{CONCLUSIONS}

1. Localized Laves phase embrittlement can exist in Inconel 718 weldments which have been solution heat treated at $1925^{\circ} \mathrm{F}$. This embrittlement is associated with un-recrystallized areas in the weldments.

2. Laves phase solution and redistribution is related to recrystallization of the weld metal as well as to solution heat treat temperatures.

3. Non-restrained surface weld beads do not recrystallize even upon heating to $2100^{\circ} \mathrm{F}$. The un-recrystallized areas continue to show stringered Laves phase after heat treating up to this temperature.

4. The recrystallization threshold temperature for the restrained portion of the weld (all but the surface bead) is slightly below $1975^{\circ}$. F. but above $1925^{\circ} \mathrm{F}$.

5. Additional strengthening of an assembly that has been solution heat treated at elevated temperature to reduce Laves phase, can be achieved by lengthening the aging time. Care should be taken to avoid excessive aging times at the higher aging temperatures to prevent over-aging. 


\section{X. REFERENCES}

(1) J. Gordine, "Welding of Inconel 718", Welding Journal Research Supplement, 531S, November 1970.

(2) J.Gordine, "Some Problems in Welding Inconel 718", Welding Journal Research Supplement, 480s, November 1971.

(3) H. L. Eiselstein, "Metallurgy of a Columbium Hardened NickelChromium-Iron Alloy",ASTM STP 369, 1965.

(4) H. J. Wagner, A. M. Hall, Physical Metallurgy of Alloy 718 , DMIC Report 217, June 1965.

(5) D. J. Bologna, "Metallurgical Factors Influencing the Microfissuring of Alloy 718 Weldments", Metals Engineering Quarterly, American Society for Metals, November, 1969.

(6) J. F. Barker, "A Superalloy for Medium Temperature", Metals Progress, May 1962.

(7) F. C. Robershaw, H. R. Stephan, "Advanced Pressure Vessel Materials," Eighth Annual Report AEC Fuels and Materials Development Program, P. 192, March, 1969, GEMP-1012.

(8) D. R. Muzyka, G. N. Monior, "Effects of Solution Treating Temperature and Microstructure on the Properties of Hot Rolled 718 Alloy", Metals Engineering Quarterly, American Society for Metals, November 1969. 


\section{APPENDIX A}

This appendix contains the results of qualification test data generated to support a proposed single solution heat treatment followed by a standard double age of the entire PBF in-pile tube assembly to be used after the nozzle weldments were made. During this test series, tensile test results were satisfactory but bend tests indicated areas of locallzed low ductility. The heat treatment procedure for all of these samples and that originally proposed for the assembled tube was 1 hour at $1925^{\circ} \mathrm{F}$ air cool, 8 hours at $1325^{\circ} \mathrm{F}$ furnace cool to $1150^{\circ} \mathrm{F}$ at a rate of $100^{\circ} \mathrm{F}$ per hour, hold at $1150^{\circ} \mathrm{F}$ for eight hours and a1r cool. See Tables XI through XV. 


\section{TABLE XI}

RESULTS OF TENSILE TEST CONTAINING TRANSVERSE WELDS

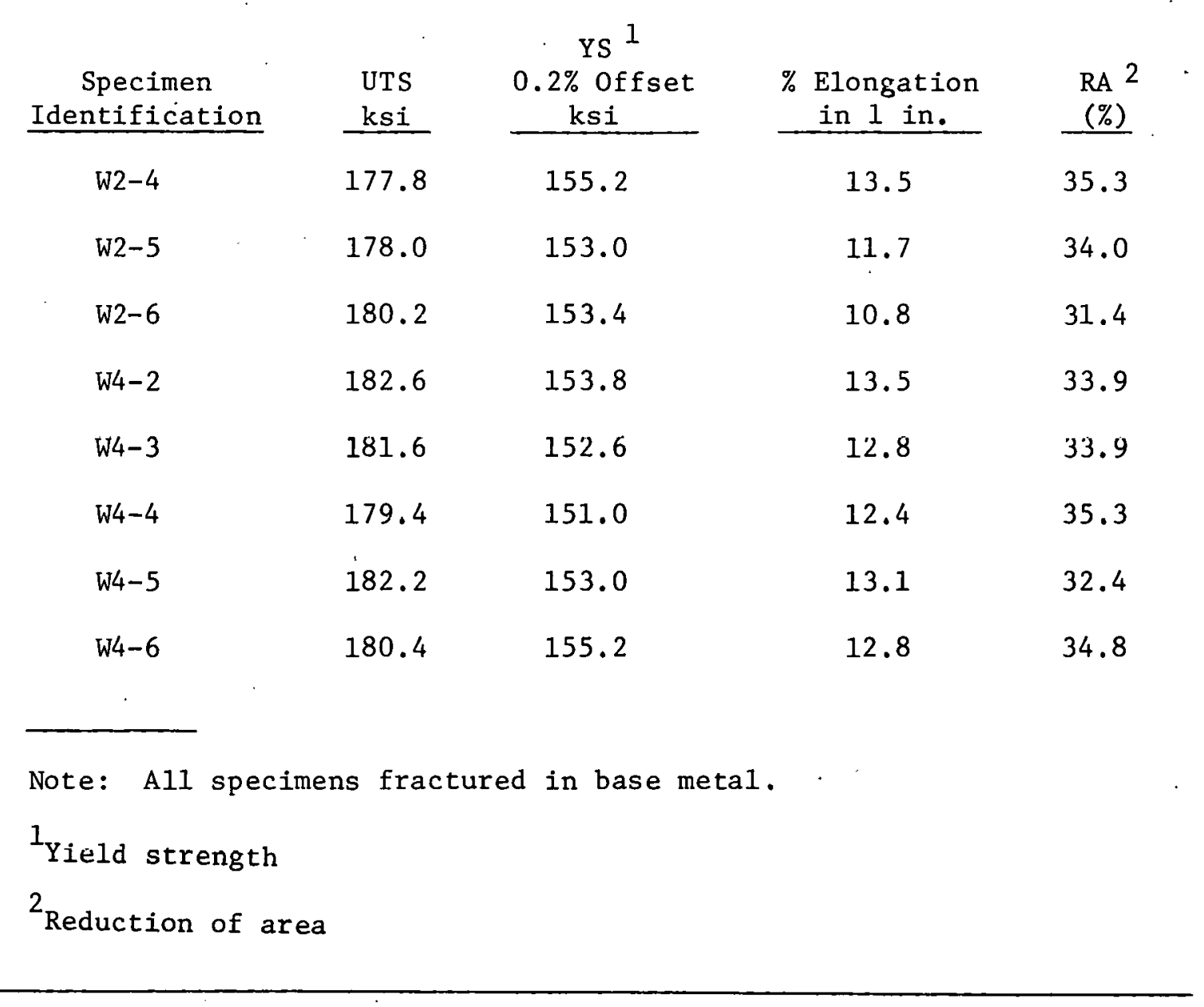


TABLE XII

IPT BASE METAL TENSILE TESTS

\begin{tabular}{|c|c|c|c|c|}
\hline $\begin{array}{c}\text { Specimen } \\
\text { Identification } \\
\end{array}$ & $\begin{array}{l}\text { UTS } \\
\text { ksi }\end{array}$ & $\begin{array}{c}\text { YS } \\
\begin{array}{c}0.2 \% \text { Offset } \\
\mathrm{ksi}\end{array} \\
\end{array}$ & $\begin{array}{l}\% \text { Elongation } \\
\text { in } 1 \text { in. }\end{array}$ & $\begin{array}{l}\mathrm{RA} \\
(\%) \\
\end{array}$ \\
\hline$I-1$ & 185.6 & 154.6 & 26.9 & .47 .0 \\
\hline $\mathrm{I}-2$ & 183.0 & 151.0 & 26.2 & 47.0 \\
\hline$I-3$ & 183.0 & 155.6 & 24.2 & 49.8 \\
\hline$I-4$ & 184.0 & 158.4 & 23.8 & 49.8 \\
\hline
\end{tabular}

TABLE XIII

ALL WELD TENSILE TESTS

\begin{tabular}{|c|c|c|c|c|}
\hline $\begin{array}{c}\text { Specimen } \\
\text { Identification } \\
\end{array}$ & $\begin{array}{l}\text { UTS } \\
\text { ksi }\end{array}$ & $\begin{array}{c}\text { YS } \\
0.2 \% \text { offset } \\
\mathrm{ksi} \\
\end{array}$ & $\begin{array}{l}\% \text { Elongation } \\
\text { in } 1 \text { in. }\end{array}$ & $\begin{array}{l}\text { RA } \\
(\%) \\
\end{array}$ \\
\hline W2-1 & 188.6 & 150.4 & 21.5 & 34.6 \\
\hline W2-2 & 189.4 & 152.8 & 21.4 & 35.7 \\
\hline .W4-1 & 187.0 & 155.0 & 23.7 & 31.4 \\
\hline \multirow[t]{2}{*}{ W4-2 } & 187.2 & 150.0 & 18.0 & 32.6 \\
\hline & & & & , \\
\hline
\end{tabular}


TABLE XIV

IPT BEND TEST RESULTS

\begin{tabular}{|c|c|c|c|}
\hline Welder & $\begin{array}{l}\text { Type } \\
\text { Bend }\end{array}$ & $\begin{array}{l}\text { Force to Bend } \\
\text { Specimens }=\mathrm{ksi}\end{array}$ & Bend Results \\
\hline $\begin{array}{l}\text { W-2 } \\
\text { Test } \# 1\end{array}$ & Face & 25 & Bend $180^{\circ}$ \\
\hline $\begin{array}{l}W-2 \\
\text { Test \#2 }\end{array}$ & Root & 23 & Bent $180^{\circ}$ \\
\hline $\begin{array}{l}\text { W-4 } \\
\text { Test \#1 }\end{array}$ & Face & 13 & Broke in center of specimen at $30^{\circ}$ \\
\hline $\begin{array}{l}W-4 \\
\text { Test \#2 }\end{array}$ & Face & 24 & $\begin{array}{l}\text { Broke approx. } 1 / 2 \text { way between } \\
\text { center and end of specimen at } 120^{\circ}\end{array}$ \\
\hline $\begin{array}{l}\text { W-4 } \\
\text { Test \#3 }\end{array}$ & Root & 21 & Bent $180^{\circ}$ \\
\hline $\begin{array}{l}\text { W-4 } \\
\text { Test \#4 }\end{array}$ & Root & 23 & Bent $180^{\circ}$ \\
\hline
\end{tabular}


TABLE XV

COMPARISON OF PROPERTIES FROM $30^{\circ}$ FAILED BEND

TEST SPECIMENS MATERIAL TO PROPERTIES OF UNFAILED BEND TEST SPECTMEN MATERIAL

\begin{tabular}{|c|c|c|c|}
\hline \multirow[b]{2}{*}{ Property } & \multirow{2}{*}{$\begin{array}{c}\text { W-2 Welder } \\
\text { Unfailed Bend } \\
\text { Test Specimen Material } \\
\end{array}$} & $30^{\circ}$ Failed Benc $\begin{array}{r}\text { W-4 } \\
\text { Mate }\end{array}$ & $\begin{array}{l}\text { Welder } \\
\text { d Test Specimen } \\
\text { erial }\end{array}$ \\
\hline & & Left One-Half, & Right One-Half \\
\hline Oxygen content & 4 to $6 \mathrm{ppm}$ & 8 to $18 \mathrm{ppm}$ & 8 to $18 \mathrm{ppm}$ \\
\hline $\begin{array}{l}\text { Tensile } \\
\text { Specimens } \\
\text { All. Weld Metal }\end{array}$ & $\begin{array}{l}\mathrm{UTS}=197 \mathrm{ksi} \\
\mathrm{YS}=165 \mathrm{ksi} \\
\text { Elong }=22 \% \\
\mathrm{RA}=33 \%\end{array}$ & $\begin{array}{l}\text { UTS }=188 \mathrm{ksi} \\
\text { YS }=153 \mathrm{ksi} \\
\text { Elong. }=20 \% \\
\mathrm{RA}=26 \%\end{array}$ & $\begin{array}{l}\mathrm{UTS}=173 \mathrm{ksi} \\
\mathrm{YS}=153 \mathrm{ksi} \\
\text { Elong }=4.5 \% \\
\mathrm{RA}=8 \%\end{array}$ \\
\hline Charpy Specimen & $27 \mathrm{ft}-1 \mathrm{~b}$ & $22.2 \mathrm{ft}-1 \mathrm{~b}$ & $19.8 \mathrm{ft}-1 \mathrm{~b}$ \\
\hline Columbium Content & $4.90 \%$ to $5.15 \%$ & $4.90 \%$ to $5.15 \%$ & 4.9 to $5.15 \%$ \\
\hline
\end{tabular}


